\title{
ONE TRACK MANY PATHS: Toward a Critique of Educating for the Knowledge Economy
}

Many paths of change are potentially possible, and which one is selected is an expression of the particular kind of structural coherence the unit has, in a continuous tinkering

(Varela, 1987, p. 61).

by

\section{WARREN WILLIAM SELLERS}

\author{
A thesis \\ submitted to the Victoria University of Wellington \\ in fulfilment of the \\ requirements for the degree of \\ Master of Education \\ VICTORIA UNIVERSITY OF WELLINGTON \\ Te Whare Wananga o te Upoko o te Ika a Maui
}




\section{ACKNOWLEDGMENTS}

Documenting ideas is a process involving many people. Of the many who are part of this document, there are some I would particularly like to acknowledge. I am very grateful to my sister Maree Telford, who motivated my embarkation on this journey and eased it through some of the more difficult moments. My deep gratitude goes to Marg Sellers, my wife, and partner in life and learning, for giving me so much inspiration, encouragement, and support.

Cedric Hall, James Irving, and Jane Gilbert have all given of their immense learning to help cultivate what I have written. My supervisor Jim Neyland, who suggested the topic of this thesis, is a principal contributor to the emergence and presentation of my ideas through his delicately firm touch. Jim has mentored my learning explorations over the last two years. His teaching and learning conversations about alternative visions of education personify what I refer to as 'ecological learning'.

Thank you Jim and Marg for being enactively in my learning. 


\begin{abstract}
In this thesis the role of education and learning in the so-called knowledge economy is examined in the light of existing and emerging, essentially different ways of perceiving and understanding the world. The study finds evidence that education is becoming ideologically and practically central to the propagation and implementation of the knowledge economy. Educating for the knowledge economy concerns not only the preparation of ideal economic citizens, it is also regarded as a valuable economic commodity in its own right. My hypothesis, however, is that education and the knowledge economy, while claiming to afford global social transformation, remain grounded in the modern worldview that is being critically challenged by postmodern views and understandings of the world. This is not to say that a modern worldview is 'incorrect', rather, it is to say that there are postmodern alternatives to carefully consider.
\end{abstract}

I distinguish 'postmodern' within three positions, each with a different perspective about knowledge: one is power-based, another anti-power-based, and yet another ecologically-based. I argue that there is a modern worldview and postmodern positions with different worldviews, giving rise to incommensurabilities between the respective understandings of the world each position has. To navigate between these understandings I have engaged with the theory of enactivism. Enactivism enfolds the exploring and performing of learning and teaching theories that embody ecological and complex postmodern characteristics. The many paths of variety and diversity these characteristics reveal are contrasted with modern educational characteristics, before each is compared to consider the merits, or otherwise, of going down the track of educating for the knowledge economy. 


\section{Contents}

0. INTRODUCTION

1. THE 'KNOWLEDGE ECONOMY' 10

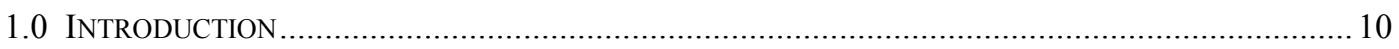

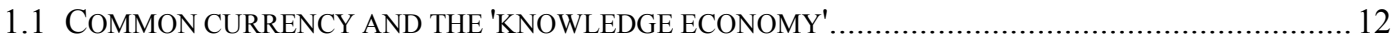

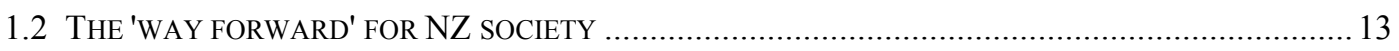

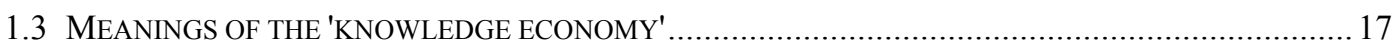

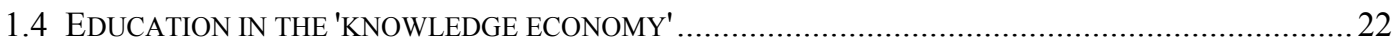

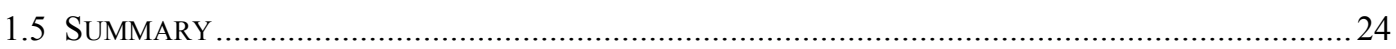

2. EDUCATING FOR THE KNOWLEDGE ECONOMY .......................................................227

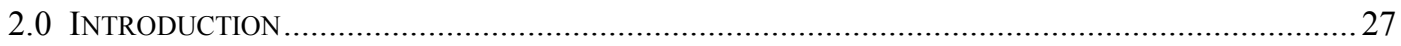

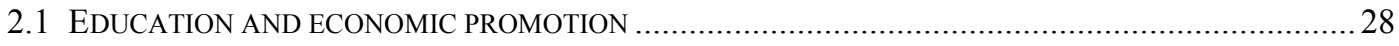

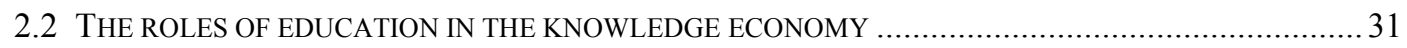

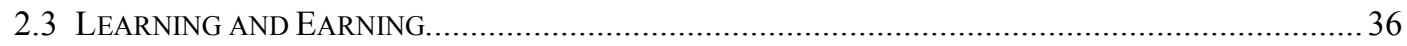

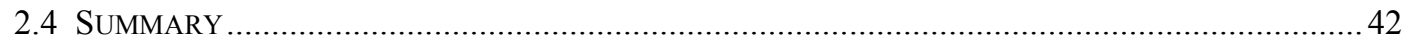

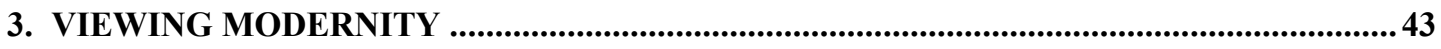

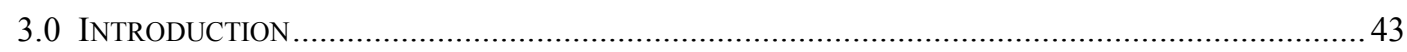

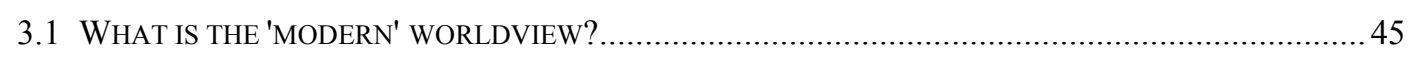

3.2 HOW IS THE KNOWLEDGE ECONOMY GROUNDED IN THE MODERN WORLDVIEW?......................50

3.3 WHY IS THE KNOWLEDGE ECONOMY EXCLUSIVELY GROUNDED IN THIS WORLDVIEW? ...............52

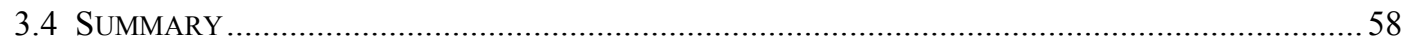

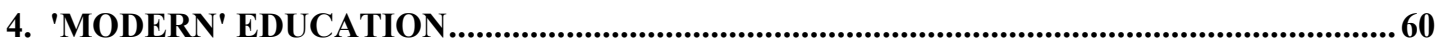

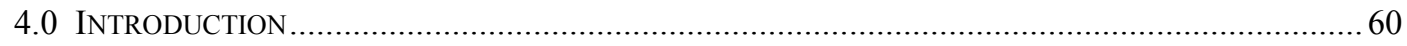

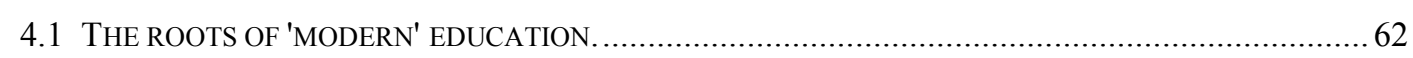

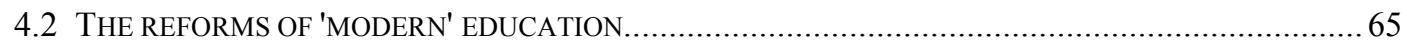

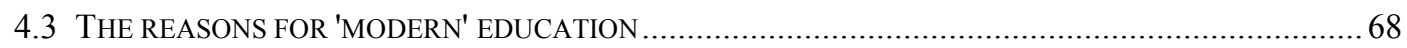

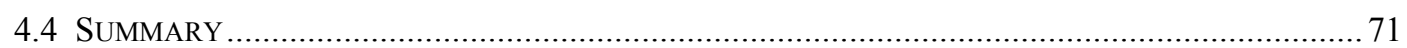

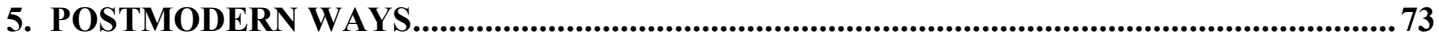

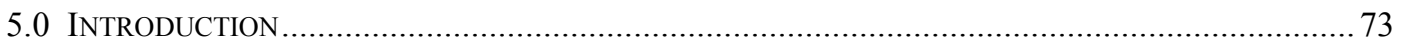

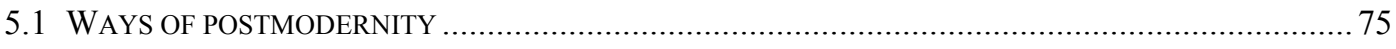

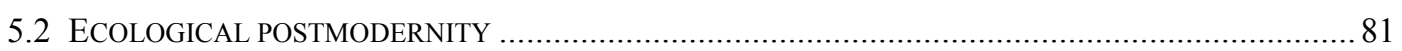

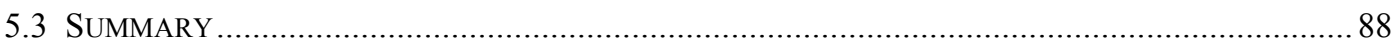




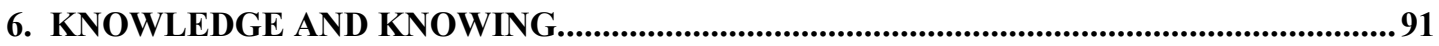

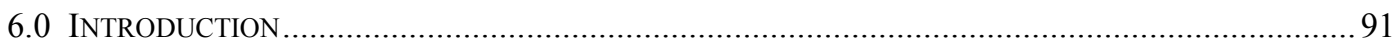

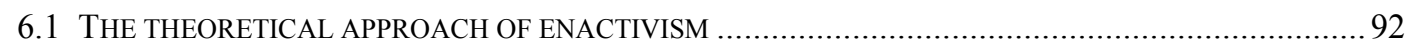

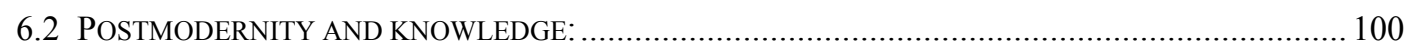

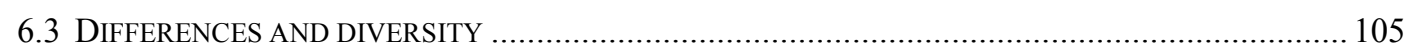

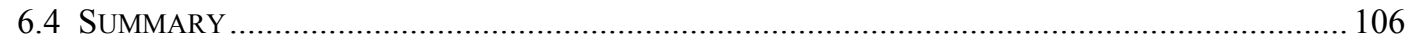

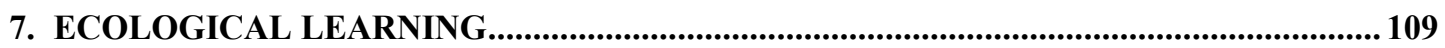

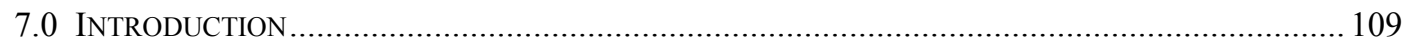

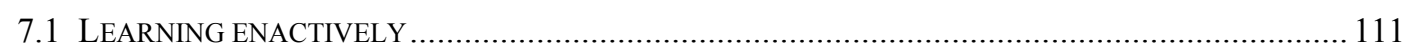

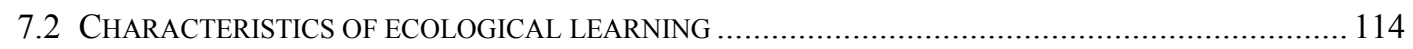

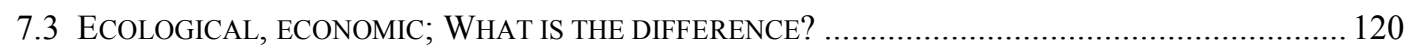

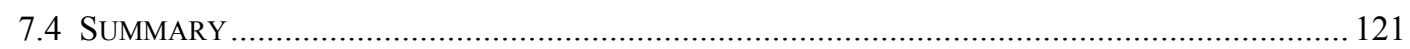

8. TRANSFORMATIVE ECOLOGICAL LEARNING.................................................................... 123

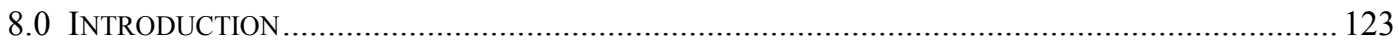

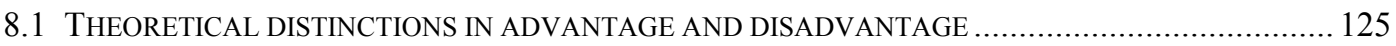

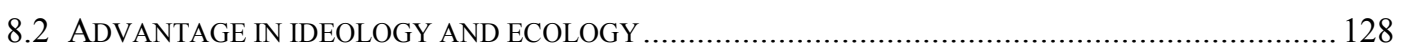

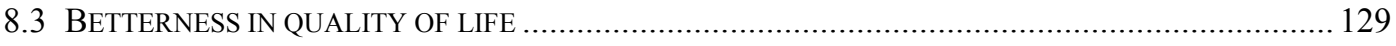

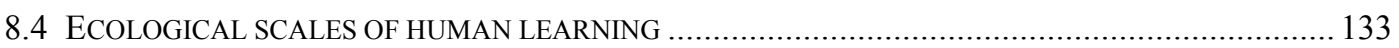

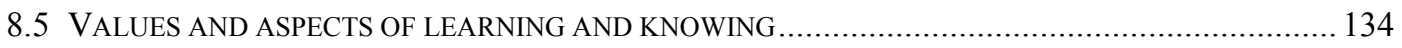

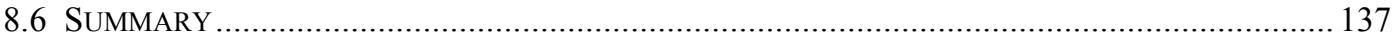

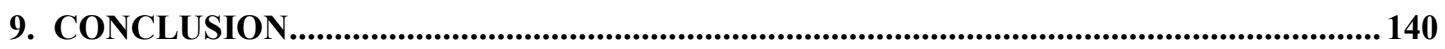

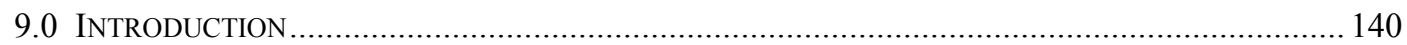

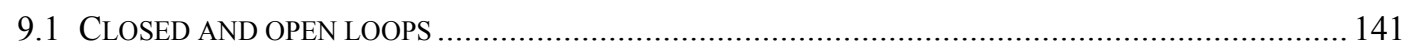

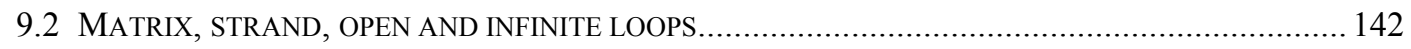

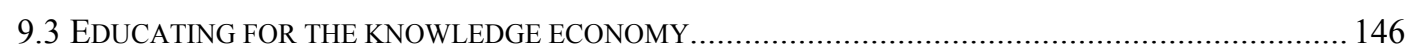

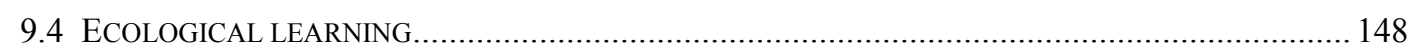

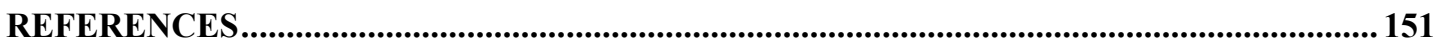




\section{LIST OF FIGURES}

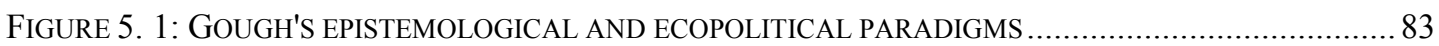

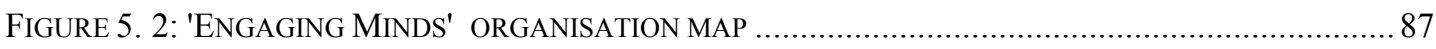

FIGURE 7. 1: 'MARK'

FIGURE 7. 2: RABBIT \& BIRD. 115

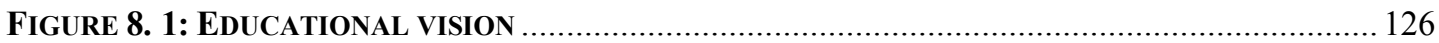

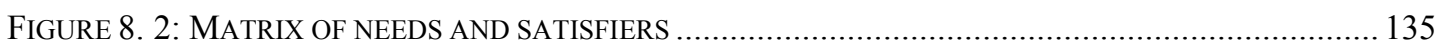

FIGURE 8. 3: LEARNING AND KNOWING EMBODYING LIVING IN ASPECTS OF EXISTENCE .......................136

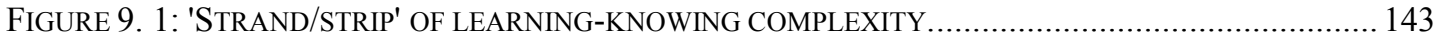

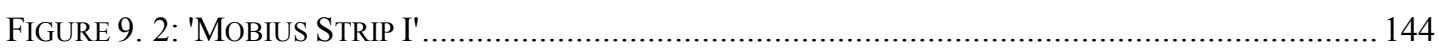

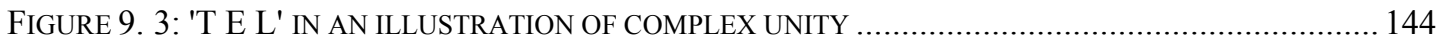

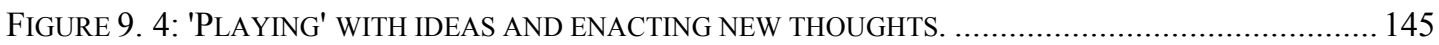




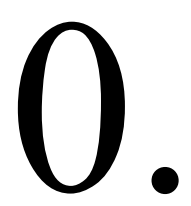

\title{
INTRODUCTION
}

\author{
Wanderer, the road is your \\ footsteps, nothing else; \\ wanderer, there is no pain, \\ you lay down a path in \\ walking. \\ In walking you lay down a \\ path \\ and when turning around \\ you see the road you'll \\ never step on again. \\ Wanderer, path there is none, \\ only tracks on ocean foam.
}

(Antonio Machado, 1930, translated by Francisco Varela, 1987, p. 63).

This study is important both for contemporary debates about the role of education in a changing world, and for me to clarify ideas that have been emerging over several decades. On the first matter, the role of education in contemporary society is at a critical moment; on one hand it is portrayed as a solid platform of knowledge and technological expertise from which the economic future of the world will be launched, and on the other hand it is projected as being like a surf board upon which the future of human society will ride the crest of the so-called 'knowledge wave' into a so-called 'bright future'. These expressions of the role of education in a knowledge 
economy, which will be explained in Chapter One, convey strong, positive, and dynamic images. But are they authentic?

On the second matter, the growth of my personal awareness and consciousness about the power of 'vision' in the world finds the rhetoric of the preceding sentence deeply disturbing. Much of my adult life was spent in producing and manipulating video messages about the world. More recently I was involved in tertiary education, and now, having committed two years to full-time academic study, it is time to comment on my perceptions and what I think about the world I understand to exist. In researching this study, I have found a substantial and significant body of literature that convincingly supports my arguing toward a critique of educating for the knowledge economy.

The argument I set out takes steps toward explaining what the knowledge economy is said to be and how it is said to be related to education. Within the first few steps it becomes apparent that interpretations of knowledge, economy, and education are being radically affected by changing views of the world. These changes are typically expressed in terms of a 'modern' and 'postmodern' worldviews. As the steps in my argument progress towards a synthesis of the terms involved, it appears that the modern 'track' is not as 'rightly' set as it purports to be. It seems, from carefully considering the different worldviews that postmodernity proposes, there are significant alternatives to the predominant modernity worldview, which are more appropriate to emerging understandings. Furthermore, an alternative theoretical approach to contemplating modern and postmodern understandings is also important and necessary. 
Within education, the emerging theoretical approach of enactivism is considered as being complementary to the thinking of many of the authors whose works I use to support my arguments. The byword of enactivism is the expression 'laying down a path in walking', which originates in the passage of poetry quoted above. In reading the poem, it will be apparent to the reader that this expression introduces an unusual interpretation of 'paths' for regarding and experiencing the world. Such paths contrast with the 'track' the knowledge economy is set on.

Within the enactivist approach, my arguments expand and include explanations about significant concepts of ecological and complexity, which transform aspects of the modern worldview, towards postmodern understandings of the world. These concepts of ecological complexity are explained within an educational context by relating them to what I call 'ecological learning', which is characterised as having 'prospective' regard for potentiality, rather than a 'progressive' attitude to prosperity.

In presenting my arguments, I bring together the different views and understandings of the knowledge economy's modern attitude to education, and postmodernity's emerging approach to ecological learning. Critiques of the modern conception, which challenge its economic foundational basis, are contrasted with explications of postmodern conceptions, which are 'ecologically transformative'. This distinguishes differences in 'advantages' between the two. In the conclusion, I re-interpret 'advantages' in an enactivist way to synthesise an alternative conception of complex learning and knowing, which is ecologically transformative for existing in the world. 


\section{1. \\ THE 'KNOWLEDGE ECONOMY'}

The so-called 'knowledge economy' is a term that has become common currency. It is used in a plethora of contexts to suit a wide variety of circumstances. Yet the question, 'What is the knowledge economy?' rarely meets with a coherent, direct answer. The purpose of this chapter is to explore uses and interpretations of the term through two questions: How do I know the knowledge economy has become common currency? And what does the term appear to mean?

\subsection{INTRODUCTION}

The currency of the term 'knowledge-based economy', and its shorter reified form, the 'knowledge economy', is officially validated by the publication The Knowledge Economy: Science, Technology and Industry Outlook (Organisation for Economic Cooperation and Development [OECD], 1996). The overview chapter, 'The knowledge-based economy: from the economics of knowledge to the learning economy', describes features of the knowledge-based economy as including: "the new dynamics in the formation of tacit and codified knowledge; the growing importance of networked knowledge; and the acceleration of processes of interactive learning" (Freeman, \& Soete, 1993, cited in Foray, \& Lundvall, 1996, p. 13). All of these features are also strongly related to the information and communication technology (ICT) revolution. Subsequently, the currency of the term knowledge 
economy has grown as exponentially as the ICT network it rides on, and it is now the primary focus of the contemporary global political worldview.

In a comprehensive report to the New Zealand Government on The Knowledge Economy, Frederick and McIlroy (1999) answer the question, 'What is the knowledge economy?' by citing the U.K. Department of Trade and Industry-"[a] knowledgedriven economy is one in which the generation and exploitation of knowledge play the predominant part in the creation of wealth" (p. 4). This is but one of many, varied, and often contradictory definitions for the knowledge economy. However, there are three significant strands identified in its development:

- The knowledge economy as the exclusive consensus for future organised development of human societies, which is clothed in positive, progressive rhetoric reinforcing that view, and the requirement of commitment to it;

- The knowledge economy as the 'natural' successor to the industrial manufacturing-based economy, which is in decline because its natural resources are no longer sustainable;

- Education as being at the centre of promoting and implementing the knowledge economy, because production of commodities and the overall sustainability of human society are now grounded in the resource of human knowledge.

The first strand is addressed in sections 1.1 and 1.2, the second strand in sections 1.2 and 1.3, and the third strand in section 1.4. 


\subsection{COMMON CURRENCY AND THE 'KNOWLEDGE ECONOMY'}

\section{National and global political focus}

The political importance of the 'knowledge economy' is now such that it has its own metaphors. According to New Zealand's current Prime Minister, Hon Helen Clark, "[c]atching the Knowledge Wave is an essential element in exploring how New Zealand can better capitalise on the know-how we already have, and invest in the new knowledge that will help underpin New Zealand's future social and economic development" (Clark, 2001). Furthermore, prior to the Labour government's 'knowledge wave', the preceding Prime Minister, Jenny Shipley, introduced the National government's policy for "...building on the sound economic framework...to position New Zealand for the knowledge-based economy" (Shipley, August 1999, p. 5). As Mrs Shipley put it, her team was "...agreed [on] a pathway into the future. 'Bright Future. Making ideas work for New Zealand' is the result" (ibid., emphasis added).

Coinciding with the release of the Bright Future policy booklet, another document was published in New Zealand titled The Knowledge Economy: a submission to the New Zealand Government by the Minister for Information Technology's Advisory Group (Frederick \& McIlroy, 1999). In the opening sentence of the foreword to this report, the Chair of the Information Technology Advisory Group (ITAG) states, "[i]n today's information age knowledge has become the gold standard...[therefore] New Zealand has a significant opportunity to become a knowledge economy - an opportunity we cannot afford to pass up" (Norris, 1999, p. i). 
From a global perspective, the knowledge economy represents what has been called a 'Second Renaissance', and a 'New World'. Dale Neef (1999) compares the success of the original Renaissance and its production of knowledge-based work with a new "...'Second Renaissance'...which in effect and longevity will far surpass that of the Renaissance, the Enlightenment, or the Industrial Revolution" (p. 25). Taking a less ardent position, under the heading 'Genesis of a New World', Spanish sociologist Manuel Castells (1998) focuses on the effect of what he terms the 'informational economy'. This has caused,

...for the first time in history, the whole planet [to be] organized around a largely common set of economic rules....It is informational capitalism, relying on innovationinduced productivity, and globalization-oriented competitiveness to generate wealth, and to appropriate it selectively (p. 338).

Castells goes on to say that a new "Fourth World" (p. 337) is emerging, which comprises socially excluded and economically irrelevant segments of societies, cities, regions, and countries (ibid). In the globalised knowledge economy, there appears to be little middle ground between, on the one hand the 'gold standard' wealth (Norris, 1999) and the opportunities of the 'bright future' (Shipley, 1999), and, on the other hand, what Castells calls the 'black holes' of the Fourth World (Castells, 1998).

\subsection{THE 'WAY FORWARD' FOR NZ SOCIETY}

\section{'There is no alternative'}

The New Zealand Information Technology Advisory Group's report on The Knowledge Economy states,

[t]he foundation stones of the knowledge economy are human ingenuity and skill and a commitment to innovation through research and development (Norris, 1999, p. i). 
This positions human ingenuity and skill at the centre of the knowledge economy's continuing intent to economically exploit resources. Norris continues:

The issue today is for the Government to focus on ensuring that its current interventions such as education and R \& D - are as focused as possible on taking New Zealand forward into the knowledge age (ibid.).

The importance of this 'issue' is highlighted by the comment-"the implication of the knowledge economy is that there is no alternative way to prosperity than to make learning and knowledge-creation of prime importance (Frederick \& McIlroy, 1999, p. 5, emphasis added). The report proceeds to 'focus the foci' for the future even further, by comparing New Zealand's competitive position with the knowledge-age cohort to determine "lessons for New Zealand" (p. 14), and to identify "six key issues for New Zealand to address" (p. 19).

\section{Knowledge economy lessons for New Zealand}

According to the ITAG's report, the 'lessons' for New Zealand are that the world's knowledge economy cohort all demonstrate similar attributes. These attributes are given as:

- an efficient and cheap universal telecommunications network;

- improved productivity through information-intensive, value-added businesses;

- improved industrial and commercial competitiveness;

- support for the information services sector;

- a focused investment in education and training (especially technical education) together with lifelong learning and upskilling;

- a better-informed populace with higher level of participation in, democracy;

- $\quad$ support for cultural values

(Frederick \& McIlroy, 1999, p. 14). 
Key knowledge economy issues for Aotearoa-New Zealand to address are said to be: education; Māori inclusiveness; immigration and the 'brain drain'; research and development; innovation as a culture; and a more appropriate 'mix' of exports. Furthermore, citing the World Bank (1999), Frederick and McIlroy say that without education's "openness to innovation and knowledge" (p. 19) economic development will not follow. Along with these issues, a projected declining youth population for approximately 50 years hence, means on-going education for middle-aged and older people is considered "critical" (ibid.) for the nation's prosperous economic future. ICT literacy is also regarded as crucial for both teachers and students in all age groups, and ethnicities, and technical graduates with practical as well as academic skills are considered to be essential.

The Treaty partnership between the New Zealand Government and indigenous Māori raises specific issues of culture and knowledge differences involving ...tension between the objectives of an intellectual property rights regime and the aspirations of Māori...[however] the more that Māori engage in discussions and debate around the knowledge economy, the more likely it is that some of the tensions between differences in the treatment of knowledge will be resolved" (p. 21).

Particular attention is also paid in the report to the "unique branding" (ibid.) opportunities that Māori culture affords-"[i]n global economies [where] nation-based brand distinctiveness is a significant asset" (ibid.). It is clear from this section of the report that Māori culture is regarded as a significant wealth-generating asset for the knowledge economy.

New Zealand's immigration policy as an impediment to attracting knowledge workers is also discussed in relation to "[t]he loss of highly educated and highly 
skilled New Zealanders to jobs overseas" (p. 24). Identifying a trend towards the imbalance of emigration over immigration, the report is concerned at the "...reduction of the number of people with the skills and knowledge to develop the knowledge economy" (ibid.). This so-called 'brain-drain', as well as issues of research and development, and also innovation, are connected in the report with the observation that New Zealand's "...desire to innovate is hampered by our low level of research and development expenditure" (p. 27). Furthermore, the issue of New Zealand's 'export mix' raises cautionary discussion on poor rates of return for product innovation in the primary sector and the vulnerability of its commodity products to the volatility of economic and climatic conditions. However, more positively, ICT, the Internet, and electronic commerce are seen in the report as important and costeffective in giving New Zealand's growing number of entrepreneurial, technologybased and knowledge-intensive small businesses access to international markets. The ultimate recommendation in the report is for the Government of New Zealand to "[c]hampion the development of a knowledge economy in New Zealand" (p. 33), because, it concludes, if the knowledge economy opportunities are not seized "we will survive only as an amusement park and holiday land for the citizens of more successful developed economies" (ibid.).

\section{New Zealand's Bright Future}

In the New Zealand Ministry of Commerce 's (1999) Bright Future: Making ideas work for New Zealand, the knowledge-based economy is distinguished from its industrial-based predecessor by perceived changes of scale and more sophisticated consumers. The Ministry proposes that "[t]he cumulative effect of change and innovation on all fronts amounts to a revolution in the way we work and live" (p. 12). The booklet goes on to list the features the knowledge economy calls for as 
an open and competitive economy; a highly skilled and flexible workforce; ready access to investment capital; robust links between industry, education and researchers; ease of communication and transportation; [and] a culture of innovation and success (ibid.).

This overview of the knowledge economy in New Zealand concludes with a quotation from the World Bank saying, "[k]nowledge has become perhaps the most important factor determining the standard of living-today's most technologically advanced economies are truly knowledge based" (ibid.).

\subsection{MeANingS OF THE 'KNOWLEDGE ECONOMY'}

\section{Incoherent definitions}

Those who profess to know about the knowledge economy are generally reluctant to specify its definition because the expression apparently represents an emerging revolutionary condition rather than a tangible entity. According to Neef (1998), "[t]he knowledge-based economy is a phrase that has been used to describe both a coming age of global prosperity and a coming economic apocalypse" (p. 1). However, he also says "a growing percentage of the US GNP is dedicated to highskilled service-provision work in which the only real assets are intangible..." (p. 6).

What those who know about the knowledge economy are prepared to say, is that the 'new knowledge' condition is global in its effects; that it involves a fusion of rapidly accelerating innovations in technological progress with ways and means of doing business in the marketplace; and that its productivity seems to be centred on a new breed of "educated, knowledgeable, and creative people...[or] knowledge workers" (Neef, 1999, p. 2) 
A common problem identified by the OECD in determining what the knowledge economy means arises from the intangibility of relevant activities. As Foray and Lundvall (1996) put it, "...subjects of analysis in which we are interested knowledge creation and distribution, innovation activity or capability, knowledge systems, etc. - are intangible activities that are difficult to measure" (p. 18).

In the opening paragraph of his introduction to The Knowledge Economy, Neef (1998) says he intends the volume "...to be a primer...to all aspects of the knowledge -based economy" (ibid.), which, he concludes, "...is an area of complex and often inaccessible debate, in which compelling arguments can easily be lost within dense academic prose-or worse, become mere soundbites in popular business weeklies" (p. 11). Neef also observes that, paradoxically, the term 'knowledge economy' is used "...enthusiastically to describe a new interconnected economy and the positive effect of newly emerging technologies in the workplace and home...[and also] to lament the effect of downsizing on the blue-collar sectors of the labor force" (p. 1). In the anthology of articles that follow Neef's introduction, discussions include "...the shift in employment from 'brawn to brains'... and the effect that 'knowledge elitism' may have on public policy concerning education and training, wealth disparity, and social exclusion" (ibid.). There is no doubt, for Neef, that knowledge has become the cornerstone of the 'new economy'. What the 'new economy' is, and what its affects might be outside the world of economy are less certain. While a distinct shift is occurring in the concern of business, from the exploitation of natural resources to the exploration of information and its capability to afford 'knowledge commodities', there are fundamental problems in "[m]easuring and managing the intangibles of knowledge" (Neef, 1998, p. 6). Furthermore interpretations of causes 
and effects of the knowledge economy also vary in ways that are apparently paradoxical and confusing.

\section{A new paradigmatic condition}

The economic summits of the late 1980's highlighted the international political concern for depleting resources and worldwide pollution, according to Wolfgang Sachs (1996) however, rather than acting for behavioural change to protect the world's environment, global knowledge was brought to bear on analysing the problem. As Sachs puts it, "[c]apital, bureaucracy and science - the venerable trinity of Western modernization-declare themselves indispensable in the new crisis and promise to prevent the worst through better engineering, integrated planning, and more sophisticated models" (p.35). In other words, new technology, information processing, and entrepreneurial innovation would solve the world's problems.

Neef (1999) identifies five trends that he proposes offer evidence of "...this new economic paradigm" (p. 3). The five trends indicate transitional attributes of the 'new paradigm' and include: the shift of production from goods to intangibles; the demand for upskilling of workers; the ascendancy of high-tech/high-skill work; the subsequent 'high-road/low-road' differentiation in companies on the path to globalisation; and the collapse and relegation of the blue collar worker to competing in the 'race to the bottom' end of notions of work (pp. 3-19). The positively progressive proposition being advanced concerning this new paradigm is that it represents a "Second Renaissance" (p.25). Neef holds that the miracle of this Second Renaissance is in its 'self-supportive cycle' of new generative technologies that create their own new markets which, in-turn, re-invest themselves in founding further 
knowledge development. Unlike single-use fossil fuels, knowledge can be recycled in unlimited renewable knowledges. And, underpinning the Second Renaissance is the new renaissance worker, who is said to benefit from involvement in this "...highskill, high-profit arena in which companies provided more stimulating work, better working conditions and higher pay" (p. 22). While plaudits for this paradigmatic revolution and its rewards abound amongst proponents, there are other, more critical views of knowledge and its connections with human beings in the so-called 'New Economy ${ }^{\prime 1}$.

\section{A 'New Economy'}

In the traditional notion of economic order, knowledge constitutes the intangible understandings and expertise people bring to the establishment, management, and operation of the production process, and to the marketing of its output. The traditional tangible knowledge component, in the sense of intellectual property, takes the form of a copyright or patented product design or production process. Behind this order, physical property such as land, buildings, and machinery underwrite capital investment and the employment of labour in production.

Today, in the 'New Economy' ${ }^{2}$ the arrangement is quite different; intangible and tangible knowledge is now fused into a 'new' form of knowledge. Physical property,

\footnotetext{
${ }^{1}$ Social critic Thomas Frank (2001) says, "what the term describes is not some novel state of human affairs but the final accomplishment of the long-standing agenda of the nation's richest class....A better term for the 'New Economy' might simply be 'consensus' " (p. 15).

2 Browning and Reiss (1998) define the 'New Economy' as: "Software for a networked world. Today's electronically mediated global economy is the biggest, most complex adaptive system ever created (outside of nature, anyway). Two centuries of industrialism spread productive capacity across the
} 
if it exists, is leased or rented, consequently, capital is unsecured and is 'ventured', and labour is intellectual rather than physical (Browning \& Reiss, 1998, p. 105). While this new arrangement is claimed as the foundation for the so-called '(new) knowledge economy' and an emerging 'knowledge society', a precise definition for this ubiquitous form of 'knowledge' is elusive.

Foray and Lundvall (1996), point out that the relationship between knowledge and the economy is hardly new-"Adam Smith $^{3}$ refers to new layers of specialists who are men of speculation and who make important contributions to the production of economically useful knowledge" (p. 11). However, the more recent and related concept of innovation "...as a major force of economic dynamics" (ibid.) became especially significant in the 1960's as a consequence of the American/Soviet space race. The American concern with winning leads to the convergence of the OECD countries on the strategic development of their knowledge base "...through massive investment in formal education" (ibid.) and the succeeding 40 years has generated an information and communication technology (ICT) revolution. While the development of the knowledge-based economy is characterised by many features that have resulted from the ICT revolution, such as digitisation, networking, and interactivity, the revolution has been far from bloodless and "[t]here is a growing risk that IT [will] become an acronym for Intellectual Tribalism" (p. 29). Moreover, it is strongly argued in this publication that ICT literacy, and access to ICT facilities, is

planet, built globe-straddling communications, and inspired generations of workers to invest in education for both their children and themselves. And that in turn has created the underpinnings for the next great leap: from making things to making choices" (p.105).

${ }^{3}$ Author of An inquiry into the nature and causes of the wealth of nations (1776). 
replacing traditional literacy as the measure of a citizen's social and economic competence (ibid.).

\subsection{EDUCATION IN THE 'KNOWLEDGE ECONOMY'}

\section{Education is the central theme}

Candice Stevens (1998) puts education plainly "...at the center of the knowledgebased economy, [in which] learning is the tool of individual and organisational advancement" (p. 87). One important feature of the knowledge economy, according to the World Bank's Senior Vice President and Chief Economist Joseph Stiglitz, is a "knowledge culture" (Stiglitz, 1999, p. 3) which intends to effect "Changing Ways of Thinking...[towards] the appreciation of the centrality of knowledge and education in general and...science and technology in particular" (ibid.).

Furthermore, it appears to Neef (1998) that "[1] earning organisations" (p. 7) are very important to bringing about this cultural reformation. The term 'learning organisation' refers here not just to educational institutions but to the idea of learning as an organisational aspect of measuring and managing knowledge. Examples of this are included in fields such as, information systems, communications and information management, electronic commerce and multi media, and media law.

\section{States of learning}

Education and 'lifelong learning' in the knowledge economy apparently concerns concepts such as " 'Learning Cities'...meeting the needs of the people....as they respond to the technological challenges of the knowledge society of the $21^{\text {st }}$ century" 
(Maharey, 2001b). In these knowledge society learning cities, there are also "learning shops" and "learning centres" (ibid.), where one presumably buys and accesses "...the breadth and depth of our knowledge base, [and]...competence in the three literacy domains (prose, quantitative and document literacy ${ }^{4}$ ) required to meet the demands of modern daily life" (Maharey, 2001a). This notion of commodifying education and learning is reinforced by the view that acquisition of competency in these literacies is no longer about schooling, it is about "...education brokers [who] facilitate entry into appropriate education programmes .... [and about] providing a learning hub and support centre for students participating in e-learning programmes" (ibid.). The underlying meaning of this complicated and obscure rhetoric is said to be "...to build pathways for increasing skills to facilitate participation in the knowledge society" (ibid.). I use the word 'rhetoric' critically here, because nowhere in the documents I am quoting does there appear any reference to what the Minister understands learning and knowledge to be. His statements certainly reify and valorise ways and means for learning, and concerns about knowledge, but they offer no clues about their meaning, other than they are to do with the 'technological challenges, demands of daily life, knowledge-base, and participation in the knowledge society' referred to above.

\section{Instant obsolescent learning}

The concern underlying the problems of educating for the knowledge economy is revealed by Neef (1998) who comments on the renewed importance of education and training in the demand for knowledge-based skills. He says:

\footnotetext{
${ }^{4}$ The 'three literacy domains' seem to be techno-rhetoric for reading, 'rithmetic, and 'riting.
} 
Unfortunately, in the US and Britain, particularly, there are clear indications that the education and training infrastructure necessary to provide these knowledge-based skills broadly throughout the population is becoming both inadequate and inappropriate for the knowledge-based economy (p. 9).

Following up on the this point, David Stern (1998) of the OECD's Centre for Educational Research adds that the need for faster and continuous learning in a knowledge-based economy may make school and university based learning obsolete before it can be used (p. 249).

\subsection{SUMMARY}

Proof for the pervasive common currency of the term Knowledge Economy is most evident in the political arena, and, most recently, in the 'catching the knowledge wave' theme of an international conference ${ }^{5}$ organised by Auckland University and the New Zealand Prime Minister's Office and attended by many of the world's 'leading thinkers'. Prime Minister Helen Clark saw the mission of the conference as about capitalising on and investing in knowledge for the country's social and economic future. Gaining political capital from the knowledge economy was also a mission of the previous government who received a report on the Knowledge Economy, and published a booklet about the 'bright future' in store for New Zealand under a knowledge-based economy.

An inherent attribute of political patronage over a feature or aspect of society, is the rhetoric the patron brings to it. In this case the 'new economy' feature is 'global' in

\footnotetext{
${ }^{5}$ Catching the Knowledge Wave Conference, 1-3 August 2001, Auckland, New Zealand.
} 
aspect and is therefore so highly regarded that it has acquired an elaborate vocabulary of rhetoric. Terms that flow forth embrace notions of efficiency, cost-effectiveness, competitiveness, comparative advantage, with lifelong learning, and upskilling, for better informed, democratically participant, and aware, populations. Moreover, and of particular importance to Aotearoa-New Zealand is the regard for Māoridom as representing a significant 'cultural' knowledge economy asset for the nation to exploit. Ultimately, however, it appears a broader conception of a knowledge economy must be seized to ensure New Zealand avoids becoming a leisure park for the global affluent.

A recurrent problematic for the knowledge economy is the construction of a coherent, concrete definition. The difficulty arises in the intangibility of the knowledge economy's activities and their resistance to measurement. In spite of this, the knowledge economy demonstrates some identifiable features, which include: employment being based on 'blue jean brains' ${ }^{6}$ rather than 'blue collar brawn'; business being concerned with exploring information for knowledge rather than with exploiting natural resources; and the fusion of electronic technology and the global marketplace with innovative entrepreneurial wealth-creating, knowledge-generation, (which can arguably be also read as wealth-generating knowledge-creation). Nevertheless, the $21^{\text {st }}$ century 'knowledge worker' is envisioned as possessing a balanced blend of educated, knowledgeable, and creative qualities.

\footnotetext{
6 An expression coined to emphasise the blue jean wearing innovators and entrepreneurs who characterise the 'brains' of the knowledge economy.
} 
In the developing notion of the knowledge-based 'new economy', the knowledge economy is portrayed as a revolutionary paradigmatic condition arising in the 'natural' progression from its previous industrial state based on resource-depleted, manufacturing industries. Trends that are indicative of the 'new paradigm' include not only the features listed in the preceding paragraph, but also the 'self-supportive cycle' of generative technologies creating new markets, which reinvest in continuous knowledge generation. There is however, a perceived downside that the knowledge economy's dependence on information technology (IT) presents a risk that IT may come to stand as an acronym for 'Intellectual Tribalism'.

The predominance of IT/ICT and its associated hardware, software and 'literacies' in educational environments, resources, and curricula, reinforce the view that education and learning reside at the 'epicentre' of the metaphorical explosion/tsunami resulting from the knowledge-based economy/knowledge wave and the 'knowledge society' that is said to be emerging. The new economy's technological 'engine', 'fuelled' by information, appears to be a major force behind the drive to commodify education and learning in order to generate wealth through knowledge-creation. These matters are the substances of the following chapter. 


\section{2. \\ EDUCATING FOR THE KNOWLEDGE ECONOMY}

Education is represented as playing a vital role in promoting, as well as implementing, the Knowledge Economy. Educational qualifications are regarded as crucial for taking part in economic life, and learning is now considered to be a 'lifelong' process. This chapter explores the relationships between notions of education and economy, which have given rise to the maxim 'learning for earning', through the questions: How do I know education is vital to the knowledge economy? And what role is education presented as playing in the knowledge economy?

\subsection{INTRODUCTION}

While the notion of linkages between education, knowledge, and economy is hardly a new idea, education and links to the conflation of knowledge with economy is. In Teaching as a Subversive Activity, Neil Postman and Charles Weingartner (1971) brought to public attention the increasingly problematic relationship between education and knowledge in what they called "crap-detecting" (p. 16). Explaining this concept, Postman and Weingartner pointed to human history's struggle to discern truth, or as they put it, "...a continuing struggle against the veneration of 'crap' " (ibid.). What made this an urgent issue for Postman and Weingartner was the impending 'change revolution' that electronic technology was engineering for the Western world, and the emerging globalised society. Today, with the ICT revolution 
at the forefront of educational resources, institutions of learning are seen as the ultimate 'portal' to the promotion of a new society and its knowledge-based economy.

New policies lead the list of calls for changes to education's role for the knowledge economy. Concerns that education is not performing in delivering either basic literacy/numeracy skills or specialised 'literacies', which the knowledge economy needs, drive demands for closer links between educators and employers. A 'cradleto-grave' education policy for the knowledge economy is also seen to be necessary as unceasing changes in types and forms of 'knowledge' demand continuous redefinition of what knowledge means. This creates an on-going need for individuals to be retrained and upskilled to remain adaptable members of 'learning nations'. In addition to its role as an educator of learners, the field of education has found a new role in the knowledge economy, that of 'wealth-generator'. In this role education not only promotes and sells its services and products domestically, it also exports them to the new global marketplace, where, it is predicted, annual revenues of one billion dollars will be achieved within five years (Maharey, 2001c).

\subsection{EDUCATION AND ECONOMIC PROMOTION}

\section{Political policy, education, and economy}

Political policy linkages between education and economics, while also not a new notion, has become a matter of course in the 'reformations' of recent decades. James Marshall (2000) argues against the 'political rhetoric', which he sees as urgently calling for new policies to satisfy the knowledge economy. He says that these calls ignore 'major criticisms' of 'traditional liberal' education, that both pre-date and 
became part of New Zealand's economic restructuring of the 1980s' (p. 189). Countering the suggestion that education is utterly unprepared for the knowledge economy and society, Marshall points to a 'raft of earlier policies' that laid the groundwork for the educational/economic reforms (ibid.). Marshall's Bright Futures and the Knowledge Society unpacks the Bright Future (Ministry of Commerce, 1999) policy, and aspects of The Knowledge Economy (Frederick \& McIlroy, 1999) report, referred to in Chapter One. He comments,

[c]learly education has a role to play [in the knowledge economy] and, it would appear, this has become one of its allotted roles for the first years of the twenty-first century, as the Bright Future package heralded major advances and scholarships and the priming of teachers for the immanent knowledge economy (Marshall, 2000, p. 189).

Marshall also identifies "...knowledge which the knowledge society 'needs' " (p. 193), as surfacing in The New Zealand Curriculum Framework (Ministry of Education, 1993). Secretary for Education Dr Maris O'Rourke (1993), in the foreword to this document highlights the significant challenges New Zealand faces in the future. She says, "...to progress as a nation, and to enjoy healthy prosperity in today's and tomorrow's competitive world economy, our education system must adapt to meet these challenges" (p. 1). Echoing Postman and Weingartner, O'Rourke notes that "...with all the rapid technological change which is taking place, we need a work-force which is increasingly highly skilled and adaptable, and which has an international and multicultural perspective" (ibid.).

Today, the extent of political commitment to education and the knowledge economy is reflected in the continual flow of ministerial announcements on the subject. For example, at primary school level the government has funded a CD-Rom to give 
teachers the ability to test what children know and have learned, and to show what they should be learning next, (Mallard, 2001c). At secondary school level, according to the Minister of Education, the Government is "...trying to encourage as many young people as possible to help us in our pursuit and application of knowledgebased creativity and innovation. That is the key to success in the global economy of the 21st century" (Mallard, 2001b). And, at tertiary level the government has established an Advisory Commission, which has recently released its third report Shaping the Strategy, in which a key message is that "...a vital tertiary education system will strongly contribute to the development of the knowledge society New Zealand aspires to" (Maharey, 2001d).

\section{Opportunity or hegemony?}

Lynn Ilon (2000) not only sees a link between education and the knowledge economy, she identifies "two dominant views" (p. 275). One view, says Ilon, contends that a technology driven knowledge economy will afford an equitable and prosperous future and "...educators need only to ride the wave and recognise the increased opportunities when they appear" (p. 275, emphasis added). However, another view, sees the education/economy linkage as augmenting global hegemony and as "...weakening non-market values of humanitarianism, equity and ecology" (ibid.).

For those with the knowledge 'wave' view, the extent of the knowledge economy's invasion into educational management and assessment, beyond classroom CD-Rom's, is exemplified by the 'GreatSchools' project, an initiative of U.S. Silicon Valley based corporation Smart Valley Inc., which will use the Internet to publish rankings and 
specific data on all American schools (Dyson, 1997, p. 100). Such enterprising links between education and business are seen by some as the evolution of education's cooperation towards corporatisation. In his MA Ed thesis Enterprise Education Dylan Braithwaite (1995) concludes that industry is leading education change, and says "Corporate Enterprise Education texts, and state produced Enterprise Education texts, combine to legitimate the language of the marketplace in education, and effectively allow business to govern educational change" (p. 161). David Gabbard (2000) extends this view into an international context with the statement, "...the demands of the global economy now drive U.S. educational discourse...[and] the observations are generalizable to all modern industrial nations" (p. xvii).

\subsection{THE ROLES OF EDUCATION IN THE KNOWLEDGE ECONOMY}

\section{Cradle-to-grave learning for earning}

One crucial change in the role of knowledge economy education is its cradle-to-grave coverage. Lesley Max (2001), leader of the Home Instruction Programme for Preschool and Year One Youngsters (HIPPY) in offering an early childhood perspective on learning for earning, claims that "[t]he cognitive capacity of the population is to the knowledge economy what the silicon chip is to the information industry" (p. 5). Max also calls on the "human services community" (p. 4), which presumably assumed includes education,

...to open its eyes to economic reality, and stop demonising business. And business, which is belatedly learning to take women seriously, needs to perform an even more unnatural act. It has to stop trivialising the world of early childhood, to see the direct cause and effect link between children's early life experiences, and their competence ultimately to participate in the knowledge economy (ibid.). 
While such a view may not be representative of early childhood educators, it resonates with contemporary policy objectives in compulsory education.

New Zealand's official early childhood education policy is set out in Te Whāriki: The Early Childhood Curriculum (Ministry of Education, 1996) In the foreword to the document, acting Secretary for Education Lyall Perris (1996) says:

This curriculum statement covers the education and care of children from birth to school entry age. Coverage of this age range is innovative and clearly reflects the concept of learning as a life long process that begins at the very start of life (p. 7).

The inclusion of terms such as 'innovative' and 'life long' learning in this curriculum statement, while not appearing overtly conscious of knowledge economy principles, is open to interpretation. As Marshall (2000) argues, it is in the process focus of the New Zealand curriculum statements on learning areas, that knowledge is either "blatantly pragmatic or rests on economic considerations" (p. 194). Through this process focus on areas of learning, he says, knowledge "...at best becomes some pragmatic outcome of skills and information acquisition in these areas" (p. 194). Therefore, extreme care needs to be taken over the wording of these documents to ensure policy concerning non-compulsory education is transparent to educators and caregivers.

\section{Warrant of learning fitness}

At the start of compulsory education, it appears there is a need for a 'warrant of fitness' to go to school. Thackery, Syme, and Hendry (1992) in A survey of school entry practices, report on the multiplicity of practices used to evaluate the learning fitness of children. The survey, which was conducted in response to the 
government's 'Achievement Initiative', appears to have formed the ground for introducing the School Entry Assessment/Aro matawai Urunga-ā-Kura (SEA/AKA) package (Ministry of Education, 1997). This package provides primary schools with a nationally standardised assessment tool to determine what a child knows, and, therefore needs to learn, on entry to primary school. As noted earlier in this chapter, the package has now been upgraded from a print-based format to a CD-Rom, thereby facilitating further systematic processing of the information obtained from the procedure.

\section{User-buys learning}

The roles of education in the preparation of secondary and tertiary students for economic life are detailed in subsequent sections of this chapter, however, there are two issues of concern in the area of non-compulsory education. Firstly, accompanying the demise of the industrial/manufacturing base to the economy, formal workplace training has all but disappeared. Secondly, the 'new economy' environment has replaced the traditional principles of permanent, and long term employment, with contracted and also casualised engagements. These situations foreground the role of what were once known as 'apprenticeships' and 'continuing education', and which are now being called 'lifelong learning'. This reformation in post-compulsory education emphasises the new commercial continuum of 'user-pays' on-going education, training, and upskilling for work. Whereas in the past learning was a shared individual-social-industrial-governmental responsibility, today is it a commodity and lifelong necessity that continually needs to be re-purchased. This shift in the conceptual access to education-from a shared responsibility notion, to one of individual responsibility-has also been accompanied by a shift from a user-pays 
concept to a user-buys concept. That is, it is no longer a matter of only paying for what is used in education, there is now an obligation to finance and buy learning; and to keep buying.

Frederick and McIlroy (1999) explain that because New Zealand's 'population bubble ${ }^{17}$ is creating an aging workforce, education and training is 'critical' for its middle-aged and older members (p. 19). The primary concern for the employability of this group is basic literacy skills to engage with increasingly specialised information. With the steady decline in availability of manual work, most employment now requires a significantly higher level of literacy abilities than it did previously. In the past good literacy skills were for many workers either initially underdeveloped, or subsequently stunted by lack of practice. To address this problem, governments are recognising more assistance is needed. In the 2001 Budget the Education Minister announced,

The Government believes all New Zealanders should enjoy a level of literacy which enables them to participate fully in all aspects of life, including work, family and the community. It is the foundation for further learning needed to build a knowledge society. This funding will help realise that goal (Mallard, 2001a).

At the 'sunset' end of the lifelong learning continuum, the increasing predominance of the knowledge economy's communication network-the Internet-has generated enormous demand for senior citizens to connect up to it. Such demands are reflected

\footnotetext{
${ }^{7}$ 'Population bubble' refers to the substantial population increase caused by the 'baby boom', which is moving through the country's demographic and coinciding with a decline of young people in the workforce (Statistics New Zealand, 1997, cited by Frederick \& McIlroy, 1999, p. 19).
} 
in user groups and training being created especially for seniors. As the Telecom New Zealand Ltd sponsored Homepage for SeniorNet explains:

Many older people may feel they're being left behind by technology and the computer age. Now SeniorNet brings older adults and computers together in a friendly, fun and stress-free way. It's for people over the age of 55 who'd like to learn more about computers and what they can do, from word-processing through to surfing the Net.

There are now 77 SeniorNet groups - or Learning Centres - throughout New Zealand. Each Learning Centre is established and run by an independent committee, who organise their own premises, classes and funding (SeniorNet, 2001).

It should be noted that behind the rhetoric of 'friendly, fun, stress-free' Net surfing, lies the commercial potential of an enormous untapped new market.

\section{Education as subservient to economic goals}

The pre-eminence of what Postman (1996) calls the "god of Economic Utility" (p. 27), as the reason for schooling, is based on the powerful promise of reward. Postman (1996) says that this god offers a covenant of a well-paid job, in return for hard work and good behaviour. As he puts it, the god's covenant makes clear "[i]ts driving idea is that the purpose of schooling is to prepare children for competent entry into the economic life of the community" (p. 27).

Chapter One in the Ministry of Commerce (1999) Bright Future document, titled 'Learning to Excel', claims that "[t]he way forward" (p. 16) for New Zealand's success as a knowledge society in the twenty-first century "...depends on us becoming a learning nation" (ibid.). To achieve this 'excellent' learning, the Bright Future notes that "[e]ffective education starts early and needs to be highly responsive to the needs of business and economy" (ibid.). 
In The Knowledge Economy (Frederick \& McIlroy, 1999) report, "living proof" (p. 19) that achievement in education is the key to economic growth is given by the example of dramatic change in the economies of Singapore, Hong Kong, Taiwan and South Korea. What caused the change, say Frederick and McIlroy, was the heavy investment in education and training, and in particular, because "...parents encouraged their children into science and technology" (ibid.).

From a philosophical perspective, the importance of economic priorities in education is reflected in the strengthening neo-liberal, and, in many cases, New Right ideological influences. Key features of such influences include the 'free market', the 'rights' of the competitive individual, 'freedom' over 'equality', an 'anti-biggovernment' stance, and 'moral conservatism' (Marshall, 2000, p. 191). Marshall comments on these attributes as underpinning a belief that excellence and quality in education stands to benefit most by market type arrangements, such as de-zoning, decentralising and competition, for schools. Under this regime, education becomes, as Marshall puts it, "...a commodity purchased by individuals for individuals, and is utilised by those individuals for their own personal advancement" (ibid.). That society at large stands to benefit, as well, is not acknowledged.

\subsection{LEARNING AND EARNING}

\section{Education as an economic commodity}

Education's role as a valuable commodity in the knowledge economy is best exemplified by its quantification as an export earner, which last year added $\$ 700$ million to the country's GDP (Maharey, 2001c). According to Maharey, the 
Associate Education Minister, "[t]he export education industry is a classic example of the knowledge economy and is well on target to achieve foreign exchange earnings of $\$ 1$ billion by 2005" (ibid.). The government's support for the value of what it sees as a 'sunrise industry' is further reflected in the Internet Home Page of its export marketing organisation, Trade New Zealand, which presents a "Student Site" alongside, and equal to, Importer, Exporter, and Investor sites (Trade New Zealand, 2001).

Education as a commodity is not restricted to just selling study in New Zealand. Several companies are also expanding their export sales of educational resources, which range from learning media to learning management. As The Knowledge Economy report says forthrightly, education is "[t]he single most important factor in stimulating the creation of a knowledge economy" (Frederick \& McIlroy, 1999, p. 19). The report illustrates this by referring to a New Zealand company said to be "pioneering Internet education" (p. 18). The company's product, called 'Galaxy Kids', is aimed at improving literacy and numeracy in three to seven year olds, and costs $\$ 120-140$ p.a. for access to the Internet site, which "...aims to provide three and a half hours of formal instruction per week" (ibid.). In globally expanding its business the company "...transmits the core issue down the satellite to the portal in the U.K. or Australia which re-transmits it to the parents and children in that country" (ibid., emphasis added). The technological rhetoric in this statement is indicative of the priority such products place on the economics of the medium as opposed to the educational interests of the messages. 


\section{Technological commodification of learning}

The technologising of education is increasingly seen as a 'naturally normalising' process that helps to embed consumer electronics into learning environments and processes. A classic example is the 'natural' connection between computers and games, which is portrayed as developing perception, cognition, and coordination skills and expertise. Another example is the pervasion, amongst youth, of electronic communications from cellular telephones to chat rooms, which are popularly valorised for their development of more evolved interpersonal communication and relationship attributes. Furthermore, much of this promotion of technology is dressed in the rhetoric of progressive advantage to ensure parents are made to feel guilty if their child is deprived of such 'important' tools for future success in the knowledge economy.

In a recent example of the government's promotion of educational technology the Minister of Education launched the 'Notebook Valley Project' "...and with it Hutt Valley students were rocketed into cyberspace" (Mallard, 2001b). Through the project, 200 students and teachers received laptop computers in a co-operative venture between business and government, which, the Minister says, is to assess the effectiveness of the technology in enhancing teaching and learning in science and mathematics at senior levels. He added that students would also get home Internet connections to continue work by remotely accessing their school network and other resources (ibid.). The overriding tenor of this promotion rides on the unsubstantiated presumption of technology's capability for enhancing learning. 


\section{Education for 'wealth creation'}

The notion of education serving the 'god of Economic Utility', referred to above, was as Postman argued, based on the reward of a well-paid job. Today, the idea of a job in the traditional sense of a business employing an individual to join its workforce and with the view of long-term commitment to the business, is increasingly rare. These days, any expectations of permanent employment, even that of the oncehallowed academic tenure, are fast eroding. Work is now usually contracted, performance-based, and casualised to particular projects-a notion that is rhetorically known as "Free Agency' ${ }^{\prime 8}$ (Frank, 2001, p. 204). Before the arrival of the knowledge economy, a trade, profession, vocation, or ordinary occupation sufficed to explain how an individual earned their living. Subsequently, occupational descriptions have taken on 'parological' ${ }^{9}$ implications with titles such as 'Knowledge Development Director' and 'Guru-level Delphi Developer' (nzjobs.co, 2001). Most of these titles reinforce the insubstantial virtual reality of their holder's relationship with the actuality of employment in the current realms of innovation and entrepreneurialism. The dubious significance of this particular realm is, in itself, valorised by a Postgraduate Diploma in Entrepreneurship and Innovation (PG Dip Entre Inn) recently introduced by Waikato University (University of Waikato, 2001).

Alongside the replacement of a traditional job with the 'independence' of Free Agency, the knowledge economy has also introduced another innovative worker 'benefit', namely, shares in the company or stock options, in place of wages. The

\footnotetext{
${ }^{8}$ Frank (2001) cites Daniel H. Pink using this term to valorise the 'independence' of casual work (pp. 204-205).

9 'Paralogical' refers to the falsity or illogical reasoning behind something that appears superficially logical (Concise Oxford Dictionary, 1999).
} 
invention of this concept is, according to Frank (2001), attributed to an event concerning the U.S. Corporation, AT\&T. In 1996, after making forty thousand workers redundant, AT\&T's share price rose sharply and in response to 'vituperation' for its 'heartless' behaviour, it was suggested that the corporation let their exemployees "...participate in the stock appreciation that their firings caused" (p. 99). While this suggestion was not adopted, by the end of the decade stock options in lieu of wages had become commonplace among U.S. Silicon Valley companies (ibid., p. 101). Frank adds that this practice offered an additional benefit of "...permitting firms to conceal their payroll expenses and artificially inflate the price of their shares, pumping the bubble even further" (ibid).

The practices of Free Agency, and employee stock options, highlight what Frank (2001) calls "Market Populism", which the flyleaf of the dustcover on his book notes as "...the morphing of the language of democracy into the cant and jargon of the marketplace". The importance of market populism to the present argument is in the ideological principles it brings to bear on socio-economic change, and, most especially in the radical reframing of young people's notions and expectations of employment and remuneration. Chapter One of this thesis (1.0), emphasises consensus as a fundamental factor in development of the knowledge economy; in concert with this factor is found complicity with market populism. The two basic concepts that uphold the, ostensibly, most radical change human society has experienced to-date are, belief in the new order of a knowledge economy being a consensus, and believing complicity with that order will be beneficial. 
In the substitution of 'wealth creation' for 'a job', it appears that the most important role education will be required to fulfil in the roll-out of the knowledge economy is to nurture and foster societies' commitments to what the World Bank's Chief Economist calls a "[k]nowledge culture [for] changing ways of thinking" (Stiglitz, 1999, p. 3). This changing of our ways of thinking does not concern the evolution of learning in the academic sense; it means the development of training in the economic sense to ensure commitment to the overarching new order of wealth creation. Moreover, Stiglitz casts this culture change in the role of a 'public good', that is, a commodity that other people cannot be excluded from consuming (Cole, 1999, p. 46). To emphasise his view, Stiglitz quotes U.S. President Thomas Jefferson who describes public good or, 'non-rivalous' knowledge and information in terms of "He who receives an idea from me, receives instruction himself without lessening mine; as he who lights his taper at mine, receives light without darkening me" $(\mathrm{p}, 8)$. There is an apparent paradox in this World Banker's beneficent portrayal of 'knowledge culture' as the 'public good' exemplifying the 'new' ethos of educating for the knowledge economy. The potential conflicts between notions of world, bank, knowledge, culture, public, good, and economy, seem to fall within the territory Thomas Frank (2001) referred to as "...the morphing of the language of democracy into the cant and jargon of the marketplace" (flyleaf).

The danger for education in this supposedly benign environment is in being induced to become a stockholder in the global transmutation of human society towards a rhetorically 'new and wonderful' world of on-going sustainable prosperity and wellbeing. 


\subsection{SUMMARY}

Education has been rehearsing its role for the knowledge economy over at least two decades and has negotiated extensive reforms throughout that period. In spite of the radical reforms to curricula and management of New Zealand's education system, demand continues for better performance to meet constantly changing needs of the new economy. As traditionally 'proper' jobs have been lost, or replaced by the ethos of Free Agency, growth in the sunrise learning 'industry' has escalated on an unprecedented scale. Learning is now lifelong from cradle-to-grave and is, potentially, both the major occupier of an individual's lifetime 'knowledge' work, and a major source of global earnings.

The World Bank Vice President talks of a new "knowledge culture [for] a change in ways of thinking" (Stiglitz, 1999, p. 3). This change is apparently necessary for appreciating the "...centrality of knowledge and education in general and science and technology in particular" (p.3). Stiglitz is arguing for the consensus view that complicity with the technology-driven knowledge economy affords the only sustainable solution to the prosperity of a global society. Furthermore, education is adorning the cover of the prospectus for this not-to-be-missed, opportunity of a lifetime.

In the next chapter the foundations of the 'Enlightened' modern worldview are explored to develop a better understanding of the grounds on which the knowledge economy has been constructed. 


\section{3. \\ VIEWING MODERNITY}

The knowledge economy denotes the most modern understanding of economic theory and practice. I argue that the knowledge economy is also grounded in the modern worldview. This chapter backgrounds and explores the notion of modern as a worldview to explicate the relationship this has with the knowledge economy. The questions asked are: What is this modern worldview? How is the knowledge economy grounded in the modern worldview? And why is the knowledge economy exclusively grounded in this worldview?

\subsection{INTRODUCTION}

The idea of a modern, or modernity, worldview is often contrasted with the ancient or antiquity worldview, which arose in the philosophy of ancient Greece and continued through to the Renaissance and Reformation of Medieval thought (Thompson, M., 1995). Modernity refers to a scientific way of perceiving and explaining the world, dating from late seventeenth century Europe, which formed a rational and individualistic view of knowledge-often called the Enlightenment (ibid.). Modernity also gave rise to a particular foundational basis of modern world order, linked to the socio-economic developments of modernisation and the cultural movement of modernism (Sarup, 1993). Despite the emergence of postmodern worldviews, the

modern worldview remains predominant and is substantiated by analytical and 
rational explanations, or 'grand narratives' that justify its fundamental beliefs about human beings and how they understand their world (ibid.).

The Modern notion of 'grand narratives' suggests there is a strong element of congruity between modernity and the knowledge economy. An example of this congruence is found in the premise that both modernity and the knowledge economy are philosophically complicit in the primarily patriarchal, anthropocentric rationalisation of a continuing economic world order (Henderson, 1996b; Chomsky, 2000). In contrast, postmodern worldviews critically engage modernity. Their critiques are made through philosophical positions ranging from one of an 'antiworldview' that deconstructs the world order 'grand narratives', to one of 'transformation' that envisions an alternative world, as being emancipatory and ecological in nature.

The exclusivity of the modern worldview in the knowledge economy is based on demand for commitment to consensus, and this is foundational to the philosophical complicity between both worldview and world order. Thus the knowledge economy, grounded in the modern worldview, upholds the virtues of the maxim, "In a time of faith, skepticism is the most intolerable of all insults" (Randolph Bourne, 1964, cited in Frank, 2001, p. v). 


\subsection{WHAT IS THE 'MODERN' WORLDVIEW?}

\section{Ancient times and Modern periods}

Since ancient times the project of human beings has been to discover what there is to perceive and know in the world. For such a project to be sensible to the human mind it must, arguably, involve ways and means that give form to matter. While matter physically exists, the fundamental attribute of form is apparent through the dichotomy of existence relative to non-existence; that is, there is no matter without form. In the antiquity of the Greek philosophical project the relationship was hierarchical, with form taking philosophical primacy over matter (Thompson, M., 1995). However, in the late modernity of twentieth century physical science, form became more concerned with energy than matter, as in the theory of its relativity to time and space, which is exemplified by Einstein's theorem $e=m \mathrm{c}^{2}$.

Historically, therefore, the modern Western world has been seen as one of dualisms and relativity, such as God and man [sic], woman and man, science and religion, self and other, mind and body, intellect and creativity, innovation and entrepreneurialism, knowledge and economy, virtual and real. The dualism of ancient and modern defines the two major Western historical periods, which split at the time of the cultural Renaissance and the religious Reformation, and declares their dichotomous modes of thinking about, understanding, and making progress in the world (Sarup, 1993). Dualisms, relativities, and dichotomies also correlate with the notion of periodisation that divides history not only into ancient and modern, but also into dark ages, middle ages, the Enlightenment, pre-modern, modern, and postmodern periods. The most significant divisions of periods in philosophical understandings are between those of ancient Greek and Medieval thought, and that of the modern 
Enlightenment worldview. Furthermore, the greatest change occurred between the antiquity of Greek and Medieval thought, and the modern Enlightenment view of the world (Thompson, M., 1995).

\section{From Dark Ages to Enlightenment}

In the thoughts of antiquity, order was regarded as fundamentally natural, or was religiously willed to be perfect. Thus, investigating any system of order either confirmed this belief, or proved an inappropriate observation wrong. 'Wrong' deducted incorrect thoughts from beliefs, leaving 'right' ideas to confirm what was 'correct'. This dominant deductive tendency to theorise and perfect beliefs, rather than observe and question evidence, was critically challenged by the fifteenth and sixteenth century sciences of cosmology and astronomy, and through the Renaissance and Reformation movements. With these renewals and reforms, came another method of gathering and sorting thoughts and ideas, namely, the inductive method. Induction overturned deduction by cautioning against 'irrational' beliefs, habits, and assumptions. Taking a position of doubt, the inductive method set out to seek, find, and accept a more modern worldview, contrary to the ancient authority of theological and religious predecessors (Thompson, M., 1995).

Modern inductive philosophical enquiry radically changed the way the world was understood. Discovery took on a new foundational character by inducing dualistic instances into principles and laws of rational thought (Thompson, M., 1995). Observations gathered verifiable information for analysis and to form experiments, to prove or disprove theories upon which natural laws of behaviour could be held to substantiate consequent theories. Furthermore, in seventeenth and eighteenth century 
Europe, the philosophical ideas of Francis Bacon (1561-1626), Thomas Hobbes (1558-1679), René Déscartes (1596-1650), John Locke (1632-1704), Isaac Newton (1642-1727), and David Hume (1711-1776) rapidly expanded philosophy into a scientific view. This is usually referred to as heralding the age of Enlightenment (ibid.). The Enlightenment idea of progress was rooted in the theory of scientific inductive rationality that 'discovered' the world to be ordered and governed by 'natural' laws that also 'naturally' organised society (ibid.). Scientific rationality, therefore, by using the logical processes of inductive reasoning, determined and fixed that which was positively and principally real in the world for the universal progress of human beings and their societies.

The Enlightenment-based philosophical worldview also links with a modern view of social and cultural history. Additionally, modernity is linked to modernisation and modernism, which respectively derive from two distinct senses of the word 'modern'. In modernisation the word modern looks forward, and is used progressively to mean up-to-date and contemporary whereas in modernism modern looks backwards to culturally denote a departure from traditional styles or value. Therefore (Enlightenment-based) modernity is seen as the period projecting progressive modern thoughts, ideas, and inventions, and modernisation is regarded as the innovative social and economic development of the Western capitalist world (ibid.). However, in the second (post-Enlightenment) instance, the cultural and aesthetic movement of modernism arises as a conscious contradiction of cultural concepts of classicism $^{10}$ (ibid.). In some respects the difference between the cultures of modernism and

\footnotetext{
10 'Classicism' refers to the dominant cultural traditions of Europe that descend from ancient Greek and Roman principles (Concise Oxford Dictionary, 1999).
} 
classicism could be said to correlate with that of the philosophy of Antiquity and of the Enlightenment-the encounter in both instances concerns radical change towards discovering new meanings of 'truth' (Thompson, M., 1995; Sarup, 1993).

\section{Big Stories}

A primary objective of modernism was to discover overarching explanations, or 'grand narratives' of meaning in the world, mainly through the stories a culture tells itself about its practices and beliefs (Sarup, 1993). Many of these stories, in literature, art, and music, believed in their enterprise as a revelational project to create unity and coherence in the otherwise fragmented evolution of human history. The confluence of all that is modern is seen in the relationships between modernisation projects, modernist cultural acts, and the correlative state of modernity. These relationships are epitomised by the developments of chemical and physical science in militarism, and the design and technology of industrialism (modernisation); the art, architecture and jazz of urbanism (modernist); and the societies of twentieth century capitalist economism, and communist socialism (modernity).

Basically, there are three differences between the terms employed in discussing the modern worldview of times. Modernity is used, in relation to Antiquity, to define the period from the Renaissance until the present time. During this period Western societies developed a coherent modern worldview rooted in rational science and underwritten by capitalist economics. Through this modern worldview, commencing in the late nineteenth century, the industrial progress of science and technology and the resulting dramatic social and economic change during the twentieth century came 
about-this is referred to as modernisation. Modernism, which is approximately coterminous with modernisation, concerns the culture and aesthetic styles that critically engage with the earlier styles of classicism and undertake a movement towards discovering deeper meaning in the world.

To summarise, modernity is used broadly to concern the period and progress of Western society over the past three to four centuries. Modernisation is more particularly concerned with economic developments and the social impacts of modern science and technology over the past century. Modernism concerns the movement, specifically through the arts, to reveal greater meaning in the world. The three notions embraced by these terms successively overlap, and in doing so progressively dissolve into each other and become less distinct. For example, the purposive distinction between the Romantic art of Joseph Turner (1775-1851) "...as a palliative for urban conditions," (Upjohn, Wingert \& Mahler, 1958, p. 503), and the evolutionary science of Charles Darwin (1809-1882), which "...radically challenged the nineteenth century's view of the universe and everything in it" (Bragg, 1998, p. 159) remain separate and clear. However, in the Surrealism of Salvador Dali (19041989) which demonstrates "...the relativity, flexibility and destructibility of time" (Upjohn, Wingert \& Mahler, 1958, p. 631), as in the 'thought experiments' of Albert Einstein's (1879-1955) theories of relativity, which "...showed that space and time are linked together" (Bragg, 1998, p. 280), meanings are complicated and indistinct, but are also conceptually interrelated through representational ideas of time and space. From these progressively dissolving and intermingling stages of worldviews are emerging 'revisionary' postmodern positions, which are more 'prospective' in nature (Griffin, 1992). However, modernity's powerful worldview remains 
predominant, and is still seen reforming 'reactionary' perspectives to maintain a controlling world order (Orr, 1992).

\subsection{HOW IS THE KNOWLEDGE ECONOMY GROUNDED IN THE MODERN WORLDVIEW?}

\section{Modern Times}

Charles Chaplin's (1936) film Modern Times is an example of a modernist expression of modernisation. In the film, Chaplin uses the principles of modernism to ironically present the tribulations of modernity man [sic] and his problems with modernisation's manufacturing machines (Monaco, 1981, p. 240). Modernisation expanded on the industrial revolution, which had developed from Enlightenment scientific discoveries, and subsequently, through the investment of financial capital, produced technological inventions. The remarkable products of science and technology, together with the capitalist system of economy, created a revolution in the organisation of human communities and their labour force. In less than the duration of the nineteenth century, the location and focus of work moved from the tranquillity of villages and agriculture, to the chaos of cities and industry, where Chaplin's modern man becomes just another cog in the wheel of progress. Amongst the enormous changes that accompanied the relocation and refocus of work were the polarisation of political ideas, of which two-capitalism and communismpredominated in the modern world order through their relationship with economy and industry (Sachs, 1996). Capitalism and communism identified opposing positions that not only distinguished ideological beliefs but also territorially separated parts of the physical world. These two ideologies contributed most of all to the immediate past 'development' of societies of human beings, especially through the 
industrialisation of scientific and technological developments for military purposes. Such 'developments' gave rise to what Hazel Henderson (1996a) theorises as the progression from two World Wars and the "...globalization of the war system...to global economic warfare, which many economists, politicians, and business leaders have hailed as a victory of capitalism and competitive free markets" (p. 2).

\section{Globalisation}

While the term 'globalisation' is subject to many varying interpretations from different perspectives, it is used here to refer to a market place. In this way globalisation identifies the coming together of economic entities to disperse production and exchanges of goods and services, as widely as is possible, around the globe. With the rise of globalisation, has come a revolution in the base of economic production. Initially, natural resources, such as coal and various mineral compounds, formed much of the base of energy generation and raw materials for the nineteenthcentury industrial revolution, but in the twentieth century, oil overtook coal as the essential fuel for the engines of progress. However, during the twentieth century the economic exploitation of these natural resources began to deplete them to an arguably unsustainable level (Orr, 1992; Capra, 1981; Rozak, 1992). This problem, together with the failure of nuclear energy to become a publicly acceptable alternative to hydrocarbon, has necessitated the identification of a new economic base of production (Henderson, 1999). Today, most economic theorists and commentators hold that the immediate future of the global market will be based on a 'knowledge economy' (Neef, 1998; Foray, \& Lundvall, 1996; Frederick, \& McIlroy, 1999). 
It is clear, therefore, the dualist world of modernity has developed dramatically over a period of four centuries from a rurally located agricultural economic base, to an urbanised unsustainable industrial economic base, which is now being supplanted by a new, globalised, knowledge-based, economy. Furthermore, overlapping the last two decades of the twentieth century, another position, namely postmodern, has emerged to critique the fundamental position of contemporary modernity, its projects of modernisation, and the modernist cultural and social 'grand narratives' of the whole global enterprise.

\subsection{WHY IS THE KNOWLEDGE ECONOMY EXCLUSIVELY GROUNDED IN THIS WORLDVIEW?}

\section{Resisting challenge}

The knowledge economy's foundational basis, and its demand for commitment to consensus, presents problems in a world where challenges to its fundamental position are emerging in postmodernism. The reason the knowledge economy is exclusively grounded in the modern worldview is, I argue, because that worldview most strongly resists challenge. As the human population and its interventions in the world increase exponentially, so is that world increasingly being exposed as disordered, or chaotic. The modern worldview, and its world order, finds this disorder intolerable because it gives rise to disbelief and skepticism, which it must act to counter. This act of countering disorder makes visible the strength of modernity on which the knowledge economy rides-its resolute faith in rational rightness and its determination to ignore any challenges. 
The following sections elaborate on ways the world is changing, the challenges that are emerging, and how the global knowledge economy project employs the modern worldview to avoid dealing with them.

\section{Modes of production}

A notion that helps to explain the increasing disorder in complicated problematic positions of modernity, modernisation, modernism, and the emerging postmodern critiques, is the Marxist idea of 'forces of production', and corresponding links to cultural representation. According to Frederic Jameson (1991), there are linkages between 'modes' or technologies of production and phases of capitalism, which generate clear distinctions in cultural formations within modernism and postmodernism. Jameson identifies three primary capitalist phases that accompany cultural formations. The first phase is identified in eighteenth and nineteenth century market capitalism, which employed the steam engine and was represented in cultural realism, that is, true-to-life imagery and literature usually representative of the bourgeois class. The second phase is found in late nineteenth century to midtwentieth century monopoly capitalism, which harnessed electricity and used petrol to fuel engines and was represented in cultural modernism, that is, impressionistic and abstract imagery, and eclectic literature that blurred distinctions of genres and classes of 'high' and 'low' art. The third, most recent, phase is found in multinational or consumer capitalism, which engages nuclear energy and electronic technology as its productive motivity and is correlated in the 'deconstruction' of cultural postmodernism, that is, pastiche, collage, bricolage, parody and irony, in sounds, imagery, and literature. 
What Jamesons' theory illustrates is the links between capitalism, technological progress, and cultural reflections of society. Over the past century and a half, it can be seen that the cultural reflections demonstrate an increase in representation of a disordered and choaotic world that correlates with the increasing expansion of capitalism and technological progress. In other words, cultural representations (television, movies, video games, Internet) are increasingly representing the chaos and disorder in a world that is none-the-less portrayed by its leaders as having a rational and ordered 'bright future' built on a knowledge economy.

\section{Totalising territory}

The central tenet of modernism, namely, rational order, is increasingly extending the territory it encompasses, and also the polarisation of boundaries between the territories. For example, it is the total territorial extent of foreign exchange dealing, satellite television, and e-commerce that enables the creation of polarised boundaries from which profits are made. However, accompanying the increased 'totalising' of territory is an ensuing increase in levels of chaos. As chaos increases, so does the necessity to impose stricter order, and, it is a subjective attitude, rather than an objective condition, that becomes of greatest importance. For the modernist, the characterisation of order as 'good', and disorder or chaos as 'bad', becomes the overriding principle, to the extent that an ideology is formed with a 'grand narrative' to prove its 'truth'. Jean-François Lyotard (1984) referred to this as a 'totalised system' through which social stability and order is maintained. For example the Marxist 'grand narrative' held that capitalism would collapse to be supplanted by utopian socialism. However, a fundamental problem arising from such an 
overarching belief system or 'meta-ideology' is that it masks the instabilities, contradictions, and paradoxes, inherent in ordinary organisation and activity.

One such paradox lies with electronic money. Money, as a token of exchange, now takes the form of a ubiquitous eft-pos card and as a consequence the physical representation of the value of the exchange is removed. In place of the tangible realisation of payment being notes and coins that must be counted and passed over, a number now appears on a screen and a piece of paper is printed rendering the transaction virtually intangible in terms of its real value. Those who are committed to the capitalist enterprise of managing money, prosper well from this change and its effect, and become affluent members of the knowledge economy. However, those with little or no money to manage, are not so fortunate. Not only are they disadvantaged by the 'virtual' characteristics of electronic money, many are also hampered by poor numeracy and budgeting skills that can be attributed to inadequate education. That the interest debts many of these transactions attract for the unmoneyed person underwrites the benefits for the affluent, seems to go unnoticed.

As the totalising territory for the organisation and activity of financial transactions relentlessly expands, so do the paradoxes and contradictions, within ever increasing variables, which the knowledge economy finds more and more difficult to deal with.

\section{Communication codes}

Communication is another crucial aspect of organisation and activity also fraught with instabilities, contradictions, and paradoxes arising from totalising power. It is also one of the most vulnerable systems on which the knowledge economy rides. In 
the late 1960's, Marshall McLuhan's (1967) famous aphorism "the medium is the message" was taken so literally that the means of communication was bolstered to absolutely overpower the content (Postman, 1985). Examples of the consequences of overselling the 'medium as message' abound in multi-media 'interactivity' with 'virtual reality', and 'participatory reality infotainment' television, where style and gratification overpower any semblance of content. Ironically, avid supporters of ICT decry the appalling low levels of literacy and numeracy in the so-called 'knowledge society', while apparently overlooking the pervasive influence of television on illiteracy, of calculators on innumeracy, and the ubiquitous technological convergence of both in computers.

Computers and digital communication are also now characterising what is regarded as knowledge. Modernist knowledge conformed to the dualist, objectives that contrasted science, as good rational progressive knowledge, and narrative as bad irrational primitive knowledge. In this view there is a distinction between knowledge and ignorance (Appignanesi \& Garrat, 1995). However, today there is more concern with discerning knowledge from the chaos of 'noise', as exemplified by CD's. If the CD decoder is unable to detect enough coherent data from the disc, it cannot continue to reproduce the sound and makes an incoherent noise that indicates this, or it stops altogether. In other words, unless information can be coded as a relevant knowledge, it is not knowledge. It is this distinction of knowledge that Lyotard (1984) identifies as most important-Who decides what knowledge is, and who knows what needs to be decided? However, in the technology driven knowledge economy much of that decision-making and taking is already pre-embedded in technological componentry. 
For example, in the software and firmware that imposes a logic framework to control and/or limit how an appliance is operated.

This illustrates the way in which really important questions about a world that is coming to be understood as complex, are lost in confusion and paradox, and obscured by the imposed rational order of the modern worldview in its service of the knowledge economy. Even the use of the word 'complex', in regard to the knowledge economy, is obfuscatory, as it is used more-or-less synonymously with complicated.

\section{Life Time Value}

Power and control over extension and discrimination of knowledge is expanding much further in the globalisation of world. This is occurring through ICT generating knowledge commodities, which are entwined in a cultural 'mediacy' or 'performativity' force effectively indistinguishable from its mode of production. Jeremy Rifkin (2000) argues that previous phases of capitalist production were characterised by the commodification of work, in which the economy, the technology, and culture were distinct. Today, he claims, production is being characterised by the commodification of play and performance, or "...the marketing of cultural resources including rituals, the arts, festivals, social movements, spiritual and fraternal activity, and civic engagement in the form of paid-for personal entertainment " (p. 7). In what Rifkin calls this new Age of Access "...the operative term is the 'lifetime value' (LTV) of the customer...In the new era, people purchase their very existence in small commercial segments" (pp. 7-8). The problem of finding, let alone understanding, the relationships between production, capitalism, and culture in this environment, illustrates the paradoxes that ensue from the power 
of 'forces of production' and the links to cultural chaos in the transitions of modernity to modernism, and on to postmodernity.

\subsection{SUMMARY}

The modernity worldview is as important to the knowledge economy, as money is to capitalism; it represents the force that underpins the foundations of the order it supports. While the form of the force may undergo change, its substance and effect continues to escalate unchecked.

Modernity, as the force that underpins the knowledge economy, also continues to change its form and also continues to escalate in its substance and effect. Proponents of the knowledge economy laud its beneficial effects for the global community; the global knowledge economy, it is said, is the only real solution to third world poverty and the sustainability of the global environment (Giddens, 2000; Huber, 1999). However, beneath the rhetoric of these claims, the mechanics and hierarchical order of science, technology, and capitalism, continue to engineer the anthropocentric future of the affluent. And those who criticise the new order are said to be chopping 'tall poppies' and intent on 'relitigating the past' (Beggs, 2001).

The strongest evidence for the congruity between modernity and the knowledge economy is, I argue, in the cultural representation that pictures the historical complicity between capitalism, technological progress, and social order-disorder. The paradox of this relationship is most ironically represented in the cancellation of 
the release of a 'blockbuster' terrorist disaster movie, as a consequence of the actual, horrific terrorist disaster in New York City on 11 September $2001^{11}$

${ }^{11}$ The terrorist attack on the World Trade Centre buildings, resulting in their total destruction and the loss of thousands of lives. 


\section{4. \\ 'MODERN' EDUCATION}

In the preceding chapter, the term 'modern' was explained as representing a distinctive view of the world that is congruent with the knowledge economy. In addition to the predominance of a modern worldview in the knowledge economy, I further argue that the notion of education as being crucial to the 'knowledge economy' is also grounded in the same 'modern' worldview. Moreover, such a view of education is, on the one hand, the subject of continual 'reform', and on the other hand, is sustaining increasing critical challenge. In this chapter the modern worldview and its relationship with modern education is explored through the questions: What sort of education are we talking about here? How and why is this sort of education typically 'modern'?

\subsection{INTRODUCTION}

In Chapter Three I argue that the knowledge economy is a continuing project in the perpetuation of an anthropocentric world order founded in the modern worldview, which descends from the rational scientific Enlightenment of society, and continues in today's technologically innovative worldview. I also argue that complicity and consensus are key contributing factors to the continuation of this modern world order. The greatest threat to any notion of order is non-compliance, therefore modernity, and its knowledge economy project, maintain order using the traditional method of inducing compliance through education. In this chapter I background the 
history of 'modern' education, and review the issues that have more recently brought about its radical reform.

To clarify the use of 'induce' in relation to 'education', I refer to the root of the word education, educare/educere, which the Concise Oxford Dictionary (1999) defines as to "lead out" or educe, in the sense of "bring out or develop (something latent or potential)" (ibid.). However, the word 'induce' from the root induct-, inducere "to lead in" (ibid.) means to "succeed in persuading or leading (someone) to do something" (ibid.). The view that 'education' is philosophically grounded in the notion of 'leading out' is, I believe, fair. However, I believe it is also fair to argue that the practical experience of most of education's 'clients' is of 'leading in'. Therefore, I advocate renaming the knowledge economy's training, upskilling, and lifelong learning processes; from education to inducation. To make this distinction even clearer I suggest that while education concerns learning to learn, inducation effects learning to earn.

The typical modern notion of education (inducation) is best reflected in the characteristics that typify compulsory educational institutions and their systems of governance. These include, an overarching 'curriculum framework', school entry 'assessment tools', achievement 'objectives' and 'indicators', 'national certificates of educational achievement', and an education review office to ensure compliance with a strictly regulated system. At the non-compulsory level, the system shifts from a compliance focus to a complicity and consensus focus. Rather than being reliant on imposed regulatory regimes, non-compulsory education is constructed around 
commercial models that induce clients with promotions of the importance of 'comparative', 'competitive', and 'commodification' in learning.

\subsection{THE ROOTS OF 'MODERN' EDUCATION.}

\section{Degrees of change}

In talking about 'modern' education it is helpful to review the scale of change in what is being called a 'modern' world. Postman and Weingartner (1971) give a useful and topical illustration of time in relation to media with a clock face, representing with sixty minutes the period of time writing systems have been known. That is, a period of approximately three thousand years, with each minute equal to fifty years. On this scale (calculated at the time of Postman's and Weingartner's writing) changes in human society progressed relatively steadily until the arrival of printing nine minutes ago. After which, six minutes later, or three minutes ago, the telegraph and photography arrived. Two minutes ago, telephones, movies, and radio, arrived, followed by television ten seconds ago, leaving computers, communications satellites to arrive within the last second (pp. 22-23). In this illustration, the 'modern' period has existed, in relation to the technology of writing, for approximately six minutes. Therefore, when considering change, knowledge, and education, it helps to keep the exponential scale of increasing change in mind, because, as Postman says, while "...change isn't new... what is new is the degree of change...Change changed" (p. 23).

A little over half a minute ago, on their scale of fifty years to the minute, Postman's and Weingartner's concern for changed change resulted in their thesis "...that change 
- constant, accelerating, ubiquitous - is the most striking characteristic of the world we live in and that our educational system has not yet recognized this fact" (p. 13). Furthermore, their concern was for "...an entirely different and relevant conception of education than our schools have so far managed to reflect" (p. 14).

Twenty or so 'seconds' later, Postman (1993) wrote in Technopoly: The surrender of culture to technology of modern American education as being

...to help the persevering student to get a good job. And that's it. Well not quite. There is also the idea that we educate ourselves to compete with the Japanese or the Germans in an economic struggle to be number one...[this] suggests...that the United States is not a culture but merely an economy, which is the last refuge of an exhausted philosophy of education" (p. 174).

What Postman is referring to here-and again, in his later book The End of Education: Redefining the value of school (1996)-is the predominance of the persisting technocratic education model in an emerging 'new' economy.

\section{Technocratic education}

Catherine Cornbleth (1990) uses the term "technocratic persistence" (p. 19) to explicate what she regards as the "decontextualisation of curriculum" (ibid.) that became apparent in America in the early twentieth century. Cornbleth explains that the coincidence of curricula reconstruction and the ascendancy of "...social efficiency and scientific management movements" (ibid.) caused the curriculum "...to be seen as a product, or plan for teaching, that was developed according to procedures of task analysis by outside experts and then made available to classroom teachers in various school settings" (ibid.). Once established, Cornbleth says, the

persistence of this model is very hard to change and it becomes embedded in 
practices. Of particular significance to technocratic persistence, she says, is the "conceptualization of modern consciousness" (Berger, Berger, \& Kellner, 1973, cited in Cornbleth, 1990, p. 20). Berger, Berger, and Kellner, (1973) conceptualise consciousness as a "network of cognitive and normative definitions of reality" ( $p$. 108), located and constructed in shared interactions between people and their institutions-in other words a "symbolic universe of modernity" (ibid.). Major themes of this symbolic universe are given by Berger et al, (1973) as functional or technical rationality, componentiality, makeability, and progressivity, derived from technological production; and orderliness and taxonomization (pp. 111-114). Two of these themes, makeability and progressivity, are also familiar in the underlying principles of the knowledge economy. Makeability, for example, refers to a "tinkering attitude...[and a]...problem solving inventiveness" (p. 30) that develops a "...certain kind of ingenuity and creativity .... which ipso facto excludes other kinds" (ibid.), while progressivity has "...an 'onward and upward' view of the world" (p. 113). While these terms for the themes are couched in the language of an industrial age, the knowledge age notions of innovation and entrepreneurialism, which they reflect, are unmistakable. Summarising her critique of technocratic persistence in the curriculum, Cornbleth (1990) notes that the linkage between technocratic curriculum practice and modern consciousness is one of "...reassurance that the right path is being trod" (p. 22). Furthermore, individual curriculum statements and their explanatory framework are taken to concern what a curriculum is, and how it works as a way of systematically organising education. As she says, "it provides an illusion of explanation that serves to direct action...[u]pon closer examination, however, the illusion of understanding fades, and the tautology emerges. A technocratic approach prescribes but does little to explain curriculum practice" (ibid.). 
Through this persistent technocratic regime, education has been brought under the stewardship of what Postman (1996) calls "...the god of Economic Utility" (p. 27) and, within the realm of this god, proper attention to schoolwork, and its prescribed homework, is supposedly rewarded with a good job. Schooling, says Postman, concerns preparing children for "...competent entry into the economic life of the community" (ibid.). Furthermore, to satisfy the liturgy of what Postman calls economic utility, managing the systematic process of education has become a matter of considerable importance, in terms of its costs, operations, and outcomes. In other words, those charged with stewarding the public resources to operate educational systems, require evidence of optimum performance from budgeted economic inputs and wealth creating outputs. Additionally, those who can afford to pay for education want to ensure they obtain the very best possible results for their money (Fiske \& Ladd, 2000). While the 'learner' receives rhetorical attention in government policy statements embracing education for the knowledge economy, such as Meeting the Needs of All Learners (Maharey, 2001a), the official learning mode of the technocratic education model remains. As Stevens (1998) says, "...learning is the tool of individual and organisational advancement" (p. 94, Emphasis added).

\subsection{THE REFORMS OF 'MODERN' EDUCATION}

\section{Critical pedagogy}

Peter McLaren (1994) writing on critical pedagogy in Life in Schools, begins with the chapter 'Broken dreams, false promises, and the decline of public schooling', and a chart titled 'Moments in America'. Like Postman's and Weingartner's 'clock', McLaren's chart is time-based and begins with the entry, "Every 35 seconds an infant 
is born into poverty...[and ends with]...Every 10 seconds of the school day a student drops out of school" (Childs Defense Fund, 1991, cited in McLaren, 1994, p. 2). McLaren's concern is with the contrast between the statistical reality of poverty and the "...confluence of patriotism and market strategy...in such an orgy of selfassertion that students are unable to evaluate the implications of their ideological allegiance" (p. 4). In other words, after two decades of 'reform', education is still having problems with what Postman and Weingartner (1971) called 'crap detecting'. The reforms, which have brought about the great social divides of the last decade, originated in reports and recommendations designed to impart a new pedagogical ideology;

...the new efficiency-smart and conservative-minded discourse encourages schools to define themselves essentially as service institutions charged with the task of providing students with the requisite technical expertise to enable them to find a place within the corporate hierarchy" (McLaren, 1994, p. 6).

This pretence of technologising learning, as being positively empowering education, has become mythologised, according to McLaren who relates how

...technocratic consciousness is looked upon as the new educational mechanism for generating classroom health....A particularly serious problem with the technocratic mentality is its appearance of objectivity and value-neutrality. What its adherents don't tell you is that a hidden political agenda oftentimes informs new policy and program directives" (p. 220).

Accompanying these observations, in a chapter titled 'New and old education myths', McLaren also writes on the myth of equal opportunity. An increasingly common theme in the technological, ideological reform model of knowledge economy education, is the "knowledge-divide" (Max, 2001) problem, also characterised as the "info-rich, info-poor" (Haywood, 1995) gap, which alienates and/or marginalises those lacking the capability or facilities to access knowledge/information. The 
solution to this 'problem' is apparently, all a matter of access-wiring up the poor classrooms to a magical web of knowledge will solve this problem overnight. However, as McLaren comments,

[1]ife chances are socially conditioned to a greater extent than they are determined by individual effort. Yet we live in a culture that stresses the merits of possessive individualism, the autonomous ego, and individual entrepreneurship. In this prevailing view, social conflicts are reduced to individual, subjective concerns rather than problems having to do with social and material inequality and collective greed and privilege" ( $p$. 222).

This suggests that the view of classrooms full of inspired, motivated, successful, 'wired' students, may be over-optimistic.

\section{Reformist pedagogy}

In Chapter Two (2.1) I refer to Marshall's (2000) comments on educational reform in Aotearoa-New Zealand, which, he argues, introduced the new managerialism, and, citing Davis (1997) he notes that "...in New Zealand the logic of managerialism (was pushed) further and faster than any other nation" (pp. 212-213). The concern Marshall identifies is that "[i]f globalisation is inevitable, then even whilst it is concerned with more than economic factors the application of managerialism to all sectors of New Zealand society opens up the possibility of rapid penetration by the sorts of world view that underlie at least the economic face of globalisation" (p. 213).

In a comprehensive volume devoted to globalisation and school reform, David Gabbard (2000) writes that the contents advances a 'threefold political agenda', which: Firstly, demonstrates that the lexicon of educational reform in the U.S. reflects an economic worldview; secondly, contends an 'economized worldview' will progress the 'nefarious' effects of political, cultural, and economic domination; and, 
thirdly, offers 'alternative concepts and meanings' (p. xi). In a chapter titled 'Reform', Thomas Popkewitz (2000), concisely locates educational reform in the context of modernity. He says "reform as the administration of social life is an invention of the $19^{\text {th }}$ century...The Progressive Era in the United States (1880-1920) [was] called the 'Age of Reform' " (p. 34). The strategies of reform in this 'Age' concerned the social construction, or "...with 'making' the individual who could participate in modern social and political institutions" (ibid.). For Popkewitz, the intervening decades have masked the governing function of reform until "[t]odays' educational reforms reconstitute the image of governing the child" (p. 38). Popkewitz concludes that the new reform practices that purport to democratise schools in the search for a 'normative ideal' are really governing strategies that "...decentralize the individual by making specific attributes and dispositions the focus of change" (p. 39). In the new focus on commodified knowledge, attributes and dispositions are centralised on consumption, consumption, consumption.

\subsection{THE REASONS FOR 'MODERN' EDUCATION}

\section{Consensus \& compliance}

The overarching rule of anthropocentric power is crucial to the maintenance of social consensus, economic compliance, and progressive development of complicitly modern human beings. Contradictions of this view are portrayed as 'backwardlooking', 'turning back the clock', 'relitigating the past' and 'neo-luddite'. In other words, modernity expects a consensus on acceptance of the rules defining the right track to the future, and education is crucial to 'learning' this worldview right from the start, that is from early childhood. As early childhood educationist Lesley Max 
(2001) says, "The first three years last forever. They largely determine whether the child will grow up to be a pro-social, competent contributor to our society, or a dangerous, expensive drain upon it" (p. 4, emphasis added). A fundamental determinant of this typically modern dichotomy is, according to Max, because "[t]here has been a massive norm-shift in regard to family formation in the last 20 years, and erosion of the foundation of the family - parental, especially paternal, responsibility" (ibid.). Moreover, Max says:

Poverty breeds poverty. We must break the poverty cycle. An American finding is that, of people who finished high school, married before they had children and had their first child after the age of 20 , the great majority were not poor. Of those who did none of the three, the great majority, were poor. Family formation can no longer remain a 'no-go' area (pp. 4-5).

In making these views known to the 'Knowledge Wave Conference', in a paper titled Social Cohesion and Bridging the Knowledge Divide: The New Zealand Perspective, Max, as the Head of the HIPPY ${ }^{12}$ early childhood education "service" [read as business] presents a modernist position on libertarian reforms (Max, 2001). Her views respect cultural and gender inclusivity and equity, autonomy, democracy, the elimination of poverty, and the lack of patriarchal parental responsibility, and, simultaneously acknowledge the support of and applaud the principles and rules of economic plentitude and its patriarchal power-base.

12 'HIPPY'-Home Instruction Programme for Preschool and Year One Youngsters. Max (2001) describes the programme involving parents as "the key, working for fifteen minutes a day with their child, over a period of two years, on cognitive enrichment. Materially poor homes become family learning centres...significantly raising levels of literacy, numeracy, problem solving skills, school behaviour, parent engagement in education, and the parent/child relationship - unarguably the foundation of the knowledge society" (p. 6) 
Max's address includes the following 'challenges': Overcoming an insular mindset bent on redistribution rather than economic growth and hostility towards wealth creation and the global economy; the fostering of national unity; making a massive shift in consciousness, which requires the "...human services community...to open its eyes to economic reality, and stop demonising business" (p. 4); and fostering our intellectual resource, which "...is to the knowledge economy what the silicon chip is to the information industry" (p. 5). The final challenge, says Max, is to "...apply the skills of the bridge-building engineer - the analysis, the understanding of foundations, mechanics, resilience, stresses - and the reliance on evidence to underpin action and expenditure, and to assure success" (p. 7). A more solidly structural, and objectively modernist worldview of education and learning in the knowledge economy, is difficult to imagine.

\section{Progress \& development}

The modern view of educational progress and development is based on a tradition of Anglo-American educational philosophy, where "...knowledge has both its literatures (content) and its languages (disciplined procedures), and successful learning initiates earners into both" (Hirst 1974, cited in Lankshear, 1999, p. 8). Such a "justified true belief" (ibid.) model of knowledge, according to Colin Lankshear, has underpinned the epistemological standard since the time of Plato. In a paper addressing 'epistemology for education in the digital age', Lankshear sets out some underlying problems of the tension between scientific and narrative knowledge in the shifting ground of modern industrial, to postmodern technological worldviews. In the new drive for wealth-generation through knowledge-creation, Lankshear points to some changing attributes of the status of knowledge, which include: its economic 
advantage as an international commodity; its abandonment of constituents that cannot be translated into information; and, its separation from the knower, that transforms it into a transactional commodity between supplier and user (p. 2). At the postcompulsory and further education end of the learning spectrum these changes are creating greater emphasis on the commercial value of knowledge. As Lankshear puts it:

The primary concern of professional-oriented students, the state, and educational institutions will be with whether the learning or information is of any use-typically in the sense of 'Is it saleable?' or 'Is it efficient?'-not with whether it is true. Competence according to criteria like true/false, just/unjust have been displaced by the criterion of high performativity (p. 3).

In the new tertiary education environment, the primary focus of knowledge is shifting from learning about learning to learning about earning; in place of a broad quest for comprehending values, is the definition of questions for apprehending the value. Lankshear (1999) cites Marshall (1998) who considers "...educational institutions ...will be used to change people away from the former liberal humanist ideals (of knowledge as a good in itself, of emancipation, of social progress) to people who through an organsized stock of professional knowledge will pursue performativity through increasingly technological devices and scientific managerial theories" (p. 12, cited in Lankshear, p. 3).

\subsection{SUMMARY}

Today education is facing the latest onslaught of criticism for its failure to deliver basic literacy and numeracy skills. It is, perhaps, the irony of postmodernity that the deconstruction of a literate and numerate society has occurred as a consequence of 
the aspirations and achievements of the "symbolic universe of modernity" (Berger et al., 1973, p. 108). Moreover, the greatest effects of modernity's symbolic universe are being realised at the precise moment they are most sorely missed by the so-called 'Knowledge Society'. It would appear that those most responsible for the destruction of education and its supplantation by the notion of what I call inducation, remain ignorant of their part in a deleterious effect on knowledge and the underlying economic cause, and relentlessly continue to reassure each other they are still riding the right track

In the next chapter the modern views of educating for the knowledge economy, outlined above, are exposed to alternative views of education and learning that are emerging in postmodern ways of thinking. Rather than seeing contrasting sets of views on a modern to postmodern continuum as being the way forward, notions of complex ecological postmodernity engage with emerging transformative pathways. 


\section{5. \\ POSTMODERN WAYS}

The preceding chapter critiques aspects of the modern worldview; which is not to argue that the modern worldview represents an incorrect way of thinking. It is, however, argued that there are alternative ways of thinking about and understanding the world. These ways include thinking in postmodern ways. This chapter addresses two questions: What are postmodern ways of thinking and understanding? And why are they fundamentally different from those found in modernity?

\subsection{INTRODUCTION}

'Postmodernity' is a contested term and a range of meanings and usages are apparent in the literature. I will discuss three positions, which I identify as; (i) neo-liberal postmodernism, (ii) anti-modern postmodernism, and (iii) ecological postmodernism. Briefly, the first understands post-modernity as the successor to modernity; the second, sometimes called 'ultramodernism' ${ }^{13}$, entails a radical critique and negation of modernism; and the third involves an 'ecological' transformation beyond modernism ${ }^{14}$.

\footnotetext{
13 'Ultramodernism' is suggested by David Griffin (1992) as an alternative term for the 'deconstructive' or 'eliminative' postmodernism of the Continental philosophers, Wittgenstein, Heidegger, and Derrida, because "...its eliminations result from carrying modern premises to their logical conclusions" (p. iv).

${ }^{14}$ Davis, Sumara, and Luce-Kapler (2000) propose 'ecological postmodern' as a term to expand on postmodern discourses that "...tend to focus on the realms of human culture and sociality. Ecological
} 
Attention will also be drawn to another term, 'the third way', which is sometimes confusingly associated with postmodernity. This neo-liberal notion is based on social democratic values and economic rationalism, and tends to be drawn into postmodern discourse through its expressions of concern for social, environmental, and ecological matters (Giddens, 1998, p. 54) However, this should not be taken to imply an association with 'ecological postmodernity', which embodies 'essentially' ${ }^{15}$ different understandings of the world.

In this thesis, ecological postmodernity is most distinctive from the other postmodern positions, in seeking to transform ideas of education and learning (Orr, 1992; O'Sullivan, 1999; Davis, Sumara, \& Luce-Kapler 2000). It proposes to do this by transcending the neo-liberal innovative reconstruction of cultural economy and the ultramodern critical deconstruction of cultural history (O'Sullivan, 1999), and through adopting an 'enactivist' approach, (Davis et al., 2000) which will be explained fully in the next chapter. The notion of ecological postmodernity also has the characteristic of what I am calling a 'planetary prospect' (which perceives potential in the world) as distinct from a worldview (that defines a perspective of the world). The planetary prospect revises and resists two fundamental aspects of modernity: it revises economy to become an intrinsic aspect within ecological learning, and it resists any condition of hierarchical order that is understood to 'exist' in modernity.

postmodernism pushes the envelope to include what modernist and postmodernist discourses have tended to categorize as not-human: bodily subsystems, the biosphere, and so on" (p. 177).

${ }^{15}$ From this point on, I am using 'essentially' and 'essential' in italics to mean a non-foundational qualitative aspect, as in "the intrinisic nature of something; the quality which determines something's character" (Concise Oxford Dictionary, 1999). 


\subsection{WAYS OF POSTMODERNITY}

\section{The postmodern condition}

In the literature, postmodernity is usually held in contrast to its companion modernity. On one hand there is the modern foundational worldview of a rational world order exemplified by the Enlightenment; on the other hand there is postmodernity, which is both against and beyond all that is modern (anti-modern), and is exemplified by Deconstructionism ${ }^{16}$. The deconstructionist view sees postmodernity as 'anti-foundational' (Sarup, 1993, p.132). However, I argue that postmodernity also has interpretations that are prospective and intuitive about diverse and emerging understandings rather than being specific or particular about defining knowledge. Furthermore, this notion of intuition and prospect links postmodernity back to postmodernism (the cultural effect of the overall postmodern position) which, having de-constructed modernity's order, makes no objective or structural distinctions of itself. The postmodern artist, for example, expects pluralistic readings of her/his work to make many meanings without relating her/himself (mind-bodyworld) to the reader-self. This 'non-worldly' condition is seen to arise from the reactionary characteristics of modernism in art and literature, referred to in Chapter Three (3.1), which are said to have transgressed the boundary of rational interpretation and opened the way for the philosophical critique of foundational, universal knowledge (ibid.). From this critique emerges Jean-François Lyotard's (1984) theory of the postmodern condition, which fundamentally concerns rejection of the totalising power of knowledge through what he calls grand narratives that

\footnotetext{
${ }^{16}$ A method of philosophical and literary critical analysis that 'deconstructs' the "relational quality of meaning, and the assumptions implicit in expressions" (Concise Oxford Dictionary, 1999).
} 
legitimated the "myths of the modern age" (ibid.). This view argues that there are no totalising 'big stories' only lots and lots of stories that happen. While I endorse the rejection of big stories that totalise power, I also interpret postmodernity as being more like an intuitive prospect than a contrasting view of the world. In this way postmodern thinking 'dissolves' the structured order of modernity into sensitivity (awareness and consciousness) about other experiences of 'structure' (complexity) that revises foundations. My interpretation does not exclude ways of thinking by rejection; it dissolves and revises thinking towards new ways for understanding.

\section{Neo-liberal post-modernity}

The neo-liberal position, in relation to postmodernity, is included in this chapter because it is predominant in educational policy discourses, which, in turn, influence interpretations of postmodernity. An important feature of neo-liberalism is the modernist continuity that positions paramount interest of the self as the determinant of wealth, this being constructed "...around the valuative characteristics of an efficiently acquisitive class type" (Apple, 1998, p. 80), that of the citizen as consumer. The relationship between the 'consumer citizen' and postmodernity is most evident in his/her consumption of 'cultural capital' that showcases access to affluence, especially through the technological literacies of new media that are associated with the new 'cultural capital' of the 'knowledge-based society' (Wallace, 1999). Examples of this 'capital' include the media products of film and television, music videos, computer games, interactive novels, and electronic 'art'. 
The cultural capital of the affluent society of neo-liberal postmodernity is exemplified by what Frank (2001) calls 'cult-stud' ${ }^{17}$ :

The active-audience faith of the cult-stud becomes less an article of radical belief and more a practical foundation for the reprioritized audience research being done by the new breed of marketing experts, who can be found commenting lucidly on the postmodern condition ...laying out plans to 'reenchant' the brand with a 'liberatory postmodernism' and warning advertisers to create with the active, emancipation-hungry consumer in mind. One day they're attentively following the Star Trek listserv or studying the counterhegemonic funeral wailing of the Warao people; the next day they're inventing brands for a nation of alienated 7-Eleven shoppers and hegemony-smashing mall walkers. Now that's interdisciplinarity (pp. 305-306).

In other words, Frank is saying that in the neo-liberal condition of 'liberating postmodernism', the emphasis is on 'capital' rather than 'culture', and what becomes apparent as the feature of this position is a 'mindless' ${ }^{18}$ commitment to the stylised 'track' to the future.

\section{Diverging postmodernity}

Before elaborating on the other two positions I identify in postmodernity, I will provide a brief explanation of their origins. The positions are distinguished by what Griffin (1992) terms deconstructive or eliminative postmodernism and constructive or revisionary postmodernism (p. iv). To develop this interpretation Griffin (1992) reviews the understanding of modern in a way that retires from implying approval and synonymity with all that is contemporary and progressive. Rather than

\footnotetext{
${ }^{17}$ Frank (2001) says of this term "[a]lthough cultural populism appeared everywhere in academia, its best known and loudest proponents were the various celebrities of the rapidly growing discipline known as cultural studies - the 'cult-studs,' to use the phrase of one starstruck reviewer" (p. 282).

${ }^{18}$ I use 'mindless' in the sense of uncritical consciousness that Ellen J Langer (1989) contrasts with 'mindfulness'.
} 
specifically denoting modernity as the revelatory period, and modernism as the reactionary movement, as explained in Chapter Three (3.1) his use of the terms take on a more connotative and critical complexion. For example, he interprets modernity as a disruptive aberration in the natural evolution of the world, and modernism as "...less and less The Final Truth, in comparison with which all divergent views are seen as 'superstitious' " (p. iii). Most significantly, Griffin holds that "[t]he modern worldview is increasingly relativized to the status of one among many, useful for some purposes, inadequate for others" (p. iii). From this view Griffin develops an alternative position on postmodernity's condition.

Following Lyotard's initial identification of a postmodern 'condition' of society there was a wide-ranging, interdisciplinary adoption of the term. Subsequently, a degree of consensus currently understands 'postmodernity' to reflect a "new condition of society" (Andermahr, Lovell, \& Wolkowitz, 2000, p. 207), that incorporates a "diffuse sentiment...that humanity can and must go beyond the modern" (Griffin, 1992, p. iv). Furthermore, Griffin says, this sentiment gives rise to the term's use in various confusing ways that can also be contradictory, such as can be found in art and literature, and "new age metaphysics" (ibid.). It is philosophy and theology, however, that Griffin says the term postmodern is used to refer to the two quite different positions he outlines. From this short explanation of interpreting 'postmodern' it will be apparent that there are no uncontested meanings of the term. Nevertheless, I will follow Griffin and advance meanings for two further positions that are distinctly divergent. 


\section{Ultramodernism}

Griffin (1992) sees the first deconstructive or eliminative position as a 'philosophical' postmodernism inspired by the Continental philosophers including Ludwig Wittgenstein, Martin Heidegger, and Jacques Derrida-it is the continental philosophers' term 'deconstruction', which gives rise to Griffin's usage (p. iv). The most significant characteristic of this position is the 'anti-worldview' employed to deconstruct, or eliminate, the necessary elements for a worldview to exist. Using concepts such as God, self, purpose, and meaning to "...carry modern premises to their logical conclusion" (p. iv), suggests, for Griffin, "Ultramodernism" (ibid.). This notion of ultramodernism is helpful in distinguishing the conventional postmodern position, which is transgressive in outlook, from the less common, constructive and revisionary, or transformative, position, which is also related to an ecological postmodern position (Davis, Sumara, \& Luce-Kapler, 2000).

\section{Transformative postmodernism}

The second, constructive or revisionary position, seeks to adopt an alternative worldview through "...a revision of modern premises and traditional concepts" (Griffin, 1992, p. iv), rather than rejecting all notions of previous worldviews. However, this position is not merely one of revision, it also proposes to be inclusive and emancipatory towards movements such as feminism, peace, and ecology (p. v). While admitting that deconstructive postmodernists will see this view as "...hopelessly wedded to outdated concepts" (p. v) (such as spirituality) Griffin concludes that his proposition "...involves a creative synthesis of modern and premodern truths and values (p. v). Edmund O'Sullivan (1999), follows Griffin and supports a 'revisioning' of modern premises, but "...within a cosmological orientation in which human experience and knowledge are situated in the unfolding 
manifestation of the universe" (p. 30). O'Sullivan emphasises he is not introducing a 'master narrative' here, rather, he is "...attempting...to provide a powerful generative vision that leaves open the place for other visions and accepts as natural that diversity is a desirable value" (ibid.).

In support of this view, I propose that O'Sullivan's distinction between a 'master narrative' and a 'powerful generative vision' lies in the purpose each is put to. That is, the former is towards ideological concentration of power, the latter towards transformative dispersion of empowerment. The nub of the argument in this issue is to do with ways of becoming postmodern, namely that there is no big story, there are only lots and lots of stories, which happen.

\section{The 'third way'}

This term represents a position that stands astride the modern pillars of social democracy and economic rationality (Giddens, 1998, p. 54). The third way lauds social democratic values, such as equality, protection of the vulnerable, freedom as autonomy, and pluralism, which are considered characteristic of 'postmodernity' (p. 66). However, because of its political commitment to philosophical conservatism, particularly by Britain's New Labour government, these values, and their associated aspirations, are paradoxically referred to as "modernization" (p. 67). In this sense, according to Giddens, modernization "...is not about 'more and more modernity', but is conscious of the problems and limitations of modernizing processes" (ibid.). The term itself is not new. As Giddens (2000) says, "[d]uring the Cold War period, many saw social democracy itself as a third way" (p. 1). This 'way' was seen as being distinctly different from American market liberalism and Soviet communism. The 
'third way' in its more recent British/American adaptation not only bridges and cohedes disparities between factions, it also lays claim to values of 'complex', 'transformation', 'equality', 'inclusivity', and 'nurturing' (Giddens, 1998). However the 'third way' also attracts its critics. Giddens (2000) cites criticisms of it, which include: a lack of coherent content; a lapse into a 'middle England' form of conservatism; a neo-liberalist attitude towards globalisation; that it is fundamentally an Anglo Saxon project; that it rides on the back of economic prosperity; and that it ignores ecological issues (pp. 22-26). Giddens' seemingly apologist position rests on "...making left of centre values count in a world undergoing profound change" (p. 163). To achieve this he proposes the 'reconnection' of the 'three spheres' of public, state, and civil, in society, through a new social contract, which recognises "[t]here is no known alternative to the market economy any longer; market competition generates gains no other system can match" (p. 164, emphasis added). This ultimate statement appears to be the third way's 'bottom line'.

\subsection{ECOLOGICAL POSTMODERNITY}

\section{Reality, nature, and human nature}

My first encounter with an ecological and postmodern regard for education was through a symposium of papers in the Journal of Curriculum Studies, introduced by Noel Gough, (1989a) thus:

Stephen Toulmin (1982: 254) has suggested that we no longer live in the modern world, but rather in a 'postmodern world...that has not yet discovered how to define itself in terms of what is, but only in terms of what it has just-now ceased to be'. The transition into a postmodern world has been explained by some scholars as a paradigm shift...As a result, speculation about the nature and character of a 'new paradigm' has exercised the minds of many scholars in a variety of fields, including the study of curriculum.... The 
common thread of the papers that follow is their concern to explore qualities of reality, nature and human nature that have been obscured by the limitations of the modern Western scientific/industrial world view and the curricula which have been designed within it (pp. 223-224).

In addressing their concerns about curriculum paradigms and the postmodern world, Noel Gough, William Doll (1989), and Richard Slaughter (1989) made me critically aware of other ways of thinking about the world and education. Despite such perceptive critiques of 'limited' ways of thinking, the conventional view continues to ignorantly exploit learning, albeit within transitional shifts in worldviews.

\section{Ecopolitics}

In Gough's (1989b) paper, From epistemology to ecopolitics: renewing a paradigm for curriculum, his 'ecopolitical' perspective emphasises the need to critically question Western educational orthodoxies, especially those that perceive learning as grounded in technical systems, as a

...process of guided induction into bodies of organized propositional knowledge, in the workings of formal logic and in the skills of textual expression and comprehension (through which the organized propositional knowledge is accumulated and accessed) (1989b, p. 227).

$\mathrm{He}$ is also very concerned about the systemic basis of mass education, which is "...founded on spurious theories of perception and knowledge...supported now by entrenched social interests and powerful elites" (p. 229). Ultimately Gough's argument is against exclusionary approaches in education, and is for, inclusive, holistic praxis moving towards what he terms "exemplary practices" (p.234). This view is exemplified in a comparison of what he identifies as 'epistemological' and 'ecopolitical' education paradigms given in Figure 5.1 (p. 238). 


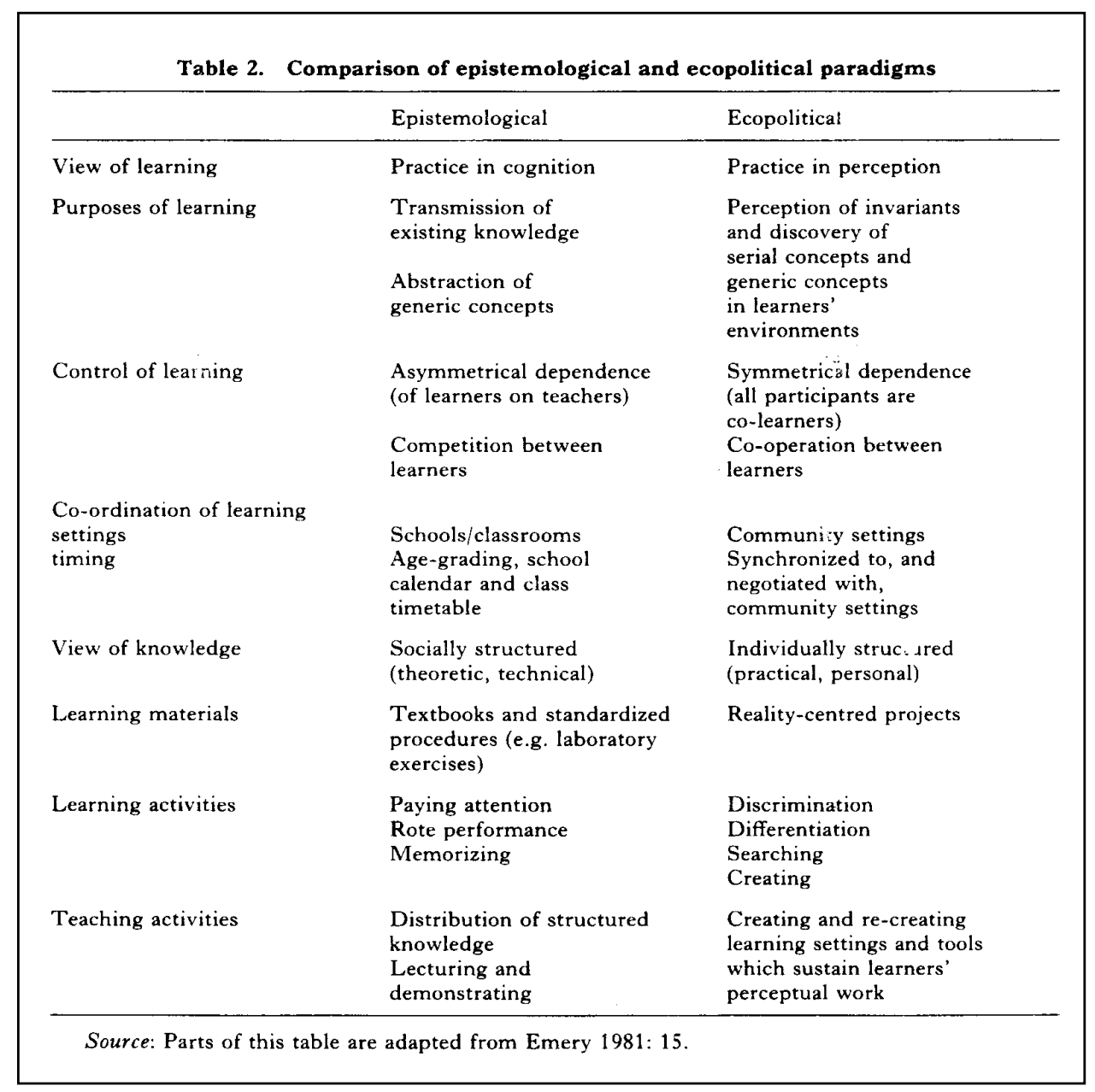

\section{Figure 5. 1: Gough's epistemological and ecopolitical paradigms}

(Gough, 1989b, p. 238).

In the epistemological paradigm, learning and teaching are cognitive, directed and induction-focused, whereas, in the ecopolitical paradigm learning and teaching are perceptive and cooperatively facilitated. Gough's paper, together with those of Doll and Slaughter, engendered for me a realisation that coherent holistic alternatives to contrived, systematic, schooling-based, mass education are emerging in the context of evolving postmodern knowledges.

A significant theme in Gough's work is the alternative educational implications of meanings of 'ecological' in the emergent postmodern worldview. This lead me to the 
question: How to identify a theoretical approach to engage with these emergences of educational alternatives and postmodernist knowledges? Gough's closing sentences gave me a clue. He says, "I find that an ecopolitical world view provides me with more interesting stories to tell (and hear), and more 'playful' work in which to engage" (p. 239). These notions of 'hearing' and 'playing' helped me engage with the theoretical approach of 'enactivism' ${ }^{\prime 19}$, which will be explained further in the next chapter.

\section{Postmodern ecological literacy}

Ecological Literacy: Education and the transition to a postmodern world (Orr, 1992) features the introduction by series editor David Griffin (1992) that sets out the diverging 'deconstructive' and 'constructive' positions of postmodernity, outlined above (5.1). Griffin argues that while the project of both positions is to transcend modernism as a worldview founded in Enlightenment discoveries in science, and modernity as the world order that accompanied the worldview (pp. iv-v), their approaches differ. Deconstructive or 'eliminative' postmodernism, Griffin argues, seeks to overthrow modernity through an anti-worldview, by deconstructing or eliminating the elements that constitute the view. In contrast, constructive or revisionary postmodernism, seeks to transcend modernism by revising premises and concepts of modernism and modernity to construct "...a new unity of scientific, ethical, aesthetic, and religious institutions" (p. iv). Such a worldview, Griffin

\footnotetext{
19 'Enactivism' is a postmodern way of thinking that complexifies learning, knowing, and acting, complexly within and without bodily being and worldly experiencing, 'all-at-once'. Enactivist theory descends from the phenomenology of Maurice Merleau-Ponty, the biology of Humberto Maturana,
} 
continues, is not limited to revision but also concerns an evolving postmodernity, which will "...support and be supported by the new worldview" (p. v). The new worldview that Griffin envisions will transcend modernity's "...individualism, anthropocentrism, patriarchy, mechanization, economism, consumerism, nationalism, and militarism" (ibid.). While acknowledging that constructive postmodernism is anathema to deconstructivists, Griffin argues that the constructive position is more genuinely postmodern because it adopts an adaptive and inclusive approach to modernism and modernity-it seeks to avoid throwing out the baby with the bath water (ibid.). Orr (1992) moves to enact Griffin's constructive approach (outlined in 5.1) to postmodernity through education. Orr sees this as having a "...primary role in the journey to a postmodern world" (p. x). He considers education for the modern world as being about the 'conquest of nature' and 'industrialisation of the planet', which "...tended to produce unbalanced, underdimensioned people tailored to fit the modern economy" (ibid.). Education in a postmodern world, Orr says, needs a different agenda-"...to heal, connect, liberate, empower, create, and celebrate. Postmodern education must be life-centered" (ibid.). Furthermore, Orr clarifies what he regards as the distinctive positions on the educative processes of 'schooling', 'training', and 'learning', and notes that schooling and learning should not be confused. Whereas training is the "...inculcation of rote habit...'Learning' is what can happen throughout life for those willing to risk it" (ibid.). He concludes, "[p]ostmodern education has to do with the integration of schooling and active learning" (pp. x-xi). The book itself is a primer on teaching and learning for an ecologically sustainable future. It sets out the problem of sustainability, a "syllabus 
for ecological literacy" (p. 109), and a critique in support of its theoretical position. While Orr articulates an eloquent literacy 'text', three other authors have recently put postmodern ecological thinking into the form of a 'handbook'.

\section{Ecologically engaging postmodern minds}

Brent Davis, Dennis Sumara, and Rebecca Luce-Kapler have collaboratively produced Engaging Minds: Learning and Teaching in a Complex World (2000), which demonstrates not only essential differences between modern and postmodern education but also differences between economic and ecological foundations of learning. Throughout this book, the praxis of learning and teaching in a complex world is encountered in exemplary practice. Structure, layout, text and illustrations, are interactively (enactively) interconnected to support the complexity of authentic content. There is no ideological position here, only open, inclusive, expansive, thoughtfulness that engages the reader in considering the implications of complex learning and teaching (illustrated in the 'map' reproduced in Figure 5.2). Engaging Minds is not so much a textbook, but more a (physical-not-virtual) 'hypertextbook ${ }^{20}$, which exemplifies the paradoxical nature of complexity through the notion of threedimensional spiralling [visualise a spider's web as part of a universe of interconnecting spiders webs]. While it is possible to begin reading from the first page and continue through to the last, there is more to gain from intuitively moving about within the book, rather than logically progressing through it. In other words, the whole of the work is greater than the sum of the pages, and I make no apologies

\footnotetext{
${ }^{20}$ Hypertext is a computing term referring to "extensive cross-referencing between related sections of text" (Concise Oxford Dictionary, 1999). By "hypertextbook' I mean a book that treats the text in an interrelated (enactive and complex) manner, rather than hierarchical way.
} 
for extolling these conceptual virtues of the work because they contribute to the themes of the remaining chapters of this study.

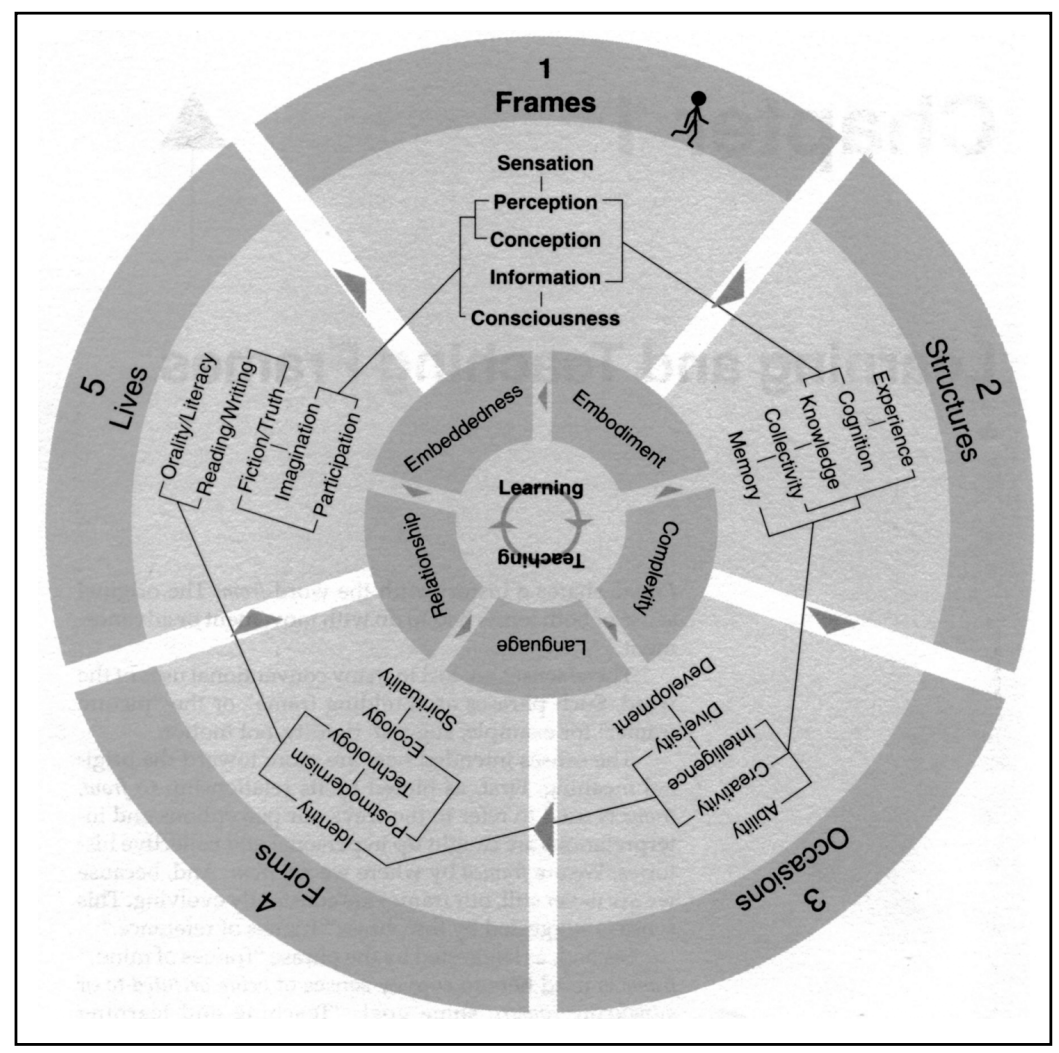

Figure 5. 2: 'Engaging Minds' organisation map

(Davis, Sumara, \& Luce-Kapler, 2000, p. 2).

\section{Ecological postmodern perspective}

For Davis et al. (2000) learning and teaching make an ecological postmodern way of thinking 'essentially' different from previous ways of thinking. In the ecological postmodern understanding, learning is embodied in living, it "...is not so much a deliberate act as an aspect of life" (p. 178). Teaching within this understanding also takes on a new 'enactive' dimension, which "...is all about effecting transformations" (ibid.). This enactive 'encouragement' of transformations brings together the dynamically complex spectrum of micro to macro, physiological, physical, 
psychological, sub-personal, personal, interpersonal and trans-personal ${ }^{21}$. The ecological postmodern complex spectrum introduces a way of thinking that radically transforms education from the worldview of training for work in the global marketplace, to a planetary prospect of living with learning for a sustainable future.

\section{Knowledge economy and ecological knowing in postmodernity}

There is an 'essential' difference between the ecological postmodern position and its modern predecessor, which concerns 'economy'. Where modernity made economy the centre of its world order, ecological postmodernity understands economy to be a phenomenon of cosmological complexity. Rather than economy hierarchically 'mastering' ecology, economy is an aspect of ecology concerning a narrow anthropocentric view of the world. Whether the view is traditionally modern or neoliberally postmodern, the so-called 'Global' view perpetuates knowledge for powerover-order in the form of 'learning for earning'. In contrast, the alternative postmodern 'prospect' concerns knowing as infinitely evolutionary, enacting, and sustaining, which can be broadly described as 'learning in living'.

\subsection{SUMMARY}

The shifting ground that characterises transitions from modern to postmodern worldviews is seen from different perspectives, and is forming new understandings. Two perspectives, and one understanding, which stand out as distinctively different, are found respectively in: the 'neo-liberal' position that effectively takes

\footnotetext{
${ }^{21}$ Used to mean transcending personal.
} 
modernisation to a new level in the economic world order; the 'ultramodernist' position that deconstructively extinguishes modernity; and the 'ecological' position that transforms the structured hierarchical order of modernity towards complexly, simultaneously, enactive engagement of minds, bodies, experiences and worlds. While there is no one postmodern 'way' of thinking there are characteristics that distinguish differences in ways of postmodern thinking. These characteristics tend to 'fall' in one direction, or 'drift' towards others.

The characteristics of postmodernity that 'fall' are exemplified in the neo-liberal and ultramodernist positions. In the former 'falling' (in behind), is seen as following the right economic path in a continuum of world order, and in the latter 'falling' (out of line), is seen as the means of eliminating an antithetical view of the world. Both these positions take strong specific stands on their place-and power-in a worldview/anti-worldview. Alternatively, the characteristics of postmodernity that 'drift' are recognisable in the ecological position.

The notion of 'drift' in the position of ecological postmodernity is not only a useful metaphor for distinguishing a non-hierarchical and non-objective, transitional nature but is also a particular term used in the literature. In the literature the term is "natural drift" (Varela, Thompson, \& Rosch, 1993, p. 196) and is used in evolutionary theory to explain that a quantitative concept of genetic change based on Darwin's theory of selection is problematic (p. 186). Rather, than selection of the fittest, natural drift recognises adapting-as process, not design-through fitness. Therefore 'drift' becomes an apt way of reconceptualising change in ways that emphasise the essential/'essential' difference between constructing a worldview as well as ways to 
control its order, and engaging with a the natural complexity of potentiality that exists in being in the world. The concepts that underlie such prospective potentials are the subject of the next chapter. 


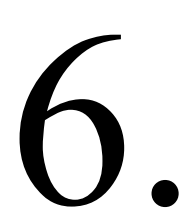

\section{KNOWLEDGE AND KNOWING}

With the emergence of alternative postmodern views and understandings of the world, what was seen as 'knowledge' is undergoing radical change. Such change presents interpretive difficulties that necessitate alternative approaches. The first part of this chapter outlines the approach of enactivism used in this study to assist with interpreting postmodern understandings. From this approach, knowledge is understood as being 'complex' and 'ecological'. These interpretations and understandandings of a postmodern world are addressed through the questions: Why is this postmodern? How is knowledge seen in this way? And why is this different from the modern view of knowledge associated with the knowledge economy?

\subsection{INTRODUCTION}

Chapter Five concludes by identifying the importance of alternative educational implications of meanings of 'ecological' in the emergent postmodern worldview, which I have followed from Noel Gough's work. The question 'How to identify a theoretical approach to engage with these emergences of educational alternatives and postmodernist knowledges?' is posed, and I note that a clue was contained in Gough's (1989b) closing sentences, which said "I find that an ecopolitical world view provides me with more interesting stories to tell (and hear), and more 'playful' work in which to engage" (p. 239). These notions of 'hearing' and 'playing' are central to 
'enactivism'. Enactivism, for this and other reasons, is the principal theoretical approach of this study and its main features are outlined below.

\subsection{THE THEORETICAL APPROACH OF ENACTIVISM}

\section{What is enactivism?}

My first response to this question is to offer a personal illustration. My postcompulsory education took the form of a studio-based diploma in Fine Arts, rather than a study-based academic degree. Several of my cohort were not only fine artists, they were also excellent musicians. The combination of aural with visual interests is common, if not a characteristic in creative fields that embrace learning and practice. As we have come to know through the technological innovations of the modern age, the audio-visual experience adds considerable power to the teaching/training process. However, the added power of AV also amplifies the differences between audience experience and performing experience, particularly when a performance overpowers an audience. I also found that in my art school learning experience, like audience and performance, there is a difference between academic study and studio practice, and learning responds well to a balance of both.

In order to undertake the course, of which this thesis is a major component, I needed special permission because 'academically' I was insufficiently qualified. In other words my 'study learning' and the qualification of my ability to process that learning could not be officially substantiated. Fortunately, I was able to articulate my capability to undertake academic study and my learning to the satisfaction of an authority. However, many are less fortunate; their learning through experience and 
practice is not only unacceptable at the 'higher education' level, often their experience has been declared as educationally dysfunctional from an early age. Such learners are characterised as 'slow', 'distracted', 'not-on-task', and so on; that is, they are regarded as not attending to being taught, and this was my own experience at secondary school. In studies other than art and music I was an assessed as a poor 'learner', which was 'confirmed' by failing School Certificate on my first attempt and barely passing on the second. Fortuitously ${ }^{22}$, I was permitted to take the Preliminary Diploma of Fine Arts (Prelim) in my sixth form year. This course enabled me to complete secondary school studying art and English and proceed to art school. Prelim allowed me to 'get-out-of-jail' and to take a 'free-turn' in learning about learning. Moreover, and most importantly, I had the chance to discover how to enact my learning. I was given the opportunity to take something that interested and challenged me, and to experience it in ways that interconnected my mind with my body with the world. That is, I 'performed' and 'played' my learning. Not only was I able to do this as an individual, initially in a one-to-one teacher/learner context at school, but at art school I joined a community of learners and teachers who interconnected with each other's experiences in thinking, visualising, 'auralising' and practising.

In the intervening years I have intuited the significance of my experience as a key to learning on a scale that exceeds the sum of the parts of what we call 'education', but have not until now begun to articulate how to understand the ideas the concept of

\footnotetext{
${ }^{22}$ I use fortuitously' here as a synonym for the word 'hap', which appears in the enactivist literature to refer to the 'richness' of 'unexpected consequence' that Davis (1996) argues, "...is the center-point of enactivist teaching" (p. 257).
} 
enactivism represents. My supervisor Jim Neyland, whom I have acknowledged as an enactivist practitioner, facilitated an excellent illustration of enactive learning by forming a small group of ' jazz ${ }^{23}$ musicians from a course ${ }^{24}$, which included enactivist theory in its content. During the trimester the musicians practiced occasionally and at the end of the course performed an original piece for the class. In a discussion after the performance we reflected on the event and noted the modulation of interaction within the performance and its effect on the music. Sometimes harmonious, sometimes dissonant, rhythmic in parts and syncopated in others, yet the performance was musically coherent. Everyone agreed that they could hear, and also see, that the enaction of the players, the music, and the performance was embodied in a community of understanding, which spiralled out to include the audience in enacting learning with, and through, the musicians' performance. The performance demonstrated that learning is embodied in complexity, not compartmentalised or contained in curriculum. As Davis (1996) puts it:

Enactivism understands the individual to be part of - that is, embedded in and a subsystem to - a series of increasingly complex systems with integrities of their own, including classroom groupings, schools, communities, cultures, humanity, and the biosphere. The notion of 'embodied knowledge' extends to bodies much larger than our own (p. 193).

\section{Explaining enactivism}

At a symposium on 'Post-Constructivist Education Theory', Andy Begg (1999) presented a paper titled 'Enactivism: An emerging theory'. In this paper Begg draws

\footnotetext{
${ }^{23}$ I use 'jazz' here in the loose sense of improvising with music.

24 The course was Victoria University of Wellington EDUC 547 'Assessment and Evaluation in Action' and took place between August and October 1999.
} 
from the literature to outline some of the influences on the emergence of enactivism as being "...criticisms of constructivism, the alternatives to the Cartesian dichotomies, phenomenology, the ideas of non-cognitive knowing, and the issues from biology..." (p. 8). He notes that ideas for the theory are based on the collaborative work of biologist Humberto Maturana and cognitivist Francisco Varela, and they have been interpreted within an educational context by Brent Davis. Begg (1999) characterises enactivism as "emphasizing knowing rather than knowledge" (p. 8), and in citing Davis, Sumara, and Kieren (1996), he emphasises 'the complexity of learning' as "...a complex choreography-of events which, even in retrospect, cannot be fully disentangled and understood, let alone reproduced" (ibid.) ${ }^{25}$. In extrapolating Begg's thoughts to my own experiences, I am aware of emphases in my learning on (instinctively) eluding the constructive and dichotomous, and (intuitively) following the phenomenological, experiential and natural 'choreographic' approach. This choreographic 'complexity of learning' approach empowers the transformation of learning from the objectivity of constructivism, to the non-objectivity of postconstructivism, for in both the 'social' and 'radical' modes of constructivist theory, the modernist components of the self, the other, and the world, remain separate. Begg notes that rather than a need to objectively locate 'something' called knowledge, it is as Bateson says "...there is no such thing as information, it is not knowledge-asobject but knowledge-as-action" (Bateson, 1972, cited in Begg, 1999, p. 8).

\footnotetext{
${ }^{25}$ Subsequently, Davis, Sumara and Luce-Kapler (2000) have collaborated to produce an educational text that focuses on enactivist principles of teaching and learning: Engaging Minds: Learning and Teaching in a Complex World (see 5.2).
} 


\section{Engaging enactivism}

In this thesis I am confronting a challenge that arises in the fundamental/essential ${ }^{26}$ conflict between the content being explored, and the means by which the content is explored. Taking a non-objective approach, the subject-'the knowledge-based economy'-is information as 'knowledge-as-object'. How then to critique a worldview that is telling its subjects 'something', which is 'non-sense' ${ }^{27}$ in other worlds of complexly choreographical phenomena? I could perhaps paint a picture, perform a song, or produce a movie, but text is the required medium of the message in the academic context of this thesis. So my challenge is how to creatively engage with the subject in a way that might expose notions of alternative perceptions to a sceptical reader. A resolution, I propose, rests in storytelling ${ }^{28}$, or rather 'storybringing', because I believe that is the essence of what emerges in 'teaching'; the enactions of our thoughts with others' thoughts bringing knowing into being, as our lived experience (that is, the stories of our lives) unfolds.

One of my favourite 'storybringer's' is William Irwin Thompson, and one of his stories is called The American Replacement of Nature: The everyday acts and

\footnotetext{
${ }^{26} \mathrm{I}$ am representing these words in this way to emphasise the incommensurable conflict between the (bold) 'fundamental' modern worldview and (italicised) 'essentially' ecological postmodern understandings of the world.

${ }^{27}$ I use 'non-sense' to emphasise the incommensurability of meanings of 'sense' in the different objective and enactive understandings of the world.

${ }^{28}$ My thinking on this idea is still developing and I have found some resonance in the story readingwriting thoughts of Dennis Sumara and Rebecca Luce-Kapler, (see Chapters 4 \& 5, in Davis et al., (2000). Additionally, 'storytelling' is problematic because as Sandy Dawson (1999) (Dawson, 1999) says "[t]eaching is not telling" (p. 154). The use of 'telling' inappropriately stresses the conduit metaphor of knowledge acquisition and obscures cognitive complexity in bringing about knowing, which storybringing better represents.
} 
outrageous evolution of economic life (1991a). In this essay Thompson ironically choreographs the story of how consumption may become salvation. His hypothesis is that 'mans' faith in his technological omnipotence is encouraging him to do such battle with 'nature' that he will cause himself to technologically 'implode'. He says:

Mankind, and we are talking about mankind here, has been waiting too long for this match, and whatever the New Age sissies in California may say about going back to the worship of the Goddess, a Riane Eisler partnership of compliant men with commanding women, and a life of quiet harmony nuzzled up against the bosom of nature, real Americans will have no truck with any of that. Just tune in to your Eurosport channel and watch those monster truck races in which the apotheosis of the Western pickup grinds down all those suburban family sedans and yuppie mother-driven Volvo station wagons, and you'll see where it's really at. America is at it with a vengeance, and what $I t$ is, is Nature" (p. 2).

The value of the 'storybringing' in this passage is in the metaphorical suggestions that are brought to it. In one paragraph Thompson brings in several 'nuggets' of civilisation's social and cultural history, such as feminist revisionist 'herstory', the 'automania' of contemporary western civilisation, and the 'mediocracy' of media culture $^{29}$. These 'nubs' are not factual knowledge-as-things to consume, but suggestive sketches-for-ideas to reflect, follow, discuss, and enact. Such ideas emerge in Thompson's enactive fields of complex performance ${ }^{30}$, which is analogous with the improvised 'jazz' of my classmates mentioned above.

\footnotetext{
${ }^{29}$ The ideas suggested by my use of 'herstory', 'automania', and 'mediocracy' are addressed at length by: Eisler (1988) The Chalice and the Blade: Our history, our future; McLuhan (1967) The Mechanical Bride: Folklore of industrial man; McLuhan (1964) Understanding Media: The extensions of man; and Postman (1993) Technopoly: The surrender of culture to technoloy.

${ }^{30}$ For a greater understanding of Thompson's work and its relevance to enactivism see Coming into Being: Artifacts and texts in the evolution of consciousness (1996).
} 


\section{My own approach}

As I say in the preceding section, I believe an essence of teaching is embedded in 'storybringing' as the enaction of articulating thoughts within evolving understandings of increasingly complex systems much larger than our own (Davis, 1996). My problem, also stated in the same section, is that conventional 'wisdom' has immense difficulty with notions of complex systems that exceed the sum of mankinds [sic] knowledge. As an example, a primary school teacher recounted to me her difficulty in gaining approval to have her class devote a full day to creating works with clay. It appears the rational logic of the compartmentalised curriculum does not allow an extended period to be allocated to one activity, despite the practical problem of clay not being easily put aside for a week. Furthermore, the complex learning experiences ${ }^{31}$ that arise within an enactive creative activity like this are not seen as appropriate achievement objectives for this teaching level, within the curriculum statements. The teacher was faced with the dilemma of either, enactively engaging teaching and learning, or complying with the decreed actions of teaching. Moreover, attempts on her part to negotiate a compromise resulted in complaints from her colleagues about interference in the 'normal routine' of the teaching plan.

Therefore, I am experiencing learning in a similar way to the primary teacher's experience of teaching. I am having to approach the problem from within its framework; that is, as a critique of the 'conventional' position and its worldview. In other words, I must approach a complex argument, which is incommensurable within that conventional framework and tends to be seen as representing positions ranging

\footnotetext{
${ }^{31}$ For example: geological and cultural features, types, handling characteristics, ways of manipulation, preserving and decorative aspects.
} 
from sceptical to nihilistic. For an objectivist thinker, the enactivist 'non-objective' coming-to-knowing, or 'knowledge-as-action', is illogical, irrational, and confuses the idea of a 'self-less' mind with 'mind-less' self, which makes enactivism appear nihilist. Varela et al. (1993) put it this way "...the nonexistence of a self that would answer to our objectivist representations is typically confused with the nonexistence of the relative (practical) self altogether" (p. 239).

To address the difficulties arising in a critique involving one worldview, which is perceived as incommensurable from outside that worldview, I have undertaken an 'approach' that is referred to in the enactivist literature as 'laying down a path in walking' (Varela, 1987, p. 48; Varela, et al., 1993, p. 237; Davis, 1996, p. 79). To recap, on this approach; Varela et al. (1993) propose the term enactive "to emphasize the growing conviction that cognition is not the representation of a pregiven mind but is rather the enactment of a world and a mind on the basis of a history of the variety of actions that a being in the world performs" (p. 9).

Moreover, this enactive conception requires a transcendence beyond the oppositional arguments of science and experience, which "... are like two legs without which we cannot walk" (p. 14). However, the conventional objectivist position regards science and self as quite separate things that require the scientist "...to ignore the experiential aspect when she does science and ignore the scientific discovery when she leads her life" (p. 239). While Varela et al., take their path towards inclusion of the Buddhist philosophical tradition, I will rest at this point and settle on the statement that their "...guiding metaphor is that a path exists only in walking" (p. 241). Davis (1996), also engages with the same metaphor when writing about the enactivist interpretation 
of the evolution of mathematics; he says "[t]he path mathematics follows-what mathematics comes to be-is a path that is laid down in walking, not one toward a pregiven end" (p. 79). Following these thoughts, I am adopting the enactivist approach to navigate a way from the 'certainty' of modernity through postmodernity's 'uncertain' terrain towards futurity. The usefulness of the enactivist approach is in its promiscuous or actively non-discriminatory attitude towards consciousness and awareness through non-objective perception. In contrast to the objectivist position, which eliminates everything that makes no sense, enactivism brings all sensibilities into being.

Thus far, my approach has been to foreground the oppositional arguments, and to reveal an alternative-to begin walking my story from the standpoint of economic knowledge towards a new direction. The next part has more to do with observations about the path being laid in walking-in order to further bring my story to ecological life.

\subsection{POSTMODERNITY AND KNOWLEDGE:}

\section{Power, or prospect?}

The preceding chapters have identified some of the important differences between modern and postmodern understandings of the world within which 'knowledge' has a fundamental/essential difference. In modernity 'knowledge is power'; 'knowledge' is control [as power] of the force [as power] that induces [through power] its consumption [of power] as a commodity [of power] to perpetuate its power. In postmodernity 'knowledge' is diverging in different directions. On the one hand 
knowledge is the perspective that sustains power, and on the other hand knowing is about prospects that transcend and transform power. The former 'perspective' is outlined in Chapter Five as including two positions described as 'neo-liberal' and 'ultramodern', which remain power oriented through the ways they 'fall' in specific directions, that is, progressively to an economic worldview or an anti-worldview. The latter 'prospect', also described in that chapter, is referred to as an 'ecological' position that, rather than 'falling' by design, 'drifts' positively and freely through processes of adaptation and fitness. The 'prospect' of an ecological position embodies engaging with the natural complexity of potentiality that exists in being in the world. The 'perspectives' of power positions exert control over either perpetuating an ideology of economy, or constructing an antithetical theory.

\section{Framed knowledge or knowing systems?}

The definition of knowledge as power sits comfortably in the predominant worldview. The notion that those with more knowledge have 'earned' more power is quite acceptable within the concept of world order our education has taught us. However, just because this notion appears to be a position of consensus, does not preclude other positions that exclude power from understanding. Knowledge and understanding are no more synonymous than are power and empowerment. For example, knowledge and power are, arguably, by definition finite, and understanding and empowerment are, arguably, by nature infinite. The problem is both complicated and complex, and concerns matters that are economic and ecological. The differences between knowledge of and understanding about what the terms mean, concerns the existence, or otherwise of 'frames'. Framed knowledge is definable; it comprises 'facts' that conform to rules, which make them 'true' or 'false'. As the 
theoretical approach section above has explained, 'knowledge' of this 'framed' kind is objective because it is 'pregiven'. In the enactivist approach it makes no sense to assume that by fixing a 'frame' around a fact, which is presented as 'true', knowledge becomes real. Such a fixed convention of 'knowledge' is considered a confused misrepresentation of reality. The enactivist sees this 'framing' notion as a complicated method of confusing complex systems about knowing, such as the example (on the preceding page) of the cognitivist scientist who must separate her 'self' from her 'science'.

\section{What is 'complexity'?}

The 'framed' definition of 'complexity' is effectively synonymous with complicated, as is evidenced in the Oxford English Dictionary definition of complexity as "the quality or condition of being complex", and defines complex as "[a] whole comprehending in its compass a number of parts, esp. (in later use) of interconnected parts or involved particulars; a complex or complicated whole" (1989). More detailed definitions of complexity in the OED include references to its 'involved nature or structure' and 'complicated condition, a complication' (ibid.). The 'unframed' understanding of complexity, however, engages with the enactivist approach. Davis, Sumara, \& Luce-Kapler (2000) who exemplify the enactivist approach in Engaging Minds: Learning and teaching in a complex world, use the word complex to contest the notion of a complicated world that holds a mechanical view of intricate discrete parts of a summative whole, of a 'clockwork universe'. They say that complexity, drawing on "complexity theory" (p. 54), regards phenomena and behaviours in the universe as 
...collectives of other, smaller dynamical systems...These are complex systems. They exceed their components. They are more spontaneous, unpredictable, and volatile - that is, alive - rather than complicated systems...complex systems are self-organizing, selfmaintaining, dynamic and adaptive. In brief, whereas complicated systems tend to be framed in the language of classical physics, complex systems draw more on biology. As such, terms like organic, ecological, and evolutionary have come to figure much more prominently in discussions of such social phenomena as learning, teaching, and schooling (p. 55).

The importance of this interpretation of 'complex' is that it brings into being natural and infinite understandings of ways of knowing and enacting the world. Unlike its 'complicated' counterpart, which considers a 'whole comprehending' of a 'structure' of 'interconnected parts or involved particulars' (OED, 1989), as finite.

\section{What is 'ecological'?}

The 'framed' definition of ecological tends towards synonymity with environmental matters. The OED (1989) defines ecological as "pertaining to ecology" and defines ecology as:

The science of the economy of animals and plants; that branch of biology which deals with the relations of living organisms to their surroundings, their habitats and modes of life, etc. [and] 2. Used with reference to ecological issues such as industrial pollution considered as apolitical context... which represent the environmental or 'green' interest.

While the word ecology is relatively recent ${ }^{32}$, it parallels the form of the word economy in descending from the same Greek root Oikos (house, dwelling), and ending with -logy from the Greek logos (word, discourse, account.) (ibid.). Therefore the distinction between the two words is in their suffixes, namely logos (word, discourse, account, or study), and nomia (an area of knowledge, or discipline). 
This raises a question as to the interrelationship between the two and suggests that, like complex and complicated, there is much confusion over what the terms are 'framing'. For example, the OED cites H. G. Wells (1932) using ecology in the following manner: "Economics...is spoken of in the Science of Life as a branch of ecology; [economy] is the ecology of the human species" (OED, 1989). This usage appears to be putting the 'branch' of economy in the shade of the 'tree' of ecology.

The 'unframed' understanding of ecological, like complexity, also engages with the enactivist approach. Likewise, Davis, Sumara, \& Luce-Kapler (2000) also provide an appropriate explication for that approach. As with enactivist complexity, ecological is not concerned with structural distinction, rather, it is about 'bringing into being' greater understandings of consciousness and awareness of experiences and perceptions of the world-ecological in this sense engages with complexity in living. That is, enactivist 'complexity' engages with ways of coming to knowing, simultaneously, the enactivist 'ecological' engages with complexity in being through knowing. In the 'framed' worldview, ecological concerns the hierarchical locations and relationships of twig and branch and trunk, and roots, when describing a 'tree'. In the 'unframed' understanding, ecological embodies evolving consciousness and awareness of being, which Davis et al., describe thus:

...trees and branches of knowledge, roots and growths of understanding, seeds and fruits of learning...apples and trees aren't autonomous forms, but aspects of more complex systems. They are embedded in larger ecologies of relationships. To understand why an apple tree produces such an abundance of fruit, for example, we must consider the life of the tree I relation to the life of the forest of which it is a part. An apple tree is caught up in webs of exchange, providing shelter and sustenance for insects, and birds and mammals.

${ }^{32}$ In English it appears in 1873 as the translation of the German zoological term okologie (OED, 1989). 
They, in turn, pollinate its blossoms, distribute its seeds, and fertilize its roots. The interdependencies extend even further, as these living forms participate with others in the interchange of oxygen and carbon dioxide and in the movement of water around the planet - aspects of seasonal patterns and annual cycles that unite ground and sky, organic and inorganic, life and death, past and present" (p. ix, emphasis added).

\subsection{DIFFERENCES AND DIVERSITY}

\section{Economic rules and ecological renewal}

The last question posed in the introduction to this chapter is: Why are complex and ecological understandings of postmodern knowledge different from those of modernity and the knowledge economy? My response involves notions of autogeny (structural self-generation methods) and autopoiesis (complex self-renewal systems). An example of autogeny is represented in the currently topical exploration of biological cloning. Having discovered the 'science' of genetically generating a living organism from pre-existing components, human beings theorise their capability to autogenically perpetuate themselves without the need to rely on 'nature'. In contrast with this anthropocentric structural regime, understanding of autopoiesis emerges through an intertwining with enactivist theory (Varela, Maturana, \& Uribe, 1974), and within transformative understandings of ecology and cosmology theory (O'Sullivan, 1999). In their paper on enactivist theory, Varela, Maturana, and Uribe (1974) developed an 'autopoiesis checklist', which includes

...a concise set of criteria for determining whether or not a 'machine' is an 'autopoietic machine'. The criteria are presented in the form of a 6-point 'checklist' by which one may proceed step-by-step in evaluating autopoiesis for a given unity" (Varela et al., 1974, quoted in Whitaker, 2001).

The intention of this autopoiesis checklist is to determine that 
...all the components of the unity produced by its components [are] realizing processes within the unity itself; [and] all the unity's components participate in the production of its components..." (ibid.).

In other words, whereas autogenically analysing and engineering life forms is a primary focus of determining ethical interpretations of economic rules in the knowledge society, autopoiesis distinguishes an understanding of constituent unity in complexity. Autopoietic renewal continuously evolves natural unities of complexity for ecological sustainability. Thomas Berry (1989) addresses the earth's autopoiesis and,

...suggests that the earth within the solar system, is a self-emergent, self-propagating, selfnourishing, self-educating, self-governing, self-healing, self-fulfiling community. Furthermore, all particular life systems must integrate their functioning within this larger complex of mutually dependent earth systems (pp. 1-3, cited in O'Sullivan, 1999, p. 213).

\subsection{SUMMARY}

This chapter began with the introduction to the theoretical approach being used in this thesis. Enactivism was explained as an approach to navigating from modernity's certainty, through the uncertainty of postmodernity, towards complex ecological 'futurity'. The need for such an approach rests on (problematic) 'framed' and unframed interpretations of 'knowledge', including knowledge 'framed' as power, and unframed understandings of knowing systems that are complex and ecological. The usefulness of the enactivist approach in engaging with problematic knowledge and knowing is said to be evident in a 'promiscuous' attitude towards consciousness and awareness through perception, whereas the modernist position on knowledge is presented as rigorously moral in rationalising its objectives. 
In the subsequent sections of the chapter aspects of enactivist theory were brought into the discussion about distinctions between 'perspectives' of modern and postmodern objectivist knowledge and other non-objective 'prospects' in understandings. The 'framed knowledge' distinguished the objectivist 'perspectives' from the non-objective 'prospects' in the 'knowing systems'. This 'framed knowledge', or knowledge as power, characterises the predominant worldview that I argue is also taught in the education system to ensure social compliance, market complicity, and global consensus. A fundamental rule of the objectivist position is the compartmentalisation of knowledge in informational facts that 'prove' the existence of right from wrong, good from bad, self from other, and other from world. In contrast, unframed understandings contest such an 'existence' of 'knowledge' in this way and argue that this is a 'complicated' method of confusing complex systems about 'knowing'. This suggestion introduced a discussion on interpretations of complexity and ecological in postmodern understandings of the world, which distinguished important differences between knowledge, coming to knowing, and being through knowing.

The chapter concluded by engaging with distinctions between the autogenically structured focus of knowledge in the knowledge society, and the embodiment of complexity and ecological understandings in a concept of complex autopoietic renewal. The contrasting distinctions were exemplified on one hand, in current arguments concerning bioethical and scientific considerations of social and economic progress in the selfishly focused objectives of a knowledge society, and, on the other hand, through emerging understandings of natural systems in which all existence is selflessly embedded and embodied. 
In the next chapter, these contrasts are explored further by discussing their characteristics in an educational context. The characteristics are explained to consider why they are distinctive of modern and postmodern forms of education. 


\section{7. \\ ECOLOGICAL LEARNING}

Distinctively different understandings of 'knowledge', which are emerging through complex and ecological interpretations, give rise to ecological approaches to knowing in education, or what I am calling 'ecological learning'. These approaches to ecological learning, which are also postmodern, have particular characteristics that are explored in this chapter through the questions: What are these characteristics? And why is this form of education distinct from the modern form?

[E]nactivist theorists begin and end their analyses with an acknowledgment of the fundamental inextricability of all things (Davis, Sumara \& Kieren, 1996, p. 157).

\subsection{INTRODUCTION}

The preceding chapter addresses matters concerning diverging postmodern knowledge and, in particular, complexity and ecological aspects that put diverse complexions on knowledges. Rather than knowledge as subjective specifications in bodies of objectivity (bodies of knowledge), diverse knowledges are embodied in continuities of non-objective systems and processes (embodiment through knowing). Knowledge is not a 'thing' to be subjected to analytical dialogue, it is a conversation through which coming to knowing is enacted in being and doing as allatonce ${ }^{33}$

\footnotetext{
${ }^{33}$ Davis et al., 1996, cite Berthoff's, (1990) use of the term as a description of the process of writing that happens allatonce "(i.e. 'all-at-once')" (p. 163).
} 
collective familiarity. Just as knowledge is not one 'thing', "[k]nowing being and doing are not three things" (Davis, Sumara \& Kieren, 1996, p. 154).

For the enactivist, consciousness and understanding of knowledges are, in themselves, different. The enactivist's consciousness emerges in 'I can (act)', unlike the Cartesian cognitive's subjective 'I think', or the empiricist's objective 'I observe' (Davis et al., 1996, p. 156; Davis 1996, p. 11). Furthermore, the enactivist's understanding is in continuously recursive cycles of 're-vision' and 're-interpretation' (Davis et al., 1996, p. 157). Notions of 'complex' and 'ecological', as explained in the preceding chapter, take on different understandings in an enactivist approach. Complex, drawing on 'complexity theory' brings about a regard for systems of natural unities of renewal, or 'autopoiesis', and, ecological, as a contemporary concept of thought, brings about knowing, doing and being as processes of co-emergence in the world.

In earlier chapters, the role of education in the knowledge economy and the predominance of modernist formulations of knowledge retained in teaching and learning is examined. In summarising the relationship between education and the knowledge economy, the aphorism 'learning for earning' is observed to encapsulate the focus, if not the raison d'être of education. This chapter presents a different proposition; it enactively 're-visions' and 're-interprets' education in learning and teaching-for learning for living in what I am calling 'ecological learning'.

The chapter begins by re-interpreting learning and teaching within an enactivist approach, which leads to another way of understanding and describing characteristics of this form of education-of 'laying down a path in walking'. An explanation of 
these characteristics and what makes them distinctive from those of the modern and knowledge economy forms of education follows, before elaborating on why the characteristics are different.

\subsection{LEARNING ENACTIVELY}

\section{What is learning?}

A common dictionary definition says learning is, "knowledge or skills acquired through experience or study or by being taught" (Concise Oxford Dictionary, 1999). Such definitions identify the objective aim (knowledge and skills), and the subjective experience (to study and be taught), but are not helpful in understanding the process (acquiring knowing). As discussed in Chapter Four (4.3), modernity has developed and maintained a purposive attitude on learning that ensures the complicity of the process with its own particular worldview-in other words, learning in modern education exerts control over what keeps human civilisation 'on 'track'. In Chapter Six (6.3) there is discussion that such a view is not as 'locked-in' as it is made to appear. Davis, Sumara \& Luce-Kapler (2000) explain 'lock-in' as common in any dynamic collective (organism, community, society), in which behaviour has become habituated or ritualised to an extent where the collective will refuse to alter its behaviour even to survive. As they say "[f]or humans, the notion applies on several levels - and, in particular to the tendency for belief and interpretive systems to become so familiar that they're not just imagined to be correct, but the only structures possible" (p. xiii). In other words, it is common for human beings to be so convinced of their correct interpretation that no other view can be entertained-" $[w]$ e do not see what we do not seen (Davis, Sumara \& Kieren, 1996, p. 160). 


\section{Learning is-}

Following the enactivist approach, I envision learning in another way that Davis, Sumara and Kieren (1996) describe as "...an ongoing structural dance - a complex choreography - of events which, even in retrospect, cannot be fully disentangled and understood, let alone reproduced" (p. 153). In this re-vision of education, learner and teacher are not complicit, but co-evolve and become co-participants in the "...bringing forth of a world of understanding" that has no discernible beginning or end points' (p. 157). The teacher and learner bring forth themselves and their identities as they also make understandings of a world together. That is, "...enactivism suggests that the teacher and the students are working on a common project-the simultaneous bringing forth of themselves and the world-even if their respective interpretations of their actions and experiences differ" (ibid.). However, such a re-vision of education also presents, as Davis et al., (1996) note, a conundrum, namely, "[h]ow can we prepare...for a world that, in part as a result of our efforts in such preparation, will be much different from the world in which we currently find ourselves?" (p. 157). The enactivist approach, therefore, not only re-visions subjective and objective attitudes in education but also re-orients the rational and logical contextual world it was seen to occupy. In the enactivist world of learning "[c]ontext is not merely a place which contains the student; the student literally is part of the context" (ibid.).

\section{Path-laying}

To address the conundrum Davis et al., (1996) have identified, the enactivist approach takes a different path of experiences in the world. That is, a path 'laid down 
in walking'. This expression recurs in enactivist literature and originates in the poem by Antonio Machado (1930) translated by Francisco Varela (1987, p. 63):

\author{
Wanderer, the road is your \\ footsteps, nothing else; \\ wanderer, there is no pain \\ you lay down a path in \\ walking. \\ In walking you lay down a \\ path \\ and when turning around \\ you see the road you'll \\ never step on again. \\ Wanderer, path there is none, \\ only tracks on ocean foam..
}

Varela (1987) cites this poem as saying, more clearly than he can, that "...what we do is what we know, and ours is but one of many possible worlds. It is not a mirroring of the world, but the laying down of a world, with no warfare between self and other" (p. 62). In this 'storybringing' (see 6.1) Varela 'teaches' about resolving the conflicts of the self, with the other, and the world, which are not separately split, rather, they are completely complex. For Varela, education, rather than following a pre-specified track to a job, is about learning in living, which brings together more than individuals acting in worlds, it extends to the entire biosphere and beyond, and is fluid, dynamic, and continuously adaptive. As he puts it "[m]any paths of change are potentially possible, and which one is selected is an expression of the particular kind of structural coherence the unit has, in a continuous tinkering ${ }^{34 "}$ (p. 61). 


\section{What is 'ecological' in learning?}

Understanding the concept of 'environment' makes ecological issues distinctive in learning. Davis (1996), uses this contrast to explain that 'environmental' directs attention towards environs, or our extended surroundings, whereas 'ecological' takes in our oikos, or our personal household that is, "...the web of relationships in which we find ourselves and against which our identities are established" (p. 58). 'Environmental', tends to concern matters of causes and effects that surround ecological issues, and consequently brings the modernist dichotomy into effect-we see environmental problems that affect ecological existence, for example, and try to find scientific solutions. Davis draws an analogy of the differences between environmentalism and ecology with those of seeing and hearing to explain that environmentalism-like seeing-is about definition, whereas ecology-like hearing-is more concerned with interpretations, particularly with hermeneutic interpretation (p. 58). Hermeneutics involves the reinterpretation of understandings, or the continuing questioning of what meaning is and how it comes about. The significance of the hermeneutic attitude to interpretation is explained in the following section.

\subsection{CHARACTERISTICS OF ECOLOGICAL LEARNING}

\section{Looking-re-visioning seeing}

Without looking we may not learn; "we do not see what we do not see" (Davis, Sumara \& Kieren, 1996, p. 160). Visual perception is so much a part of what we think we know of our world that we are 'locked-in' to how we see. An example of this is seen in the 'Magic Eye' images (N. E. Thing Enterprises, 1993) that were

\footnotetext{
${ }^{34}$ I take 'tinkering' to reflect the idea that nothing is ever finished and always continues.
} 
popular a few years ago. For those who could look into these 'pictures' they were a revelation about complex image-eye-mind relationships, whereas for those who were unable to see them, they simply did not exist. In another example, Oliver Sacks (1995) cites the case of a man who had his sight restored after almost a lifetime of blindness. When the bandages were removed the man said he had no idea what he was seeing, "[t]here was light, there was movement, there was colour, all mixed up, all meaningless, a blur" (p. 107). Only after hearing the surgeon talking to him did he understand the chaotic blur was a face. What we believe we see is context dependent. Davis, Sumara \& Luce-Kapler (2000) present some excellent examples of context dependence; one is illustrated by the mark below (figure 7.1), which they say could be the capital letter "I", the lowercase letter "l", the numeral "1", or a back slash "/", or many other things. As they say, "the meaning is not in the symbol, but in the complex webs of associations that the symbol triggers when it is deployed in a particular context" (ibid.).

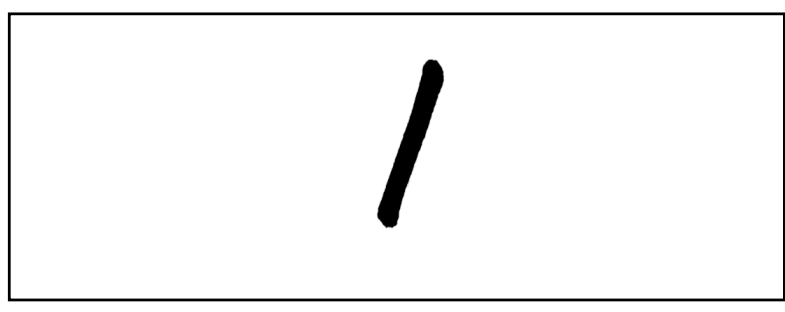

Figure 7. 1: 'Mark'

(Davis, Sumara, \& Luce- Kapler, 2000, p. 17)

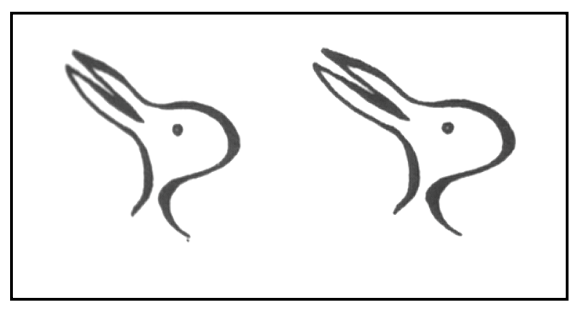

Figure 7. 2: Rabbit \& Bird (p. 21)

In the second illustration (figure 7.2) there are two 'pictures': Of two rabbits? Two birds? One rabbit, one bird? One bird, one rabbit? The problem is that while we can visually distinguish a pair of images, we can only cognitively consider one image (rabbit or bird) at a time. Davis et al., say "[i]t appears that consciousness is able to juggle about half a dozen interpretive possibilities (or discrete thoughts) at a time, but 
must flip back or forth among them" (p. 21). The point being made here concerns the modern distinction between seeing and looking; we can see the 'mark' and the bird rabbit 'pictures', but through modern conditioning we interpret them in knowing what to look for. In the modern, formulated view of learning, the ability to interpret what we see is considered to be taught; as in the 'magic eye' example, which is assumed not to 'work' unless one acquires 'knowledge' of how to use it. The implication being that 'someone' has written the instructions. Contrary to the modern view, I believe the capability to see in this 'way' is intrinsically complex, and possibly descends from a more 'primitive' ancestor who learned to use it to discern a predator camouflaged by surroundings. However the 'new' computerised presentation of this perception ability as Magic Eye: A new way of looking at the world, makes the process appear to be a 'magic trick'. In the enactivist unformulated understanding of learning, that is ecological learning, there cannot be seeing without looking as they are embedded in each other's existence. It is only the modern belief in a separated cognition of the mind from the body, and the world, that seeing and looking are thought of as different things.

\section{Listening — re-interpreting hearing}

Our perception of hearing is, like seeing, prejudiced by what we 'think' we 'know' the 'world' to be. We often hear people say, "No one is listening to me!", or politicians say to people "Yes! I'm hearing you". Once again, the modernist separation of these faculties conditions the belief that they are different functions. For example, in the classroom, "listen to me!" probably competes (synonomously) with "look at me!" as a teacher's most used command. However, for the enactivist, within ecological learning there is no hearing without listening. The auditory learning experience is a 
continuity of conversations embedded in the complexity of recursively 'articulating' (enjoining distinct sounds in meanings), hearing, listening, interpreting, understanding, articulating. Davis (1996) uses the subtitle '...toward a sound alternative' to call attention to how he "...felt a particular resonance with the sound foundations of hermeneutics...for the hermeneutic attitude is a listening attitude" ( $p$. 31). Listening is not a passive or inactive process, it is enactive; Davis uses the expression 'looking for listening' as a way of emphasising how bodily interactions are apparent in people in conversation with each other (pp. 37-38). This notion of conversation, as mentioned earlier, has much to do with enactivism in learning, and like many of the terms arising in this chapter, such as ecology and environment, or seeing and looking, there is a contrast between formulated and unformulated ${ }^{35}$ understandings of them. Distinctions between understandings of the words have to do with attitude towards them. 'Discussion', like seeing, is a very subjective experience intended as a 'coordinated action' ${ }^{36}$ for speakers to "...impose their perspectives on each other" (p. 39). The associated attitude is grounded in analysis from an individual perspective with little concern for the view of others. In contrast, 'conversation' is about the exchange of thoughts and about movement towards sharing understandings. There is also a sense that discussion is oriented towards (objective) performance, and conversation as more about (non-objectively) performing. The former implies more of a professional attitude to presentation, whereas the latter is more playful and 'amateur', in the sense conveyed by the Italian origin amatore meaning lover, and suggesting one who participates 'for the love of' doing so (Concise Oxford Dictionary, 1999).

\footnotetext{
35 'Formulated' and 'unformulated' are synonyms for 'framed' and 'unframed' used in Chapter Six (6.2).

${ }^{36}$ Davis (1996, p. 39) attributes this term to Charles Taylor (1991).
} 


\section{Playing — re-shaping working}

Distinctions between work and play in the adult world are usually formulated into activity concerned with occupation, and leisure (free, unoccupied) activities. For many children the work distinction applies to their experience of school, yet play and learning have been associated in pedagogy since the time of Plato, when paidia (play), and paideia (education) were conceptually related (Davis, 1996, p. 212). More recently, educationists such as John Dewey and Jean Piaget regard play as a highly significant aspect of younger children's learning, especially in the creative interaction between the individuals energy and materials at hand. The 'learning' of shaping and 'shaping' of learning through enactively engaging the child with doing and knowing in the world is a familiar notion in pre-school environments. Once again, as with looking and listening, the distinctions between the formulated knowledge of working and playing, and the unformulated enactivist understandings are evident. In the formulated view, work and play are quite separate activities, and are also considered to be co-dependent. That is, if someone is not working she/he is 'playing around', also, she/he 'gets to play' as a reward for hard work. In the enactivist understanding the ecological learning characteristic of playing, embedded in working, brings about another dimension of shaping experience. This ecological learning experience is about the complex nature of creative and re-creative (recreational) activities. In formulated 'work' the individual is inured in the task of making things, and the essence of the activity involves method and procedure in objective, quantifiable results. However, in unformulated 'play', there are a plethora of meanings, which, in themselves, make the contrast with 'work' fundamentally/essentially problematic. Nevertheless, even in education there is playschool, play time, wordplay, gameplaying, and piano playing, for example, all of 
which concern objective interpretations of subjective experiences. Davis in explaining his interpretation of what makes play work ${ }^{37}$ for education, suggests that it brings out the "...as yet unexperienced, the unpredictable, the uncontrollable" (p. 216). He continues by citing Shaun Gallagher (1992):

The unfamiliar that we experience in play is first of all interpreted in terms of the world. In play we become so fascinated with the world that we move beyond ourselves, we transcend the limits of the self.... The self-transcendence that is essential to play involves a projection toward ones' own possibilities....Play bestows reality on the unreal; it gives weight to that which is possible or fanciful (cited in Davis,1996, p. 216).

Such an interpretation contrasts sharply with the regimented constraints of formulated 'work'.

\section{Haps}

While looking, listening and playing describe characteristics that are embedded in ecological learning, this begs the question: Embedded how and where in learning? To help answer this formulated question in an unformulated way, Brent Davis (1996), citing following Joel Weinsheimer (1985), refers to the notion of 'hap', meaning 'event', and particularly events of good fortune. 'Hap' is the archaic precursor of 'happen' and other words from the same root such as happy, perhaps, and mishap. To explain an application of 'hap', Davis suggests that "...efforts to formulate a program of studies and to prescribe appropriate instructional methods are tightly linked to the desire for a hapless curriculum wherein the teacher is able to prescribe all learning and foresee every possible contingency" (p. 257, bold emphasis added, italics in original). Rather than being reliant on planning for every contingency, the enactivist regards haps as the 'centre-point' of teaching: "[s]uch

\footnotetext{
${ }^{37}$ The ambiguity of these two words exemplifies paradox in complexity. Does this mean: What turns play into work? Or: What makes play successful? My answer is yes-to both interpretations.
} 
teaching is an attendance to the unexpected consequence, to the sudden insight, to the inexplicable interest that is conditioned or occasioned by the teachers actions" (ibid.). Therefore, within ecological learning the learning occasion in time and space is revisioned, re-interpreted and re-created as anticipation of potentials, to re-place planning for mishaps.

\subsection{ECOLOGICAL, ECONOMIC; WHAT IS THE DIFFERENCE?}

\section{Economic knowledge creation and wealth generation}

What makes this ecological understanding of learning different from the system of education founded on, and formulated through, modernity in which creating knowledge and generating wealth for a society based on the knowledge economy is paramount? In the knowledge economy, the terms 'knowledge creation' and 'wealth generation' exemplify a foundational difference, that is, the relationship between the subjective interpretation (creation and generation) and objective acquisition (knowledge and wealth). The knowledge economy requires the compliance of education, in 'teaching' the interpretive philosophy that underpins its particular notions of knowledge and wealth. It also expects education's complicity in its specific projects for 'research and development' in creativity (innovation) and generation (entrepreneurship) as techniques for knowledge commodification. For postmodern ecological learning, such separations and distinctions are most unhelpful because they occlude all ways of engaging with the world except those that suit the objectives of subjects. In ecological learning there are no objects, objectives, objectivity, nor are there subjects or subjectivity - there is complexity. 


\section{Ecological complexity}

Rather than an education grasping for ways forward in the ever-narrowing focus of an economic worldview, learning within ecological understandings of worlds that continue to come into being are continuous occasions of ever broadening experiences. The characteristics of ecological learning are not separate elements in a hierarchy of knowledge, rather, they are complex experiences in worlds of coming to knowing. They are characteristics of looking for listening in conversing about playing and anticipating haps. On the one hand there is a 'worldview' that places a few 'powerful' human beings at its centre in the pursuit of a self-ist vision of the future-the anthropocentric worldview-that demands the complicity of planned systematic education. On the other hand there is a re-emerging understanding that human beings are not subjective objects in some 'clockwork universe', rather they are embodied in ubiquitous complexity that embraces learning as transformative and revelatory for all existences. One momentarily grasps, the other is always reaching.

\subsection{SUMMARY}

In the modern worldview, future is the light at the end of the tunnel that human beings-mainly men-are grasping towards with the 'sense' of science and the tools of technology. In this view, education is formulated to suit the project, its characteristics are theoretically narrow and focused, philosophically logical and rational, and practically pragmatic and applied. As the project becomes exponentially unstable through unsustainable resources, erratic performance, and unfulfilled objectives, exponentially increasing pressures are brought to bear. More and more demands are made of the system of education to address the project's 
increasingly complicated problems, with less and less fulfilment. The fundamental problem for the project is the limits of its view-'it cannot see what it cannot see'. However, another understanding of human beings and the worlds they inhabit is available-an understanding that transcends tunnel drilling towards light grasping, and transforms 'project management' systems of education. This alternative understanding re-visions the light at the end of the tunnel, into laying down a path in walking. Rather than desperately grasping towards something recognisably secure, and prosperous, there is a reaching out to experience all that constitutes continuous moments of existence and participation. In the next chapter, the modern knowledge economy's education is contrasted with postmodern ecological learning to contemplate the advantages of paths over tunnels. 


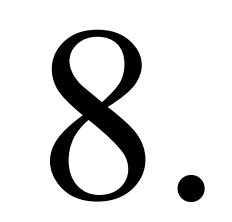

\section{TRANSFORMATIVE ECOLOGICAL LEARNING}

This chapter undertakes an exploration of postmodern 'ecological learning' conceptions in contrast with modern conceptions of education. Using an enactivist approach, the notions of 'comparison', and of 'advantage', are re-interpreted to discuss distinctions of 'betterness' between the concepts of ecological learning and modern education. The questions used to initiate the discussion are: What are these advantages? And why are they better?

\subsection{INTRODUCTION}

'Advantage', in the knowledge economy lexicon, is commonly used in connection with 'competitive' or 'comparative'. Advantage, meaning a favourable position in conditions or circumstances that results in benefit or profit, derives from the French word avant, meaning 'in front'. In Chapter Seven (7.2) the word 'hap' was explained as meaning a fortuitous event, which in an enactivist interpretation has a complexly propitious (favourable disposition) tone. In this chapter the distinction between the modern, economic conception of advantage (as being in front) is contrasted with the ecologically postmodern enactivist, or hap-like understanding of advantage (as propitiousness). Also in Chapter Seven (7.2), it was explained that distinctions between modern and postmodern concepts found in related terms (vision, sound, activity) is a matter of formulated or unformulated attitude towards them. In this case both formulated and unformulated concepts of advantage coincide on the notion 
of 'front', but the formulated interest is with getting ahead, while the unformulated concern involves ways of experiencing the future.

'Better' is also a word that takes on different complexions in the contrast between modern meaning and postmodern re-interpretations. The common understanding of better is as being 'more than good'. However, in the context of this chapter, the distinctions in advantage is drawn between, on the one hand, 'more advantageous' in the subjective/objective sense of 'better off' and 'better than', and on the other hand, in advantage as a non-objective, complex understanding of 'betterness' or well-being.

Given these interpretive distinctions of terminology, 'advantages' of ecological learning and explanations about their 'betterness' will be contemplated in relation to objectively educating for the knowledge economy. The contemplation begins by looking at a theoretical notion of 'cenozoic', 'technozoic', and 'ecozoic' distinctions. These terms are explained, along with the concepts they represent, which are contrasted in ecological and economic interpretations of 'ideology', together with their overall effect on the transformation of education towards learning for 'qualities of life' (O'Sullivan, 1999). The ecological learning 'advantages' for 'better' life qualities is brought into a 'matrix' representation of intersecting values of living and aspects of existing, which leads to a synthesis of these values and aspects into a theory of learning and knowing embodying living and existing.

A summary of the theme of this chapter is concisely encapsulated in the following quotation from Eva Nordland (1994):

One recurring theme is that something must be wrong with an education that substitutes knowledge of technology for the understanding of human beings; substitutes inquiry into 
fragments for the study of nature in its complexity; substitutes efficiency in producing things for caring about living beings; and stresses the importance of competition instead of encouraging cooperation between human beings" (p. 10).

As Nordland implies, and this chapter argues, the problem is not with education, it is with the attitude toward it.

\subsection{THEORETICAL DISTINCTIONS IN ADVANTAGE AND DISADVANTAGE}

\section{Cenozoic, technozoic, ecozoic}

These three terms are from Edmund O'Sullivan (1999) who uses them to illustrate distinctions in the transitional milieus between modernity and postmodernity that apply to his educational visions. O'Sullivan uses the terms in arguing that there is a terminal dysfunctional conflict between positions of economic interest and ecological concern in the world. As he puts it:

We have reached an impasse in the world economy. The era of colonizing open frontiers is in its final stage. There is nowhere else to go on this planet. Colonization of land is no longer a physical possibility. All we have left in this new information age is the colonization of the mind. In the wake of the affluent society, we have the wreckage of the terminal cenozoic (pp. 159-160).

He uses 'cenozoic', to distinguish the period occupying the past sixty-five millennia, which coincides with 'modern' human beings. The term 'technozoic' is used to focus the technological impact of the last century of the 'terminal cenozoic' period. He says:

There is a public commitment to the development of 'democratic citizenry'. There is also an abiding commitment to the idea of progress and its integral linkage to the technological-industrial society. This, in a nutshell, is the core of the progressive technozoic vision (p. 49). 
However, he argues, the succeeding progressive technozoic vision is in decline rather than being in ascendancy, and compounds the 'terminality' of the cenozoic period, because its proponents fail to see the terminal qualities (ibid.). What is needed, says O'Sullivan is a new educational vision, namely an 'ecozoic' vision to help "...extricate ourselves from the industrial trance state that we have been in since the beginning of the twentieth century" (p. 45). The 'transformative ecozoic' vision is characterised as "...a new earth period...in which a relationship of mutual enhancement between humans and the natural world is regarded not only as possible but essential to planetary survival" (p. 46).

\section{Educational visions}

To elaborate on his argument O'Sullivan presents a table of 'Educational visions' (Figure 8.1), which sets out some of the features and qualities that characterise the 'progressive technozoic' and the 'ecozoic transformational', and, positioned between them, the 'conservative' vision of contemporary education.

\begin{tabular}{|c|c|c|c|}
\hline Features & Progressive technozoic & Conservative & Ecozoic transformational \\
\hline Educational world view/history & Modern & Anti-modern & Postmodern \\
\hline $\begin{array}{l}\text { Orientation to community and } \\
\text { natural world }\end{array}$ & Exploitive & Traditional & Reflexive/interactive \\
\hline View of time & Evolutionary & Cyclical/static & Time developmental \\
\hline View of space & Pluralistic & Organic essentialist & Organic/interactive \\
\hline Pre-eminent metaphor & Mechanistic & $\begin{array}{l}\text { Anthropological organic } \\
\text { (human body) }\end{array}$ & $\begin{array}{l}\text { Biocentric (i. e. organic web } \\
\text { of life) 'circle of life' }\end{array}$ \\
\hline Vicw of conflict & Superficial/ameliorative & Deviant/anarchic & Creative \\
\hline $\begin{array}{l}\text { Contemporary educational } \\
\text { features }\end{array}$ & Progressive & Traditional & Emergent \\
\hline
\end{tabular}

Figure 8. 1: Educational vision

(O'Sullivan, 1999, p. 48). 
The table is most helpful in emphasising the relationships between many of the issues and arguments that have been raised in my previous chapters. Moreover, it is a graphical way of interpreting how complex understandings of living are in transition from extant evolutionary knowledge of the world.

\section{A time developmental process}

Taking time as an aspect of the visions, the conservative mechanical clockwork view is positioned between the progressive technozoic scientific evolutionary view, and the ecozoic 'time developmental' idea. This time developmental 'milieus' is clarified by O'Sullivan, citing Swimme and Berry (1992) who refer to it as 'space-time emergence'. They say

...the universe has emerged into being through an irreversible sequence of transformations that have, in the larger arc of their movement, enabled the universe to pass from a lesser to a greater complexity in its structure and functioning as well as to a greater variety and intensity in its modes of conscious expression as this can be observed on the planet Earth (p. 223, cited in O'Sullivan, 1999, p. 71).

Therefore, in the conservative view, time is a complicated, mechanically regulated concept. In the progressive technozoic view, time is innovatively evolving on a linear continuum, from the previous view towards a more progressively technological view, which remains reified and managed by humans. However, in the ecozoic vision, the infinite complexity of dimensionality in time-space is understood transformatively as emerging into being. This view re-visions, re-interprets, and recreates all previous, evolving and emerging ideas of time and space into another understanding of dimension. 


\subsection{AdVANTAGE IN IDEOLOGY AND ECOLOGY}

\section{Egotistical rules and ecological concepts}

Distinctions between ruling ideas and understandings of concepts are explained through notions of consensus and conformity (associated with subscribing to an ideology), and notions of differences and diversity (associated with ecology). Cultural historian William Irwin Thompson (1987) putting his work in education into a 'non-ideological' and 'contemplative association', pre-dates O'Sullivan with the argument that "one ideology [cannot be] simply replaced with another one" (p. 33). Rather, he says "...in the Lindisfarne Fellowship ${ }^{38}$ we have worked to create, not a new ideology to which we all subscribe, but an ecology of associated differences" (ibid.). While O'Sullivan (1999) is cautious about cognitive science, which he considers still sees that it is for the human mind to "...correct nature through the development of technologies of the human mind" (p. 55). He is also supportive of Thompson's biocentric vision of the mind as a "...self-regulating autopoetic [sic] structure embedded in the natural world (p. 55).

\section{Economics and Gaia}

In a later essay on the mind-nature theme, Thompson (1991b) attempts to bring economic ideology and ecological understandings into focus through the idea of 'schools of thought'. He envisions the 1990's as the period of shifting power from

\footnotetext{
38 The Lindisfarne Fellowship is a 'non-institutional' group of individuals, coordinated by Thompson, with diverse interests in fields of ecology, biology, cognitive science, economics, botany and genetics; they include people such as Gregory Bateson, John Todd, James Lovelock, Lynn Margulis, Humberto Maturana, Francisco Varela, Hazel Henderson, Wes Jackson (Thompson, W., 1987).
} 
economics to empowerment of ecology-"[j]ust as the 'Chicago School' provided the orientation for Thatcher, Kohl, Reagan, and Bush in the eighties, I think the 'Gaian School' can provide us in the nineties, not with a new ideology, but with a new understanding for complex dynamical systems in which opposed ideologies must coexist to structure an ecology of consciousness" (p. 256). In balancing Thompson's thoughtful re-vision of schools, and O'Sullivan's cautious view of the mind-nature relationship, there arises, perhaps, what may be the greatest hurdle to achieving the transformative view of learning; that is, the enormous leap of imaginative belief required to retire the ideology of the unique ego and release the contemplative complexity of ubiquitous eco. In a society driven by, and also towards, instantaneous self-gratification, it is a big ask to put aside personal hedonic pursuits for panoptic contemplation.

\subsection{BETTERNESS IN QUALITY OF LIFE}

\section{What is the problem?}

In considering the 'advantages' of the modern knowledge economy worldview, O'Sullivan brings us back to the views of time and space within the technozoic vision. Time, as was explained above, places growth, development, and competition in an evolutionary framework of progress. In this view change is progressive and moves forwards and upwards, leaving the past behind as an enemy of the future. As O'Sullivan puts it, "[p]rogress, in its contemporary form, is the movement into the global competitive marketplace" (p. 53). Along with this progressive view of time, the technozoic vision also sees space as a foundational motif of competition. Space 
in the same contemporary form as time is seen as pluralistic; that is, as a "...cluster of freely operating or isolated parts" (ibid.)-exemplified by the so-called free market. Within what O'Sullivan styles as this " 'pluriverse'...the role of the educational system is to prepare the learner for the newly emergent market that is expanding beyond the nation-state into the sphere of transnational corporations" (ibid.). Within New Zealand's rarefied atmosphere, the newly merged global dairy conglomerate Fonterra, uses the fuzzy rhetoric of an eco-manipulative name (fountain of earth?) to lull any sense of unease about its eco-exploitative motives. It is precisely this sort of action that O'Sullivan emphasises in unpacking the technozoic view of conflict. Here he sees the way in which combat and competition takes on a rhetorical starring role on one hand, but on another, any critical conflict that arises is either "unnecessary and superficial...[or/and]...precipitous and an overreaction" (p. 54). Criticism of the technozoic vision is ameliorated by an insistence that change is not only gradual, and incremental, but that "[a]nything that has been done can be undone" (ibid.). Conflict in this predominant mode of human economic and social organisation is "...closely managed by politicians, business persons and ultimately, the educator who acts as the apologist of this system" (ibid.). O'Sullivan concludes with this characterisation of educational complicity by commenting, "[a]s it is frequently put in ironic terms within this vision, 'What's the problem?' " (ibid.). Locked in to the circular rhetoric and ambiguity of this question is the closed loop that also asks, "Problem? What problem?"

\section{Transformative vision}

The transformative ecozoic vision is, says O'Sullivan, "an alternative to the global market vision" (p. 63). One of the more significant advantages of the transformative 
ecozoic vision has already been outlined as the 'time-developmental' view in a new understanding of 'space-time emergence'. In place of the 'progressive time' and 'pluriverse' of the knowledge economy, the alternative vision contemplates the universe as a unity, in the enactivist sense as explained in Chapter Seven (7.0), that is, as an integral coherent dynamic whole that cannot be explained by its constituent parts. Such a view transforms the elusive mechanistic, and atomistic problems of the technozoic vision into another dimension of understanding, which O'Sullivan, citing Graham Pike and David Selby (1988), characterises as a universe where "[h]owever much we compartmentalize for practical purposes, everything, in the final analysis, is woven into a multi-layered, multi-dimensional web of interaction and significance" (p. 75). At the foundation of this vision, O'Sullivan places an educational vision that transforms conceptions of knowledge as a mechanistic analytical view of parts being the sum of the whole, into a "synthetic holism" (p. 75), which embodies learning and teaching as a "...holistic educational paradigm and holds that all things are part of an indivisible unity or whole" (ibid.). In this vision knowledge is not a separate component of the physical world, rather, "[t]hought is part and parcel of the natural world since human life is embedded in nature...[also] human thought is nature's way of reflecting on itself" (ibid.). Such a statement, while using rather subjective and objective language, helps to express the essence of reflecting on the holistic and complex nature of O'Sullivan's transformative learning vision.

\section{Standard or quality?}

One common standard by which the 'part and parcel' of the modern world is measured is gross national product (GNP), and the aim of every nation is to see its raised standard of living measured on the world index of GNP. The notion of 
standard of living used here is however a modern relativistic measure, which is, according to O'Sullivan, "...only a comparative phrase to tell you if your buying power has increased or decreased in wage potential" (p. 235). He emphasises "[s]tandard of living does not add up to quality of life" (ibid.). What comes of this comparative evaluation of affluence and constraint is a "...bottom line of materialism and glorification of self-interest" (ibid.), which has us pitched in a "...world filled with mutual distrust and self-interest" (ibid.). This foundational problem, namely, disparity, inequity, gap, divide, or whatever one wants to call it, is rooted in the incommensurability of human needs and the world's capability to satisfy them. In other words, what human beings have come to regard as their scale of needs is not commensurable with the world that satisfaction of those needs are complexified within. O'Sullivan puts it this way, "...our Western scale of progress and development is not tuned to the human scale or, for that matter, the scale of the earth" (p. 240). When we talk of standards and quality in an educational context, these are not the standards of attitudes and knowledge, or the quality of values and skills that "...are an integral part of the [modern] New Zealand Curriculum" (Ministry of Education, 1993). Rather standard needs to be re-interpreted in the light of the root of the word, which refers to the extending of a ceremonial flag and relates to the representation of celebrating fulfilment. In the modern analytical worldview the standard has been converted from a celebrating condition to an evaluative measure. Similarly with quality, the Latin root of this word concerns "of what kind, of such a kind" (Concise Oxford Dictionary, 1999), and is thus about qualitative description rather than assessment of quality. In the modern human world, standards and quality are about scales in the sense of measurement; in the ecological world scales are all about balance, that is, interdependence of "harmony within a whole" (Reardon, 1994, 
p, 29) The bottom line advantage and betterness of an ecological learning conception is in concern for scales in ways that transform measure towards pleasure-in the root sense of satisfaction. In trying to measure human needs we have lost all sense of scale about what satisfaction means.

\subsection{ECOLOGICAL SCALES OF HUMAN LEARNING}

\section{Changing scales of needs}

One important distinction to be made about ecological scales is the integration of human beings into balance with the world, rather than their claiming superiority over it. In the modern worldview of hierarchical order, the needs of humankind are prioritised as supreme. However, in the ecological postmodern understanding of worlds, hierarchical order is transformed into complex systems. This is not to say needs as such are changed, only that needs are understood in different ways. As O'Sullivan says, it is through an "...understanding of the complexity of human needs and how human needs provide the basis for our understanding of quality of life" ( $p$. 240), that a different sense of scales emerges.

\section{Understanding needs and satisfiers}

Another important distinction in ecological scales is in understanding what constitutes needs and satisfiers. In the modern conception, categorisation tends towards specificity of demands, in the ecological postmodern conception the trend is otherwise. O'Sullivan citing Max-Neef and Hopenhayer (1989) explains that

...food and shelter must not be seen as needs, but as satisfiers of the fundamental need for Subsistence. In a similar manner, education (both formal and informal), study, 
investigation, early stimulation and meditation are seen as satisfiers of the need for Understanding" (p. 241).

What we have here is the exposition of the inverted way that the modern conception of the world is looking at itself through the wrong end of a telescope, which is manufactured to its own specialised design. Human beings conceive of, and teach their young about, a world to be exploited to satisfy human needs in order for that world to progress. However those needs are built on a concept of the world that is incommensurable not only with their satisfaction, but also the very nature of existing in the world. Education, in its modern conception, is teaching human beings about needs, and satisfiers, and about the world, as particular parts that constitute the sum of the whole of human existence. Teaching and learning in an ecological understanding contemplates the world as a holistic complexity wherein the whole is infinitely greater than any of its so-called 'parts'.

\subsection{VALUES AND ASPECTS OF LEARNING AND KNOWING}

\section{A matrix}

In attempting to come to an accessible way of representing this alternative conception of needs and satisfiers, O'Sullivan has drawn on Max-Neef and Hopenhayer (1989, in O'Sullivan, 1999, p. 240), to devise a categorical matrix (see Figure 8.2). On this matrix, needs are represented on one axis as axiological values and on the other as existential aspects. Axiological values are seen to include: Subsistence; Protection; Affection; Understanding; Participation; Idleness; Creation; Identity; Freedom. Existential aspects are given to include: Being; Having; Doing; Interacting. The last aspect in the list, 'interacting', is especially noted as it 
...registers locations and milieus (as times and spaces). It stands for the Spanish estar and the German befinden, in the sense of time or space. Since the there is no corresponding word in English, INTERACTING was chosen 'à faut de mieux' " (p, 243).

\begin{tabular}{|c|c|c|c|c|}
\hline \multirow{2}{*}{$\begin{array}{l}\text { Needs according } \\
\text { to axiological } \\
\text { categories }\end{array}$} & \multicolumn{4}{|c|}{ Needs according to existential categories } \\
\hline & Being & Having & Doing & Interacting \\
\hline Subsistence & $\begin{array}{l}\text { Physical health, mental } \\
\text { health, equilibrium, sense } \\
\text { of humour, adaptability }\end{array}$ & Food, shelter, work & $\begin{array}{l}\text { Feed, procreate, rest, } \\
\text { work }\end{array}$ & $\begin{array}{l}\text { Living environment, social } \\
\text { setting }\end{array}$ \\
\hline Protection & $\begin{array}{l}\text { Care, adaptability, } \\
\text { autonomy, equilibrium, } \\
\text { solidarity }\end{array}$ & $\begin{array}{l}\text { Insurance systems, } \\
\text { savings, social security, } \\
\text { health systems, rights, } \\
\text { family, work }\end{array}$ & $\begin{array}{l}\text { Cooperate, prevent, plan } \\
\text { take care of, cure, help }\end{array}$ & $\begin{array}{l}\text { Living space, social } \\
\text { environment, dwelling }\end{array}$ \\
\hline Affection & $\begin{array}{l}\text { Self-esteem, solidarity, } \\
\text { respect, tolerance, } \\
\text { generosity, receptiveness, } \\
\text { passion, determination, } \\
\text { sensuality, sense of } \\
\text { humour }\end{array}$ & $\begin{array}{l}\text { Friendships, family, } \\
\text { partnerships, relation- } \\
\text { ships with nature }\end{array}$ & $\begin{array}{l}\text { Make love, caress, } \\
\text { express emotions, share, } \\
\text { take care of, cultivate, } \\
\text { appreciate }\end{array}$ & $\begin{array}{l}\text { Privacy, intimacy, home, } \\
\text { spaces of togetherness }\end{array}$ \\
\hline Understanding & $\begin{array}{l}\text { Critical conscience, } \\
\text { receptiveness, } \\
\text { curiosity, astonishment, } \\
\text { discipline, intuition, } \\
\text { rationality }\end{array}$ & $\begin{array}{l}\text { Literature, teachers, } \\
\text { method, educational } \\
\text { policies, communication } \\
\text { policies }\end{array}$ & $\begin{array}{l}\text { Investigate, study, } \\
\text { experiment, educate, } \\
\text { analyse, mediate }\end{array}$ & $\begin{array}{l}\text { Settings of formative inter- } \\
\text { action, schools, universities, } \\
\text { academies, groups, } \\
\text { communities, family }\end{array}$ \\
\hline Participation & $\begin{array}{l}\text { Adaptability, receptiveness, } \\
\text { solidarity, willingness, } \\
\text { determination, dedication, } \\
\text { respect, passion, sense } \\
\text { of humour }\end{array}$ & $\begin{array}{l}\text { Rights, responsibilities, } \\
\text { duties, privileges, work }\end{array}$ & $\begin{array}{l}\text { Become affiliated, co- } \\
\text { operate, propose, share, } \\
\text { dissent, obey, interact, } \\
\text { agree on, express } \\
\text { opinions }\end{array}$ & $\begin{array}{l}\text { Settings of participative inter- } \\
\text { action, parties, associations, } \\
\text { churches, communities, } \\
\text { neighbourhoods, family }\end{array}$ \\
\hline Idleness & $\begin{array}{l}\text { Curiosity, receptiveness, } \\
\text { imagination, recklessness, } \\
\text { sense of humour, } \\
\text { tranquility, sensuality }\end{array}$ & $\begin{array}{l}\text { Games, spectacles, } \\
\text { clubs, parties, peace } \\
\text { of mind }\end{array}$ & $\begin{array}{l}\text { Day-dream, brood, } \\
\text { dream, recall old times, } \\
\text { give way to fantasies, } \\
\text { remember, relax, have } \\
\text { fun, play }\end{array}$ & $\begin{array}{l}\text { Privacy, intimacy, spaces of } \\
\text { closeness, free time, } \\
\text { surroundings, landscapes }\end{array}$ \\
\hline Creation & $\begin{array}{l}\text { Passion, determination, } \\
\text { intuition, imagination, } \\
\text { boldness, rationality, } \\
\text { autonomy, inventiveness, } \\
\text { curiosity }\end{array}$ & $\begin{array}{l}\text { Abilities, skills, method, } \\
\text { work }\end{array}$ & $\begin{array}{l}\text { Work, invent, build, } \\
\text { design, compose, } \\
\text { interpret }\end{array}$ & $\begin{array}{l}\text { Productive and feedback } \\
\text { settings, workshops, cultural } \\
\text { groups, audiences, spaces for } \\
\text { expression, temporal freedom }\end{array}$ \\
\hline Identity & $\begin{array}{l}\text { Sense of belonging, } \\
\text { consistency, differentiation, } \\
\text { self-esteem, assertiveness }\end{array}$ & $\begin{array}{l}\text { Symbols, language, } \\
\text { religion, habits, customs, } \\
\text { reference groups, sexuality, } \\
\text { values, norms, historical } \\
\text { memory, work }\end{array}$ & $\begin{array}{l}\text { Commit oneself, integrate } \\
\text { oneself, confront, decide } \\
\text { on, get to know oneself, } \\
\text { recognize oneself, } \\
\text { actualize oneself, grow }\end{array}$ & $\begin{array}{l}\text { Social rhythms, everyday } \\
\text { settings, settings which one } \\
\text { belongs to, maturation stages }\end{array}$ \\
\hline Freedom & $\begin{array}{l}\text { Autonomy, self-esteem, } \\
\text { determination, passion, } \\
\text { assertiveness, open- } \\
\text { mindedness, boldness, } \\
\text { rebelliousness, tolerance }\end{array}$ & Equal rights & $\begin{array}{l}\text { Dissent, choose, be } \\
\text { different from, run risks, } \\
\text { develop awareness, } \\
\text { commit oneself, disobey }\end{array}$ & Temporal/spatial plasticity \\
\hline
\end{tabular}

Note: The column of BEING registers attributes, personal or collective, that are expressed as nouns. The column of HAVING registers intu itions, norms, mechanisms, tools (not in a material sense), laws, etc. that can be expressed in one or more words. The column of INTERACTIN registers locations and milieus (as times and spaces). It stans for the Spanish estar or the german befinden, in the sense of time or space. Since there is no corresponding word in English, INTERACTING was chosen 'à faut de mieux'.

\section{Figure 8. 2: Matrix of needs and satisfiers}

(O'Sullivan, 1999, pp.242-243).

In contemplating this matrix, the most significant consideration is that rather than seeing needs and satisfiers separated into divisions of components, needs and 
satisfiers can be looked upon as interdependently interrelated. O'Sullivan puts it thus-"[n]eeds and satisfiers are not related to one another in a one-to-one correspondence. Thus a satisfier can contribute to the satisfaction of different needs, and, conversely, a need may require various satisfiers in order to be met" (p. 241).

\section{A conception}

In thinking carefully about the ecological learning implications of O'Sullivan's transformative vision, I have considered another conceptual interpretation. This interpretation brings the existential aspects of living into a representation of learning and knowing as enactively recursive around existentially Being, Having, Doing, and Interacting for the axiological values of Subsistence, Protection, Affection, Understanding, Participation, Idleness, Creation, Identity, and Freedom. The representation of my conception is given in Figure 8.3, and shows Learning embodying Being, Having and Doing, and Knowing embodying Having, Doing, and Interacting. However, unlike the closed loop problem generated in the technozoic vision of the world, my representation is open and infinite and is visualised more like a helical strand than a length of chain.

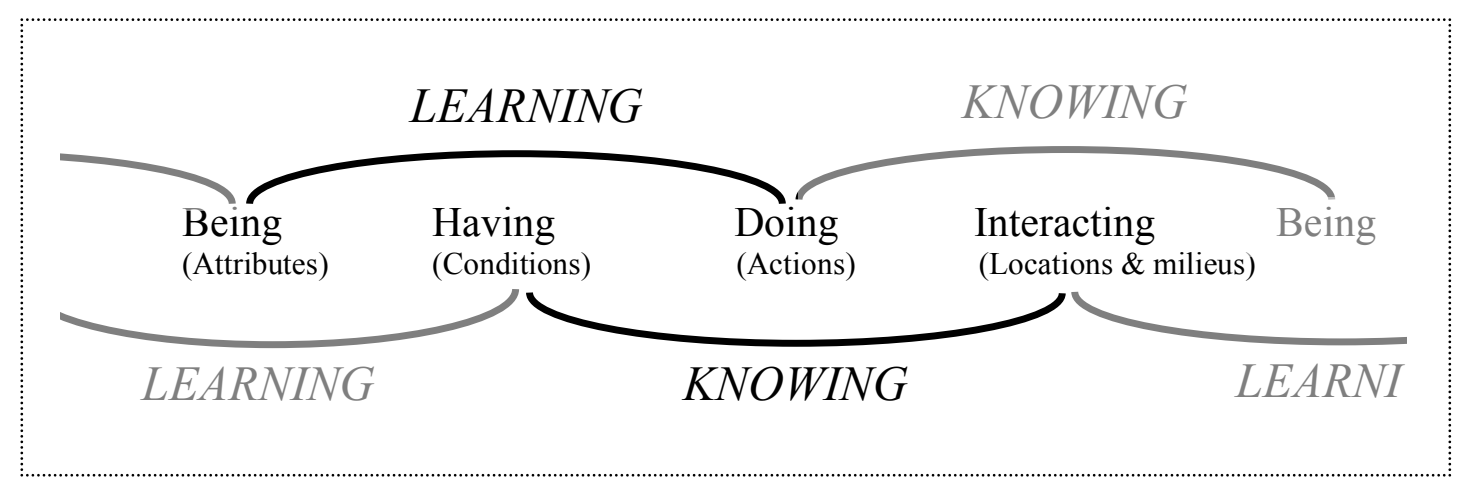

Figure 8. 3: Learning and knowing embodying living in aspects of existence 
The advantages for ecological learning in this conception are towards transforming understandings from polarised, fundamental positions to complex 'essential' potentials of being human, having humanity, doing humane acts, and interacting humanistically, in other worlds of existence, which are emerging through being, having, doing, interacting, being, having, doing, interacting...ad infinitum...

\subsection{SUMMARY}

To explain 'advantages' and 'better' as within ecological postmodern and modern conceptions of education requires a re-interpretation of the terms themselves. The distinction has been drawn in attitudes towards understanding the terms. On one hand the modern interpretation sees advantage as betterment by 'getting ahead', whereas the ecological postmodern understanding concerns betterness in ways of 'experiencing the future'. The thematic concern of this chapter is suggested in the revisioning of the problematic question of education systems and economic knowledge societies. Rather than competition and fragmented inquiry, the re-vision contemplates understanding in cooperation and natural complexity in learning.

To come towards such understanding, another conception of distinctions in the world is suggested through a critique of the predominant conception and the offer of an alternative. These re-interpretations of conceptions are expressed as a transformative vision within learning or educational visions. The visions are related to periodic distinctions that incorporate the terms 'cenozoic', 'progressive technozoic', and 'ecozoic', with the latter two being separated by a conservative position, which is antithetical to both. The significant concepts within the educational visions are 
elaborated upon in terms of dimensionality (time and space) to illustrate distinctions between the visions. Such distinctions help to present a way of understanding distinctions between ideology and ecology as being co-implicated in concepts rather than self-cancelling conflicts. However the notion of progress is drawn into contrast with critical questions about how this relates to educational priorities, economic ideology, and ecological concerns. The problem, therefore, resides in the question "What problem?"

The transformative vision is offered as an alternative to the elusive modern 'problem' through the re-conception of the world in complex unity "...woven into a multilayered, multi-dimensional web of interaction and significance" (Pike \& Selby, 1998, cited by O'Sullivan, 1999, p. 75). However significance is also a matter of standard and quality, which in a modern educational context, focuses on scales of measurement that are not only part of attitudes and knowledge, but also values and skills to be taught within a curriculum framework. Ecological learning concepts reinterpret this measuring idea of scales towards better understandings of balance, which draw out some of the qualitatively significant distinctions in what constitutes quality of life, rather than living standards.

Underpinning standards and values in the modern conception of education is the conviction that qualifications are the foundation of employment advantage, which meets the needs of the economy and results in personal satisfaction. Against this view, it is argued that the scale of human needs is incommensurable with the demands being placed on the ecological world to satisfy them. What is called for is a re-conception of scales as balance, or the "interdependence of harmony within a 
whole" (Reardon 1994, p. 29). The argument puts the bottom line of advantage and betterness in ecological learning conceptions as transforming measure towards pleasure-as satisfying fulfilment.

To better understand distinctions between modern and postmodern ecological notions of needs and satisfiers they are presented in a matrix view that helps to explain that, rather than being hierarchically ordered and humanly prioritised, they are re-visioned in the ecological learning concept as complexly interdependent. The matrix of aspects of existing and values of living are interrelated in ways that bring learning and knowing into Being.

In the concluding contemplation of transformative ecological learning, the matrix of existential aspects and values for living is redrawn as a strand, which intertwines complexities that are embodied in learning and knowing occasions, which, in turn are embedded in alternative understandings of the dimensionality of existence. The unpacking of this last sentence will be the focus of the final chapter, which also resolves the conclusions that have been reached. 


\section{9. \\ CONCLUSION}

In contemplating the 'advantages' of 'betterness' discussed in the preceding chapter, the conclusion becomes apparent that it would be a mistake to embrace too exclusively the idea of educating for the knowledge economy. The final question is: Why?

\subsection{INTRODUCTION}

In the preceding chapter reference was made to the modern question 'What's the problem?' and the way in which this question is locked into a 'closed loop' of rhetoric and ambiguity-'Is there really a problem? What is the problem really?' Thus, the implication of the question is that if a problem exists, its existence must be proved to the satisfaction of a consensus that agrees the problem exists. Such is the 'nature' of the modern mind and its notion of knowledge-we do not see what we do not see.

In this concluding chapter, two matters will be re-solved; the first is to fulfil the promise of unpacking the penultimate sentence of chapter eight, and the second is to fulfil the overall promise of this thesis, namely to draw together the many thematic strands that I have teased out of the topic, and weave them into a coherent manifestation of my thinking.

At the outset I indicated that I am a picture thinker operating in a textual world, and this has been illustrated by the metaphor of laying down a path while walking. The 
convention for presenting a work such as this is to use words in a stepwise fashion to lead the reader down a well defined road. However, I have started with the reader down such a road in order to introduce her or him to the infinite paths that are constantly made in bringing the world into being. My re-solution is that there is not 'one track' there are 'many paths', and to manifest that position I will use words and some pictures.

\subsection{CLOSED AND OPEN LOOPS}

\section{Strands in a matrix:}

In the modern sense words like strand and matrix have very industrial meanings, as in strands of synthetic fibre, and the matrix of a plastic casting. However pre-modern and postmodern interpretations and re-interpretations of the words regard them differently. The origin of matrix is in the notion of 'woman who breeds', and while the origin of strand is unknown its meaning as 'an element that forms part of a complex whole', such as the tributary strands of streams in a river, is also more natural than industrial. In postmodern re-interpretations, matrix comes to represent the complexity within which strands can be regarded, whether in a populist sense, like the movie The Matrix 'virtually' visualises, or in the academic sense that O'Sullivan (1999) graphically tabulates (as in figure 8.2). In other words, while the objective of the movie 'matrix' was exploitation of human minds-in a closed loopO'Sullivan's matrix is to extend capability for human minds' to understand nonobjectivity-in open loops. 
The earlier chapters of this thesis are concerned for the way in which some human beings see the world and how they believe it should progress. Such a view, I have argued, is on a track that has a concrete foundation, a solid structure, a rigid framework, a finite perspective, and a sharp focus. I described this view as grasping towards the light at the end of the tunnel, wherein the 'light' is seen in the sense of that outlined in the 'bright future' for New Zealand — a closed loop.

The latter chapters have concerned diverse ways in which human beings are part of worlds of experiences, and how re-creating understandings of being human brings about other interpretations of living, learning, knowing, and existing—open loops.

\subsection{MATRIX, STRAND, OPEN AND INFINITE LOOPS}

\section{Coming to visions of Transformative Ecological Learning}

In the penultimate sentence of Chapter Eight, I said that transformative ecological learning contemplates 'the matrix of aspects of existing and values for living redrawn as a strand intertwining complexities that are embodied in learning and knowing occasions, which, are in turn embedded in alternative understandings of the dimensionality of existence'. And, as was promised, this chapter unpacks that sentence.

O'Sullivan's (1999) matrix of 'needs and satisfiers' sets out aspects and values on a table (see Figure 8.2), which establishes a complexity of interrelationships between the axes of the matrix. That is, "a satisfier can contribute simultaneously to the satisfaction of different needs, and, conversely, a need may require various satisfiers 
in order to be met" (p. 241). I have'taken' O'Sullivan's two-dimensional table off the flat page, transformed it into a 'strip', and twisted it into a strand, to demonstrate that the ideas it contains exist in dimensions other than on a 'flat' surface (Figure 9.1).

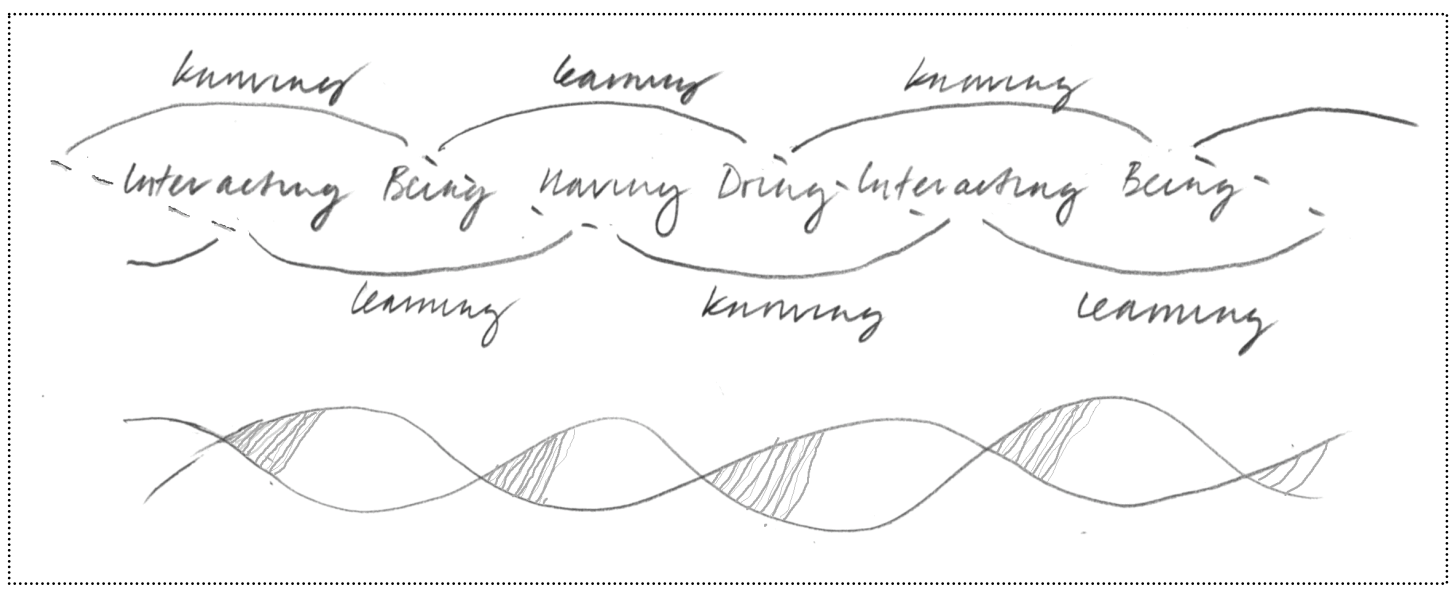

Figure 9. 1: 'Strand/strip' of learning-knowing complexity.

Along the strand, I have visualised continuous occasions of being, having, doing and interacting, during which learning and knowing are also occurring within overlapping experiences bringing into being other notions of dimensional existence in 'spacetime'. Thus, I have redrawn the matrix in a way that suggests intertwining complexities, embodied in learning and knowing occasions, which are in turn embedded in alternative understandings of the dimensionality of existence. These alternative understandings of 'dimensionality of existence' extends the initial 'strand' in Figure 8.3 into an 'infinite loop' by continuing to twist the 'strip' of the strand and then joining its 'ends'. A representation of such an 'infinite loop' is found in M. C. Escher's (1984) Mobius Strip I (Figure 9.2). This idea of representing complex dimensionality reminded me of Douglas Hofstadter's (1980) Godel, Escher, Bach: an Eternal Golden Braid, which in turn lead me to his image of the initials GEB (p. 1) embodied in a visualisation of complex unity. I 'played' with this idea and re-created 
my own version for Transformative Ecological Learning (TEL), which appears in Figure 9.3. For sketches showing my 'playing' with these ideas see Figure 9.4.

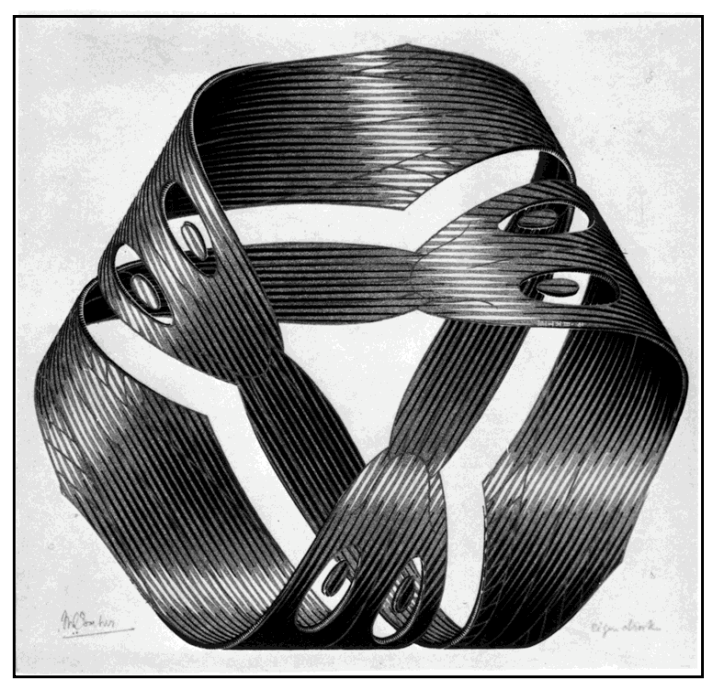

Figure 9. 2: 'Mobius Strip I'

(M.C. Escher, In Locher, 1984, p.144)

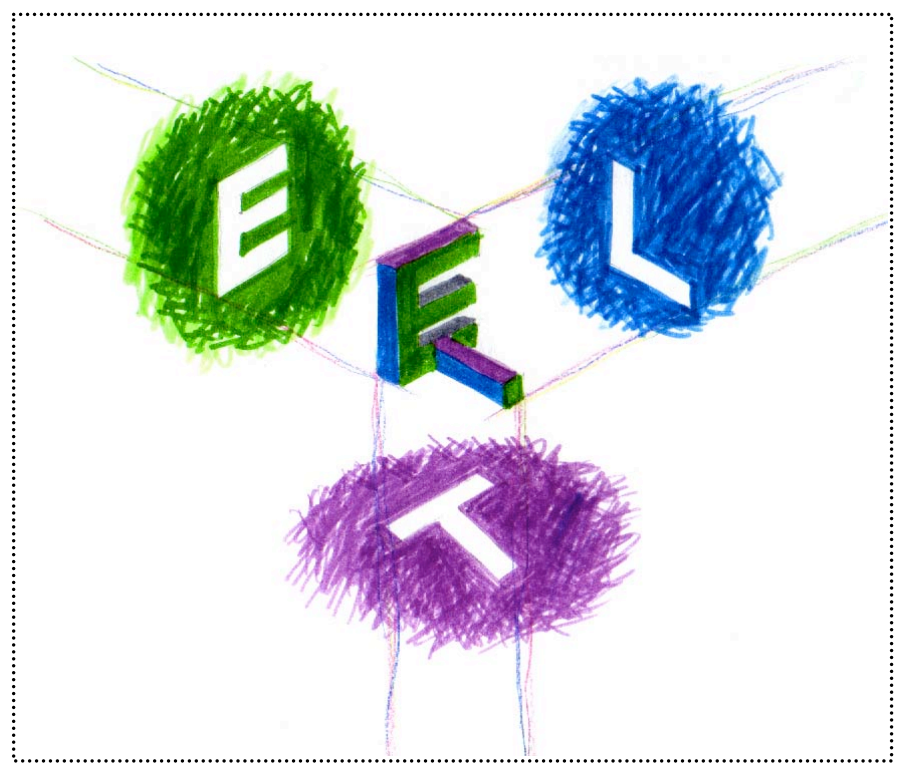

Figure 9. 3: 'T $E \mathrm{~L}$ ' in an illustration of complex unity

Ecological Learning and Teaching, and Transformative Ecological Learning, embedded as pathways in an illustration of complex unity. Each of the letters is a projected 'pathway' from each of the three faces of the complex unit. The symbols can only be seen by either projecting the images as illustrated, or by rotating each face of the unit in the observer's field of view. 


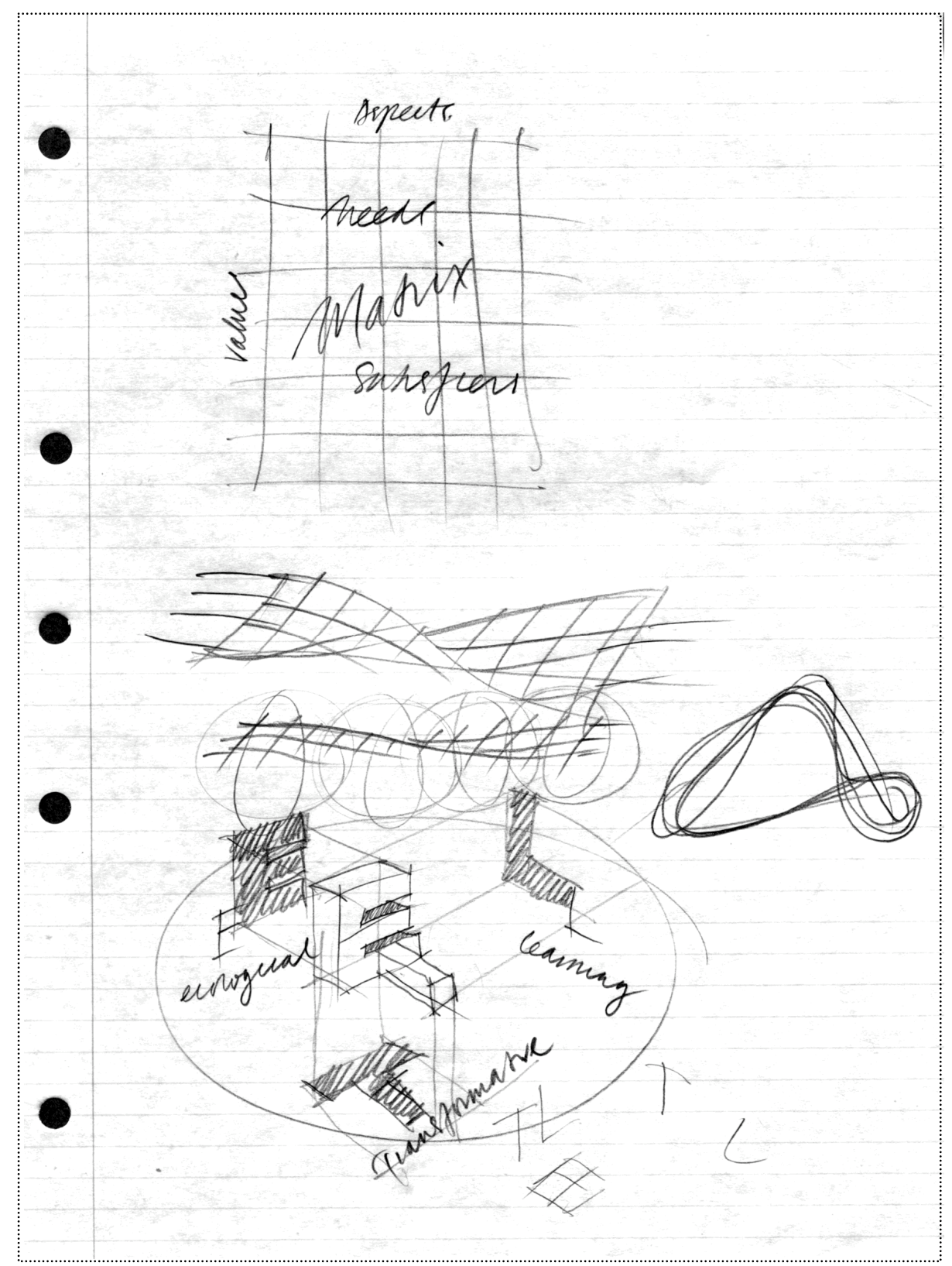

Figure 9. 4: 'Playing' with ideas and enacting new thoughts.

Sketches of a matrix, a strand, infinite loops, and 'TEL' as a complex unity. 


\subsection{EDUCATING FOR THE KNOWLEDGE ECONOMY}

Why would it be a mistake to embrace the idea of the knowledge economy too closely?

An answer to this question rests in the understanding the reader has gathered from what has been presented. So this becomes an occasion to return to the beginning, reinterpret what has been set out and replay the essence of the argument, to illustrate that there is not an, that is only one, answer; there are all-ways of, and there always is, coming to knowings in meanings for questions. Each of the first five chapter statements is therefore briefly summarised to recover the thoughts leading to the paths I have laid down while walking, in the subsequent chapters.

\section{The knowledge economy is a term with common currency}

The knowledge economy is a powerful force driving the current worldview through 'sustainable' technology, 'free' markets, and 'knowledge' workers. A dominant feature of the force is its rhetorical 'inclusiveness', or appropriation of certain characteristics of the world into the notion of a knowledge society. Such characteristics include 'cultural' assets, 'natural' products, 'sustainable' exploitation, and 'creative' knowledge.

\section{Education is vital to promotion of the knowledge economy:}

Recent effects of economic and ideological confrontations have compromised principles of education. Such confrontations include 'reforms' of management and 'reformations' of philosophy over the purposes of and approaches to education, thereby ensuring the 'progress' of an economically ordered society of consumers. 
The fundamentals of these 'reforms and reformations' are grounded in making 'wealth' an autonomous objective.

\section{The knowledge economy is grounded in a modern worldview}

The 'modern' worldview is built into the knowledge economy. While the rhetorical exterior cladding may have a postmodern appearance, the structure retains the dualisms, dichotomies, and rational logic of the scientific philosophy that supports it. Furthermore, the modern worldview maintains the primarily patriarchal, anthropocentric ruling order that ensures the knowledge economy profits those who invest in it, financially and ideologically. In the modern worldview the knowledge economy is inevitably 'on the right track'.

\section{Education for the knowledge economy takes a modern worldview}

Education is under enormous pressure to 'deliver' assurance of compliance and conformity to rules. Under the modern knowledge economy rule, education has been reformed as what I call 'inducation'-a commodity that leads or persuades people to learn to earn, and to be quantified and qualified to the most competitive of standards. Furthermore, knowledge economy 'inducation' is expanding economically to become a global commodity to be marketed as 'lifelong learning' products and services that can be delivered 'virtually' anywhere on the planet. The irony of the deconstruction of 'education' (in drawing out potential) to reform 'inducation' (to induce conformity) is lost on those who are 'on the right track' to the future.

\section{There are alternative, postmodern ways of thinking in the world}

While it is evident that living with change has become 'a way of life', there is difference between the modern worldview, which sees change as a condition to manage, and postmodern understandings of change as being synonymous with 
complexity. Modernity sees change as evolutionary and progressively linear, while postmodernity experiences change as complex fluxes in time and space. Rather than 'falling into line' to manage change, postmodernity understands 'natural drift' as adaptive processes to realise potentials for changes.

\subsection{ECOLOGICAL LEARNING}

What postmodern being, having, doing, and interacting embodies, is embedded in ecologically complex learning and knowing, transformatively emerging in thinking and understanding.

\section{Enactivism and Ecological complexity}

Differences between the modern worldview and alternative postmodern understandings of the world call for alternative approaches to navigating between these differences. Enactivism is such an approach-it adopts a 'promiscuous' attitude towards consciousness and awareness in complex experiences of perception. The byword of enactivism is expressed in the phrase 'laying down a path in walking', as a metaphorical way of bringing experiential understanding into being in the world through interacting with experiences in space and time.

Through enactivist interpretations, the distinctions of modern worldviews that insist upon strict definitions of knowledge in terms such as 'ecological' and 'complexity', are 'unframed' from 'hard and fast' objectivity. Ecological as a non-objective understanding brings into being, understandings about living in the world, that is, critical awareness of consciousness. This contrasts with the modern view of 
ecological as a discipline for the study of human-environmental discourse, or managing critical 'con-science'. Likewise, enactivist understandings of complexity transform knowledge as 'structure' from an artificial notion of solid foundations and rigid frameworks, to knowing 'systems', which embody existing as dynamical potentials continuously emerging in learning occasions embedded in living in the world.

\section{Postmodern learning includes ecological complexity}

Modern education and lifelong learning in the knowledge economy are being promoted as THE answer to inconsistencies in the way the world is managed for the future of human beings. This view is exemplified as 'the right track', which, as long as everyone is committed to it as a consensus, will secure and assure individual prosperity; education is the platform from which this view is launched, promoted, and applauded. Postmodern ecological learning has no platform because it transforms, re-visions, re-interprets, re-shapes, and re-creates, understandings of experiencing worlds that 'happen' along the path being laid in walking. In place of complicated structures of the frameworks of curriculum, authorisation of qualifications, and assessment of units of standards, which are constantly being reframed, re-assessed, and re-formed, and that require upskilling and re-training, there are alternatives to consider. Transformative ecological learning is such an alternative for opening human beings to reaching rather than grasping, cooperating rather than competing, participating rather than profiting, and sowing rather securing.

\section{There is 'advantage' and 'betterness' in ecological learning}

Enactivism re-interprets 'advantage' and 'better' from modern notions of quantification and qualification of getting ahead, to transformative understandings of 
experiencing future ways, or 'futurity'. Modernity is on the track to prosperity; enactivism experiences ecological postmodernity as paths to potential. Transformative understandings of 'advantages' and 'betterness' include re-solution of 'problems' into potential, re-interpretation of measures of 'scales' into balance and harmony, and the re-creation of rules of 'economy' into heuristics of ecological existence. The 'bottom-line' of advantage and betterness in ecological learning is the transformation of measures of wealth into pleasures of well-being. Goodbye grasping, hello helping.

\section{The knowledge economy excludes paths of ecological learning}

The knowledge economy is being portrayed as not only the right track to the future, but also as the ONLY track to the future. This portrayal is mistaken. To hold such a narrow view of the world is the height of human ignorance; to do so in the cause of human prosperity is, as Edmund O'Sullivan says, 'terminal'. There are not only other ways in future paths for the world, there are also other worlds of paths in the futurity of prospective potential.

There is a day for every one of us in our existence where we become conscious and aware that we just are. We did not ask to be here, we did not choose to be here, we are just here (O'Sullivan, 1999, p. 280).

Life is the gift of celebrating existence and living is a celebration of life

Life and living are both celebrated in laying down a path in walking 


\section{REFERENCES}

Andermahr, S., Lovell, T., \& Wolkowitz, C. (Eds.). (1987). A concise glossary of feminist theory. London: Arnold.

Appignanesi, R., \& Garrat, C. (1995). Postmodernism for beginners. Cambridge: Icon Books.

Apple, M. (1998). Conservatism and education policy. In K. Sullivan (Ed.), Education and change in the Pacific rim: Meeting the challenges (pp. 79-99). Wallingford: Triangle Books.

Begg, A. (1999, November). Enactivism: An emerging theory. Paper presented at Post-constructivist theories in education symposium, Victoria University of Wellington, Wellington, New Zealand.

Beggs, M. (2001, August 13). The emperor's new economy. Salient, 17, 24-25.

Berger, P., Berger, B., \& Kellner, H. (1973). The homeless mind: Modernization and consciousness. New York: Vintage Books.

Bragg, M. (1998). On giants' shoulders: Great scientists and their dicoveries from Archimedes to DNA. London: Hodder \& Stoughton.

Braithwaite, D. (1995). Enterprise education and the restructuring of the state: Business as Government? Unpublished MEd Thesis, Victoria University of Wellington.

Browning, J., \& Reiss, S. (1998, May). Encyclopedia of the new economy. Part 3. Wired, 6.05, 105-114.

Capra, F. (1981). The turning point. New York: Simon \& Schuster.

Castells, M. (1998). End of millennium. The information age: Economy society and culture (Vol. 3). Oxford: Blackwell.

Chaplin, C. (Director, Producer, Writer). (1936). Modern Times. [Film]. Los Angeles: Charles Chaplin Production/United Artists. 
Chomsky, N. (2000). Global Economy. In D. Gabbard (Ed.), Knowledge and power in the global economy: Politics and the rhetoric of school reform (pp. 3-16). Mahwah, NJ: Lawrence Erlbaum Associates.

Clark, H. (2001). 'Catching the knowledge wave' conference. Prime Ministerial press release, 30 May, 2001.

Cole, K. (1999). Economy-Environment-Development-Knowledge. London \& New York: Routledge.

Concise Oxford Dictionary (10 ${ }^{\text {th }}$ ed.). (1999). Oxford: Oxford University Press.

Cornbleth, C. (1990). Curriculum in context. London: Falmer Press.

Davis, B. (1996). Teaching mathematics: Toward a sound alternative. New York \& London: Garland Publishing.

Davis, B., Sumara, D., \& Kieren, T. (1996). Cognition, co-emergence, curriculum. Journal of Curriculum Studies, 28, 151-169.

Davis, B., Sumara, D., \& Luce-Kapler, R. (2000). Engaging minds: Learning and teaching in a complex world. Mahwah, NJ: Lawrence Erlbaum \& Associates.

Dawson, S. (1999). The enactive perspective on teacher development: 'a path laid while walking'. In B. Jaworski, T. Wood, \& S. Dawson (Eds.), Mathematics teacher education: Critical international perspectives (pp. 148-162). London: Falmer Press.

Doll, W. (1989). Foundations for a postmodern curriculum. Journal of Curriculum Studies, 21:3, 242-254.

Dyson, E. (1997). Release 2.0 a design for living in the digital age. London \& New York: Viking.

Eisler, R. (1988). The chalice and the blade: Our history, our future. New York: Harper San Francisco.

Escher, M. (1984). Mobius Strip 1, In J. Locher (Ed.), The infinite world of M. $C$. Escher (p. 144). New York: Harry N. Abrams. 
Fiske, E., \& Ladd, H. (2000). When schools compete : A cautionary tale. Washington, DC: Brookings Institution Press.

Foray, D., \& Lundvall, B-A. (1996). The knowledge-based economy: From the economics of knowledge to the learning economy. In The knowledge economy: Science, technology and industry outlook (pp. 11-30). Paris: Organisation for Economic Cooperation and Development.

Frank, T. (2001). One market under God: Extreme capitalism, market populism and the end of economic democracy. London: Secker \& Warburg.

Frederick, H., \& McIlroy, D. (1999). The knowledge economy: A submission to the New Zealand Government by the Minister for Information Technology's IT advisory group. (A. French, Ed.). Wellington: Ernst \& Young.

Gabbard, D. (Ed.). (2000). Knowledge and power in the global economy: Politics and the rhetoric of school reform. Mahwah, NJ: Lawrence Erlbaum \& Associates.

Giddens, A. (1998). The third way: The renewal of social democracy. Cambridge, UK: Polity Press.

Giddens, A. (2000). The third way and its critics. Cambridge, UK: Polity Press.

Gough, N. (1989a). Curriculum paradigms and the postmodern world: three perspectives. Journal of Curriculum Studies, 21.3, 223-224.

Gough, N. (1989b). From epistemology to ecopolitics: renewing a paradigm for curriculum. Journal of Curriculum Studies, 21:3, 225-241.

Griffin, D. (1992). Introduction to SUNY series in constructive postmodern thought. In D. Orr, Ecological literacy: Education and the transition to a postmodern world (pp. iii-vi). Albany: State University of New York Press.

Haywood, T. (1995). Info-rich--info-poor: Access and exchange in the global information society. London; New Jersey: Bowker-Saur.

Henderson, H. (1996a). Building a win win world: Life beyond global economic warfare. San Francisco: Berrett-Koehler.

Henderson, H. (1996b). Creating alternative futures: The end of economics (2nd ed.). West Hartford: Kumarian Press. 
Henderson, H. (1999). Beyond globalization: Shaping a sustainable global economy. West Hartford: Kumarian Press.

Hofstadter, D. (1980). Godel, Escher, Bach: an eternal golden braid. Harmondsworth: Penguin Books.

Huber, P. (1999). Hard green: Saving the environment from the environmentalists. A conservative manifesto. New York: Basic Books.

Ilon, L. (2000). Knowledge, labour and education. Compare, 30:3, 275-282.

Jameson, F. (1991). Postmodernism, or, the cultural logic of late capitalism. Durham, NC: Duke University Press.

Langer, E. (1989). Mindfulness. Reading, MA: Perseus Books.

Lankshear, C. (1999). Information, knowledge and learning: Rethinking epistemology for education in a digital age. Retrieved October 10, 2000, from http://www.geocities.com/Athens/Academy/1160/information.html.

Lyotard, J-F. (1984). The postmodern condition: A report on Knowledge. Manchester: Manchester University Press.

Maharey, S. (2001a, 7 May). Meeting the needs of all learners: The contribution of distance education and e-learning. Address presented at The Open Polytechnic of New Zealand Graduation Ceremony, Michael Fowler Centre Wellington.

Maharey, S. (2001b). Papakura's 'learning city' bang on, says Maharey. Ministerial Announcement, 7 June, 2001.

Maharey, S. (2001c). Foreign fee-paying students in record numbers. Ministerial press release, 11 July, 2001.

Maharey, S. (2001d). A tertiary education strategy for a knowledge society. Ministerial press release, 1 August, 2001.

Mallard, T. (2001a). BUDGET 2001: Early childhood and adult literacy big Budget winners. Ministerial press release, 24 May, 2001. 
Mallard, T. (2001b). Launch of notebook valley. Ministerial press release, 29 June, 2001.

Mallard, T. (2001c). Primary schools getting new ways of assessing children's progress. Ministerial press release, 31 July, 2001.

Marshall, J. (2000). Bright futures and the knowledge society. In J. Marshall, E. Coxon, K. Jenkins, \& A. Jones (Eds.), Politics, policy, pedagogy: Education in Aotearoa/New Zealand (pp. 187-215). Palmerston North: Dunmore Press.

Max, L. (2001, August). Social cohesion and bridging the knowledge divide: The New Zealand Perspective. Paper presented at the Catching the Knowledge Wave Conference, Auckland University, Auckland, New Zealand.

McLaren, P. (1994). Life in schools: An introduction to critical pedagogy in the foundations of education. New York: Longman.

McLuhan, M. (1967). The mechanical bride: Folklore of industrial man. London: Routledge \& Kegan Paul.

McLuhan, M. (1964). Understanding media: The extensions of man. London: Routledge \& Kegan Paul.

Ministry of Commerce. (1999). Bright future: Making ideas work for New Zealand. Wellington: New Zealand Government Ministry of Commerce.

Ministry of Education. (1993). The New Zealand curriculum framework. Wellington: Learning Media Ltd.

Ministry of Education. (1996). Te Whâriki: the early childhood curriculum. Wellington: Learning Media.

Ministry of Education. (1997). School entry assessment/Aro matawai Urunga-āKura. Wellington: Learning Media.

Monaco, J. (1981). How to read a film: The art, technology, language, history, and theory of film and media (Revised ed.). New York \& Oxford: Oxford University Press.

N. E. Thing Enterprises. (1993). Magic eye: A new way of looking at the world: 3D illusions. Ringwood, Vic: Viking Penguin. 
Neef, D. (Ed.). (1998). The knowledge economy. Boston: Butterworth-Heinemann.

Neef, D. (1999). A little knowledge is a dangerous thing: Understanding our global knowledge economy. Boston: Butterworth-Heinemann.

Nordland, E. (1994). New World-New Thinking-New Education. In B. Reardon \& E. Nordland (Eds.), Learning peace: The promise of ecological and cooperative education (pp. 1-20). Albany, NY: State University of New York Press.

Norris, R. (1999). Foreword. In A. French (Ed.), The knowledge economy: a submission to the New Zealand Government by the Minister for Information Technology's IT advisorygGroup (p. i). Wellington: Ernst \& Young.

nzjobs.co.nz (2001). Search for jobs. Retrieved July 25, 2001, from http://www.nzjobs.co.nz/search.cfm.

O'Rourke, M. (1993). Foreword. In Ministry of Education (Ed.), The New Zealand curriculum framework (pp. 1-2). Wellington: Learning Media.

O'Sullivan, E. (1999). Transformative learning: Educational vision for the 21st century. London \& New York: Zed Books.

Orr, D. (1992). Ecological literacy: Education and the transition to a postmodern world. Albany: State University of New York Press.

Oxford English Dictionary. (2 ${ }^{\text {nd }}$ ed.) (1989). Oxford: Oxford University Press.

Perris, L. (1996). Foreword. In Ministry of Education (Ed.), Te Whāriki: the early childhood curriculum (p. 7). Wellington: Learning Media.

Popkewitz, T. (2000). Reform. In D. Gabbard (Ed.), Knowledge and power in the global economy: Politics and the rhetoric of school reform (pp. 33-42). Mahwah, NJ: Lawrence Erlbaum Associates.

Postman, N. (1985). Amusing ourselves to death : Public discourse in the age of show business. New York: Viking.

Postman, N. (1993). Technopoly: The surrender of culture to technology. New York: Vintage Books. 
Postman, N. (1996). The end of education: Redefining the value of school. New York: Vintage.

Postman, N., \& Weingartner, C. (1971). Teaching as a subversive activity. Harmondsworth: Penguin Books.

Reardon, B. (1994). Learning our way to a human future. In B. Reardon \& E. Nordland (Eds.), Learning peace: The promise of ecological and cooperative education (pp. 21-44). Albany, NY: State University of New York Press.

Rifkin, J. (2000). The age of access: How the shift from ownership to access is transforming capitalism. London \& New York: Penguin.

Rozak, T. (1992). The voice of the Earth. New York: Simon \& Schuster.

Sachs, W. (Ed.). (1996). The development dictionary: A guide to knowledge as power. Johannesburg: Witwatersand University Press; London \& New Jersey: Zed Books.

Sacks, O. (1995). An anthropologist on Mars. Sydney: Picador.

Sarup, M. (1993). An introductory guide to poststructuralism and postmodernism. London: Harvester Wheatsheaf.

SeniorNet. (2001). SeniorNet homepage. Retrieved August 28, 2001, from http://www.seniornet.org.nz/shtmls/home.html.

Shipley, J. (1999). Foreword. In Ministry of Commerce (Comp.), Bright future: Making ideas work for New Zealand. Wellington: New Zealand Government Ministry of Commerce.

Slaughter, R. (1989). Cultural reconstruction in the post-modern world. Journal of Curriculum Studies, 21:3, 255-270.

Stern, D. (1998). Human resource development in the knowledge-based economy: Roles of firms, schools, and governments. In D. Neef (Ed.), The knowledge economy (pp. 249-265). Boston: Butterworth-Heinemann.

Stevens, C. (1998). The knowledge driven economy. In D. Neef (Ed.), The knowledge economy (pp. 87-94). Boston: Butterworth-Heinemann. 
Stiglitz, J. (1999). Public policy for a knowledge economy. Retrieved January 9, 1999, from http://www.worldbank.org/html/extdr/extme/knowledge-economy.pdf.

Thackery, S., Syme, K., \& Hendry, D. (1992). A survey of school entry practices: How schools gather information on new entrants. Wellington: Learning Media.

University of Waikato. (2001). Diplomas in entrepreneurship and innovation. Retrieved June 15, 2001, from http://www.mngt.waikato.ac.nz/depts/sml/DipEnt.pdf.

Thompson, M. (1995). Teach yourself philosophy. London: Hodder \& Stoughton.

Thompson, W. (1987). Introduction: The cultural implications of the new biology. In W. Thompson (Ed.), Gaia a way of knowing: Political implications of the new biology (pp. 11-34). Great Barrington, MA.: Lindisfarne Press.

Thompson, W. (1991a). TheAmerican replacement of nature: The everyday acts and outrageous evolution of economic life. New York: Doubleday.

Thompson, W. (Ed.). (1991b). Gaia 2: Emergence, the new science of becoming. Hudson, NY: Lindisfarne Press.

Thompson, W. (1996). Coming into being: Artifacts and texts in the evolution of consciousness. New York: St Martins Press.

Trade New Zealand. (2001). Trade New Zealand corporate web site homepage. Retrieved August 28, 2001, from http://www.tradenz.govt.nz/CWS/page_Index/.

Upjohn, E., Wingert, P., \& Mahler, J. (1958). History of World Art (2nd ed.). Oxford: Oxford University Press.

Varela, F. (1987). Laying down a path in walking. In W. Thompson (Ed.), Gaia a way of knowing: Political implications of the new biology (pp. 48-64). Great Barrington, MA.: Lindisfarne Press.

Varela, F., Maturana, H., \& Uribe, R. (1974). Autopoiesis: The organization of living systems, its characterization and a model. BioSystems, 5, 187-196.

Varela, F., Thompson, E., \& Rosch, E. (1993). The embodied mind: Cognitive science and human experience. Cambridge, MA \& London: MIT Press. 
Wallace, D. (1999, 9 March). Knowledge as capital: Towards a cultural economy of innovation. Paper presented at Seizing the Future-Cultural Value in the Knowledge Economy seminar, Turnbull House, Wellington.

Whitaker, R. (2001). Autopoiesis checklist. Retrieved August 26, 2001, from http://www.informatik.umu.se/ rwhit/Checklist.html. 